\title{
Cannulation practice and complications in hemodialysis vascular access
}

Citation for published version (APA):

Loon, M. M. (2011). Cannulation practice and complications in hemodialysis vascular access. [Doctoral Thesis, Maastricht University]. Maastricht University. https://doi.org/10.26481/dis.20110526ml

Document status and date:

Published: 01/01/2011

DOI:

10.26481/dis.20110526ml

Document Version:

Publisher's PDF, also known as Version of record

\section{Please check the document version of this publication:}

- A submitted manuscript is the version of the article upon submission and before peer-review. There can be important differences between the submitted version and the official published version of record.

People interested in the research are advised to contact the author for the final version of the publication, or visit the DOI to the publisher's website.

- The final author version and the galley proof are versions of the publication after peer review.

- The final published version features the final layout of the paper including the volume, issue and page numbers.

Link to publication

\footnotetext{
General rights rights.

- You may freely distribute the URL identifying the publication in the public portal. please follow below link for the End User Agreement:

www.umlib.nl/taverne-license

Take down policy

If you believe that this document breaches copyright please contact us at:

repository@maastrichtuniversity.nl

providing details and we will investigate your claim.
}

Copyright and moral rights for the publications made accessible in the public portal are retained by the authors and/or other copyright owners and it is a condition of accessing publications that users recognise and abide by the legal requirements associated with these

- Users may download and print one copy of any publication from the public portal for the purpose of private study or research.

- You may not further distribute the material or use it for any profit-making activity or commercial gain

If the publication is distributed under the terms of Article $25 \mathrm{fa}$ of the Dutch Copyright Act, indicated by the "Taverne" license above, 
Cannulation practice and complications in hemodialysis vascular access 
(C) Maaike Maria van Loon, Maastricht

Coverdesign: Eric Lemmens - D\&L graphics

Illustrations page 23, 24 and 28 : Eric Lemmens - D\&L graphics

Layout: Tiny Wouters

Printed by Schrijen-Lippertz

ISBN: 978-90-8590-047-4

The financial support for this study and the publication of this thesis was gratefully acknowledged by: Baxter B.V., CZ Medical Insurance Company, Dirinco B.V., Fresenius Medical Care B.V., the Dutch Kidney Foundation, and VGZ Medical Insurance Company. 


\title{
Cannulation practice and complications in hemodialysis vascular access
}

\author{
PROEFSCHRIFT \\ Ter verkrijging van de graad van doctor aan de Universiteit Maastricht, \\ op gezag van de Rector Magnificus, Prof. mr. G.P.M.F. Mols, \\ volgens het besluit van College van Decanen, in het openbaar te verdedigen \\ op donderdag 26 mei 2011 om 14.00 uur
}

door

Maaike Maria van Loon

Geboren op 24 september 1963 te Drimmelen 


\title{
Promotor:
}

Prof. dr. P.J.E.H.M. Kitslaar

\section{Copromotores:}

\author{
Dr. J.H.M. Tordoir \\ Dr. F.M. van der Sande
}

\section{Beoordelingscommissie:}

Prof. dr. K.M.L. Leunissen (voorzitter)

Prof. dr. M.J.H.M. Jacobs

Dr. H. Burger, voormalig specialist afdeling chirurgie ASZH, Dordrecht Dr. G.M.T. de Jong, ASZH, Dordrecht 
Aan mijn ouders

Aan Hein 
"We believe to be able to keep patients suffering from uraemia and anuria alive so long as bloodvessels for puncture are available"

W.J. Kolff, 1944 


\section{Contents}

Chapter 1 Introduction and aim of the thesis 9

Chapter 2 Type of hemodialysis vascular access cannulation and 19 practice patterns

Chapter 3 Implementation of a vascular access quality

programme improves vascular access care

Chapter 4 Cannulation and vascular access-related complications 47 in hemodialysis: Factors determining successful cannulation

Chapter 5 Cannulation practice patterns in hemodialysis vascular access: predictors for unsuccessful cannulation

Chapter 6 Buttonhole needling of hemodialysis arteriovenous

fistulas results in less complications and interventions compared to the rope-ladder technique

Chapter 7 Surgical techniques to improve cannulation of hemodialysis vascular access

$\begin{array}{lll}\text { Chapter } 8 & \text { General discussion } & 103\end{array}$

Summary

Samenvatting

Dankwoord

Curriculum Vitae 



\section{Chapter 1}

Introduction

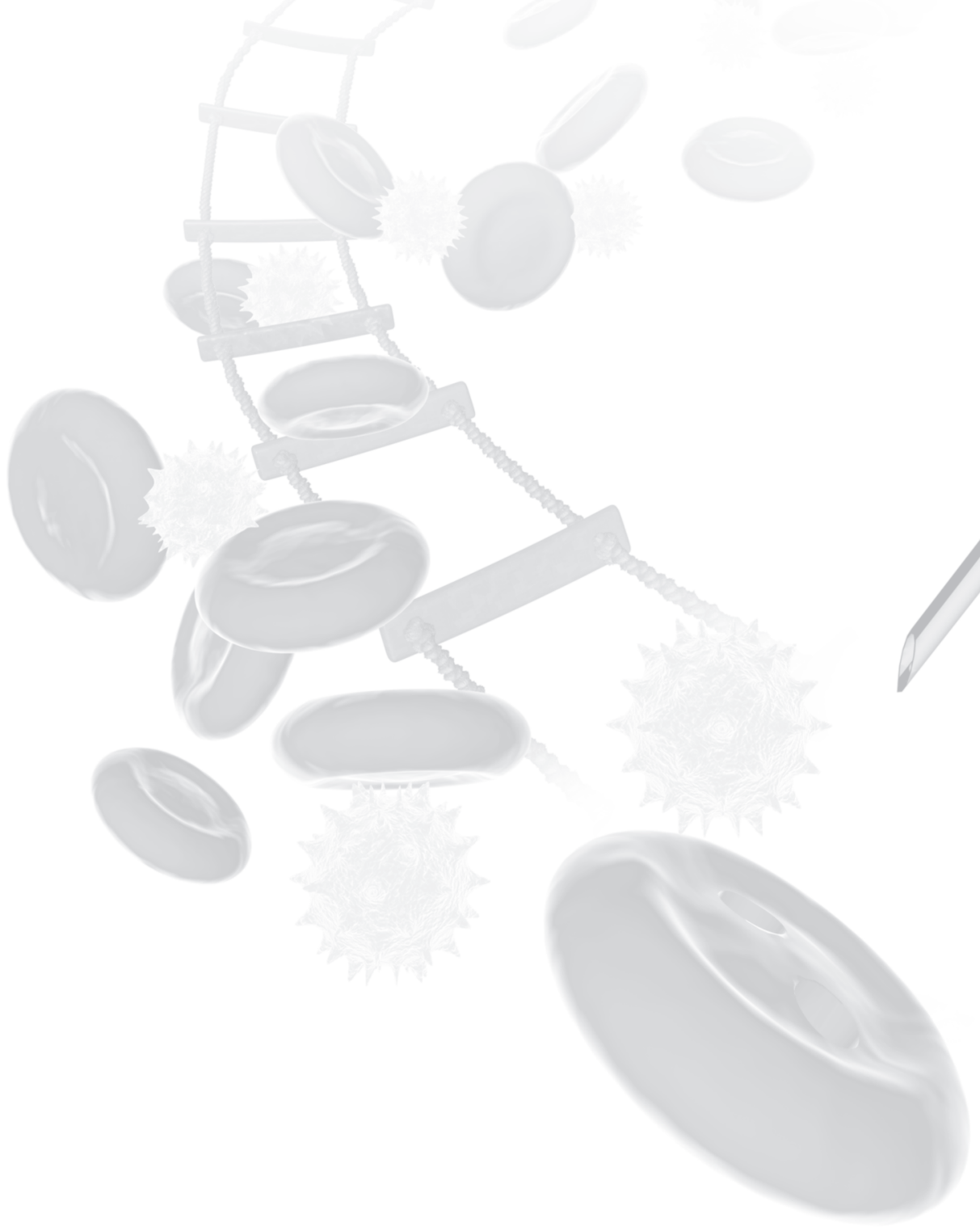


10 Chapter 1 


\section{Introduction}

The loss of renal function, which results in renal failure, is called end-stage renal disease (ESRD). Ideally, ESRD is treated with renal transplantation. However, because of a shortage of donor kidneys, the majority of ESRD patients are treated by renal replacement therapy (RRT). The options for RRT are hemodialysis or peritoneal dialysis. In the year 2004 the number of patients undergoing RRT for ESRD worldwide was 1.783 .000 , of which 1.222 .000 patients were treated by hemodialysis ${ }^{1}$. In 2008 , in The Netherlands 5840 patients with ESRD relied on RRT, of which 4579 patients were dependent on hemodialysis ${ }^{2}$.

Hemodialysis is a method to withdraw blood from the patient through a tube ("arterial line") transfer it to the dialysis machine, which removes waste products and fluid from the blood and reinfuse it through a tube ("venous line") back to the body. Therefore, a good functioning vascular access to the circulation is a prerequisite for successful hemodialysis, which serves as a lifeline for hemodialysis patients. Access function implies that the access not only delivers adequate blood flow for dialysis, but can be easily cannulated, due to a superficial subcutaneous position. In general, such an adequate access has a flow of approximately $600 \mathrm{ml} / \mathrm{min}$, is less than $0.6 \mathrm{~cm}$ below the surface of the skin, and has a minimal diameter of $0.6 \mathrm{~cm}^{3}$. Unfortunately, it is not always possible to create and maintain a vascular access which meets these criteria because of insufficient vessel diameter and length or inadequate maturation. This may affect the quality of the vascular access and therefore negatively affect its accessibility which can result in hematoma formation, infection and aneurysms. Complications caused by cannulation may seriously affect vascular access outcome and impair the quality of dialysis treatment and life of the patient.

\section{Types of vascular access}

The first hemodialysis treatment in humans lasted $15 \mathrm{~min}$, and was performed in 1924 by Georg Haas. He first used glass cannulae to obtain arterial blood from the radial artery and returned it to the cubital vein. Later a surgical cut-down to place one or two cannulae into the radial artery and into an adjacent vein was performed ${ }^{4}$. In 1943, William Kolff ${ }^{5}$, invented the first clinically usable artificial kidney. The technical device was available, but a reliable and repeated vascular access was the most important drawback to perform chronic RRT by means of an extracorporeal blood purification. First, venapuncture needles to obtain blood from the femoral artery were used with reinfusion into a cannulated vein. Later, surgical vessel cut-down of the radial artery was used, which however caused severe bleeding during heparinization. In 1945 the first of Kolff's 17 patients survived. Due to a lack of a reliable vascular access at that time, the long-term usability for adequate hemodialysis was limited. 


\section{Autogenous arteriovenous fistula}

In 1966, Brescia, Cimino, Appell and Hurwich $^{6}$ described the first internal surgically created arteriovenous fistula (AVF) in the forearm. They created a side-to-side anastomosis between the radial artery and cephalic vein, which ensured function as a vascular access. The vein will dilate due to the increase in flow, enabling cannulation for hemodialysis with large dialysis needles (14-17 gauge). Whenever forearm vascular access options are not possible or have failed, access options remain at the elbow and upper arm site, with the anastomosis between brachial artery and cubital or cephalic veins $^{7,8}$, or between the brachial artery and basilic vein ${ }^{9,10}$. The deeply and medially located basilic vein is usually inaccessible for cannulation and needs therefore to be superficialized before it can be used.

The autogenous AVF is the preferred form of vascular access for hemodialysis, delivering superior patency with a low risk of thrombosis and infection. AVFs are usually created in the non-dominant arm. Although initially cannulated immediately after surgery, these fistulas are now allowed to mature for a period of 4 tot 6 weeks until there is sufficient venous dilatation. Unfortunately, with the changing demographics of patients with ESRD, not all patients have suitable vessels to construct an AVF, due to the lack of usable arteries or veins due to arteriosclerosis and/or phlebosclerosis.

\section{Arteriovenous graft}

An alternative to the autogenous AVF is the use of arteriovenous grafts (AVG) using synthetic material ${ }^{11}$. These AVG are typically located in the forearm, in a loop or straight configuration. Of the various synthetic materials (polyester, polyurethane and polytetrafluoroethylene [PTFE]), PTFE is the most favourable graft material. AVGs mature faster than AVF, and may be used within hours to days after creation. However, prosthetic AVGs are associated with a significantly higher risk of thrombosis and infection when compared to $\mathrm{AVF}^{11,12}$.

\section{Central venous catheter}

Although AVFs and AVGs are the preferred vascular access for permanent hemodialysis access, central venous catheters (CVC) are often required for varying intervals when acute access is needed because of acute renal failure, delayed fistula maturation or failure of the permanent vascular access. Long-term CVCs are used in patients without the possibility of creating a functional arteriovenous access. 
The CVC generally consists of a double-lumen plastic catheter which is inserted into a large vein. Generally the internal jugular vein or the femoral vein is used. CVCs are discouraged because of their increased risk of luminal thrombosis and infection, unreliable blood flows, risk of central venous stenosis, shorter lifespan, and patient cosmetic concerns. A recent study found that, compared with AVF, long-term hemodialysis with tunneled cuffed CVCs is associated with two to threefold increased risk of death, a five to 10 -fold increased risk of serious infection, increased hospitalization, a decreased likelihood of adequate dialysis, and an increased number of vascular access procedures ${ }^{13}$. The Dialysis Outcomes and Practice Patterns Study (DOPPS), shows that there is an increase in the use of catheters since national - and international guidelines recommend autogenous AVF over AVG for permanent vascular access. In nearly half of the countries, $50 \%$ of patients initiates dialysis with a catheter, ranging from an incidence of $23 \%$ to $73 \%{ }^{14}$.

\section{Management of hemodialysis vascular access}

An ideal vascular access should provide adequate blood flow for hemodialysis, through two needles that can be repeatedly and easily placed. Complications such as thrombosis, infections and hemorrhage should be minimal. However in daily practice such an ideal access does not exist. The maintenance and longevity of hemodialysis vascular access remains one of the most problematic topics in the care of dialysis patients. Vascular access complications are the leading cause for hospitalization and morbidity in patients with ESRD. These complications have a negative impact on the quality of life of dialysis patients and may even result in mortality.

The best treatment of access complications is prevention. Management of the vascular access has been receiving increased focus by dialysis providers since the Kidney Disease Outcome Quality Initiative ${ }^{3}$ clinical practice guidelines for Vascular Access (update 2006) recommended an increased use of autogenous AVF and prevention of access dysfunctions by a surveillance program and pre-emptive intervention for access dysfunction ${ }^{3}$.

This requires an integrated multidisciplinary approach by professionals involved in the care of vascular access such as nephrologists, access surgeons, interventional radiologists ultrasound technicians and dialysis staff.

\section{Cannulation practice}

Cannulation of the vascular access for hemodialysis treatment may be stressful to patients and medical staff. There are several factors which currently make cannulation problematic such as the increase in number of elderly dialysis patients with additional 
cardiovascular co-morbidities and diabetes mellitus. These factors have a negative influence on the vascular access quality. Furthermore, there is an increase in number of patients with obesity in all western countries. In obese patients the vessels are often deeply located which make the cannulation cumbersome. A third factor is an increased number of arteriovenous fistulas since the national and international guidelines recommend the use of the autogenous arteriovenous fistula because of their better survival and lower complication rates than those in grafts. Cannulation of an arteriovenous fistula requires more technical skills than cannulation of an arteriovenous graft, which is more accessible.

\section{Aims of this thesis are}

1. To analyse the effect of the implementation of a quality improvement program (QIP) on the quality of vascular access care.

2. To analyse predictors for unsuccessful cannulation for, time to occurrence of cannulation complications, and for vascular access failure, and to identify factors that may be associated with cannulation-related complications.

3. To analyse characteristics of the cannulation practice predicting the time to unsuccessful cannulation, cannulation-related complications, and vascular access failure in AVFs and AVGs.

4. To compare the so called rope-ladder and buttonhole cannulation techniques with respect to several outcome parameters.

5. To review the various surgical techniques to improve cannulation of the vascular access.

\section{Overview of this thesis}

Chapter 2 describes the assessment process before cannulation of the vascular access and explains the different cannulation techniques. Chapter 3 addresses the value of the implementation of a quality improvement program (QIP) on the quality of vascular access care. Chapter 4 and 5 reports the results of a prospective, observational study about the complications caused by cannulation and the clinical consequences in newly created vascular accesses in incident patients. Chapter 6 evaluates the results of a prospective observational study in prevalent hemodialysis patients with an AVF, concerning the use of the rope-ladder versus buttonhole cannulation technique, with respect to several outcome parameters: the incidence of miscannulation, cannulation ease, hematoma and aneurysm formation, CVC dependence or single needle dialysis and interventions. Needle pain and fear associated with both cannulation techniques were also evaluated. Chapter 7 presents the description and outcome of a literature 
review on the various surgical techniques aim at improving hemodialysis vascular access cannulation. Chapter 8 includes a general discussion of the findings of this thesis, in relation to reports from the literature, future perspectives, and conclusions. Chapter 9 and 10 provides a summary in English and Dutch respectively. 


\section{References}

1. Grassmann A, Gioberge S, Moeller S, Brown G. ESRD patients in 2004: global overview of patient numbers, treatment modalities and associated trends. Nephrol Dial Transplant 2005;20:2587-93.

2. Stichting RENINE. Therapy treatment distribution. 2009.

3. NFK-K/DOQI. Clinical practice guidelines for vascular access: update July 2006. American Journal of Kidney Disease 2006;48:187-277.

4. Haas G. Über Versuche der Blutauswaschung am Lebenden mit Hilfe der Dialyse. Klin Wochenschr 1925;4:13-4.

5. Kolff WJ, Berk HTJ, ter Welle M. The artificial Kidney: a dialyzer with a great area. Acta Med Scand 1944;117:121-31.

6. Brescia MJ, Cimino JE, Appel K, Hurwich BJ. Chronic hemodialysis using venipuncture and a surgically created arteriovenous fistula. The New England journal of medicine 1966;275:1089-92.

7. Crockett RE. Blood access for haemodialysis. Nephron 1974;12:338-54.

8. Gracz KC, Ing TS, Soung LS, Armbruster KF, Seim SK, Merkel FK. Proximal forearm fistula for maintenance hemodialysis. Kidney international 1977;11:71-5.

9. Cantelmo NL, LoGerfo FW, Menzoian JO. Brachiobasilic and brachiocephalic fistulas as secondary angioaccess routes. Surgery, gynecology \& obstetrics 1982;155:545-8.

10. Dagher F, Gelber R, Ramos E, Sadler J. The use of basilic vein and brachial artery as an A-V fistula for long term hemodialysis. The Journal of surgical research 1976;20:373-6.

11. Tordoir J, Canaud B, Haage P, Konner K, Basci A, Fouque D, Kooman J, Martin-Malo A, Pedrini L, Pizzarelli F, Tattersall J, Vennegoor M, Wanner C, ter Wee P, Vanholder R. EBPG on Vascular Access. Nephrol Dial Transplant 2007;22 Suppl 2:ii88-117.

12. Vascular Access 2006 Work Group. Clinical practice guidelines for vascular access. Am J Kidney Dis 2006;48 Suppl 1:S176-247.

13. Rehman R, Schmidt RJ, Moss AH. Ethical and legal obligation to avoid long-term tunneled catheter access. Clin J Am Soc Nephrol 2009;4:456-60.

14. Ethier J, Mendelssohn DC, Elder SJ, Hasegawa T, Akizawa T, Akiba T, Canaud BJ, Pisoni RL. Vascular access use and outcomes: an international perspective from the Dialysis Outcomes and Practice Patterns Study. Nephrol Dial Transplant 2008;23:3219-26. 
18 Chapter 1 


\section{Chapter 2}

Type of hemodialysis vascular access cannulation and practice patterns 


\section{Introduction}

The maintenance of the vascular access not only depends on the quality of the blood vessels, and the surgical technique used, but also on the way in which the vascular access is handled, in particular is cannulated.

After placement of the initial vascular access, preferably an autogenous arteriovenous fistula (AVF), the correct needling technique has a favourable influence on maturation and fistula lifespan ${ }^{1}$. Nurses play a pivotal role in the care for vascular access: they see the patient every hemodialysis, perform cannulation and assess function of the vascular access ${ }^{2}$.

Cannulation of the vascular access is a basic but essential part of the hemodialysis treatment. A chronic hemodialysis patient needs at least 312 needle insertions per year. It is reasonable to assume that complications caused by cannulation, like haematoma, infection and aneurysm formation can have great consequences in terms of suboptimal hemodialysis, need for extra needle insertions, patient discomfort, interventions and even loss of the access.

Although much attention has focused on superiority of autogenous over synthetic access materials, monitoring techniques and interventions, there is little knowledge about the influence of repeated vessel cannulation on the quality of the vascular access.

Cannulation of the AVF requires more technical skills than cannulation of an arteriovenous graft (AVG), which is usually easily accessible. Since the national and international guidelines recommend the AVF as the preferred vascular access, there is a growing number of patients dialysing by means of an AVF. From the Dialysis Outcomes and Practice Pattern Study (DOPPS) ${ }^{3}$ it appeared that fistulas were used by $80 \%$ of the European and $24 \%$ of the USA patients. In the Netherlands overall, $67 \%$ of the prevalent hemodialysis patients are dialysed through an AVF. Because the anatomy of the vein differs from person to person, the quality and usability of the vein, after creation of the fistula, is not always predictable. Despite these possible disadvantages it is preferable to create AVFs.

\section{Assessment of the vascular access before cannulation}

Vessel assessment is the key to determine the usability of the vascular access. Timing of first cannulation of an AVF remains a controversial subject. Optimal waiting time before first use of vascular access is not known. The K/DOQI practice guidelines ${ }^{4}$ state that one should wait for $\geq 1$ month, but preferably 2-3 months, before first cannulation of an AVF. In the Dialysis Outcomes and Practice Patterns Study (DOPPS) ${ }^{5}$, early cannulation of newly placed vascular access was not associated with an increased risk of vascular access failure. Only if AVFs were first cannulated within 14 days of creation, there was a significant, detrimental effect on subsequent AV fistula 
survival. If the fistula is not clinically matured, the time elapsed since its creation alone should not form the basis of the decision to cannulate ${ }^{6}$.

After creation of an AVG most patients experience significant tissue swelling as a result of the tunneling, and palpation of the graft is difficult for the cannulator and painful for the patient. Therefore, an AVG should not be cannulated for at least 24 hours after placement and not until swelling has subsided so that palpation of the course of the AVG can be performed ${ }^{4}$.

Clinical examination not only prior to the first cannulation but also before any following cannulation is of utmost importance. This examination consists of inspection, palpation and auscultation.

\section{Inspection}

Inspection of the access site for signs of infection (redness, discharge, oedema), aneurysms, haematoma and of the colour (red, blue, white) of the hand is important for the early diagnosis of impending complications ${ }^{6}$. Swelling due to venous hypertension and the potential progression of acral necrosis should be monitored prior to hemodialysis treatment. Venous dilatations and aneurysms in grafts without stenosis (low pressure aneurysms) can be cannulated using the lateral side provided that the skin is completely healthy.

\section{Palpation}

Palpation with the fingertips, along the access site from its arterial anastomosis up to the outflow veins may give an idea of the function of the access. In fistulae normally a strong thrill and weak pulsation is felt. The patency of a vascular access can be determined by assessing the thrill which is associated with flows of $>450 \mathrm{ml} / \mathrm{min}^{6}$. The intravascular pressure should be equal at any segment. Differences in intravascular pressure and an increase in pulsation indicate an outflow stenosis. In fistulae a stenosis can be felt along the access tract by palpation. Palpation of peripheral pulses (radial and ulnar at the wrist) is indicated in patients with hand perfusion disturbances (white/blue hand). However, in one third of proximal access procedures with the brachial artery as inflow artery there is no distal pulse as a consequence of a mild non limb-threatening steal. Digital pressure or wrist-to-brachial pressure index measurements could be used instead. An index $>0.5$ or a digital pressure $>50 \mathrm{mmHg}$ rules out a limb-threatening steal ${ }^{7,8}$. If there is no thrill present, no needles should be placed until further evaluation with a stethoscope is completed. Palpation should also be used to check the temperature of the skin around both the arterial and venous anastomosis for abnormal warmth and comparative temperature of fingers in both access and non-access hands ${ }^{9}$. Another reason to palpate the vascular access is to determine width and depth of the vessels. 


\section{Auscultation}

Auscultation should be used prior to every session of hemodialysis treatment, listening for the sound of the blood flow through a vascular access. Pressing a stethoscope gently onto it, the whole vascular access path is listened, noting any changes in pitch and amplitude of the bruit. Auscultation normally reveals a typical thrill with a long diastolic component that is shortened in case of hemodynamically relevant stenosis. A stenosis causes a high-pitch bruit. In thrombosis, there will be no bruit at all $^{6}$. In patients with grafts, palpation may be difficult due to the deep subcutaneous position of the graft. Auscultation is more reliable and should concentrate on the venous outflow tract for detection of graft-to-vein anastomotic stenosis.

\section{Preparing before access cannulation}

Cannulation is an invasive procedure and proper preparation of the access sites can eliminate the possibility of contamination and/or access infection. The Center for Disease Control and Prevention (CDC) ${ }^{10}$ states that, in patients on dialysis, infection is the second leading cause of death (15\%) with vascular access infection being the number one cause. Staphylococcus aureus is the microorganism most frequently found. Patients on dialysis have more Staphylococcus aureus on their skin and in their nose than the general population ${ }^{11}$. Therefore, patients should wash the access site using soap or scrub prior to the cannulation. The dialysis nurse cleanse the skin by applying $2 \%$ Chlorhexidine gluconate/70\% isopropyl alcohol or $70 \%$ alcohol and/or $10 \%$ Povidone iodine as per manufacturer's instruction for use. Disposable clean gloves should be worn by dialysis staff for cannulation ${ }^{4}$. There has been discussion around circular vs. east-west cleansing techniques; although evidence does not exist at present to support a recommendation for one technique over the other, the circular, rubbing motion cleansing technique has proven over time to be the best practice $^{4}$.

There are several anaesthetics available for needle insertion. For instance, intradermal injection with Lidocaine, spray which freezes the surface tissue causing temporary numbing such as Ethyl Chloride ${ }^{\circledR}$ spray, and topical anaesthetic creams, that may be used in patients who are concerned with the discomfort of needle insertion. The lidocaine/ tetracaine patch (lidocaine $70 \mathrm{mg} /$ tetracaine $70 \mathrm{mg}$, Synera ${ }^{\mathrm{TM}}$, known in Europe as Rapydan ${ }^{\mathrm{TM}}$ ) is a novel drug delivery system designed to warm the skin and enhance the delivery of local anaesthetics through the skin ${ }^{12}$.

Intradermal lidocaine is a vasoconstrictor, so it will cause the vein to become smaller and sometimes make it deeper. Intradermal lidocaine causes a bee sting-type burning sensation that can be minimized by injecting the lidocaine more slowly. There are no studies citing scarring from Lidocaine use, however, certain ethnic groups form keloid scars that can make cannulation through them very difficult ${ }^{13}$. Ethyl Chloride $^{\circledR}$ spray freezes the surface tissue causing temporary numbing. Because Ethyl Chloride ${ }^{\circledR}$ is not 
sterile, it must be applied prior to the antimicrobial prep, not after. If the patient's access is deeply located, this may not be the most effective product to use. A study by Suriti and Suraj ${ }^{14}$ indicates that depth of anesthesia with topical anesthetics depends on the contact time. In order to reach a maximal depth of $3 \mathrm{~mm}$, the topical anaesthetic cream has to remain on the skin for 60 minutes and to reach a depth of $5 \mathrm{~mm}$ the cream has to be on the skin for 120 minutes.

\section{Selection of cannulation techniques}

There are three methods for cannulation of the vascular access (Figure 2.1); rotation of cannulation sites (rope-ladder), constant site cannulation (buttonhole), or repeated cannulation in a small circumscribed area of the vascular access (area technique).
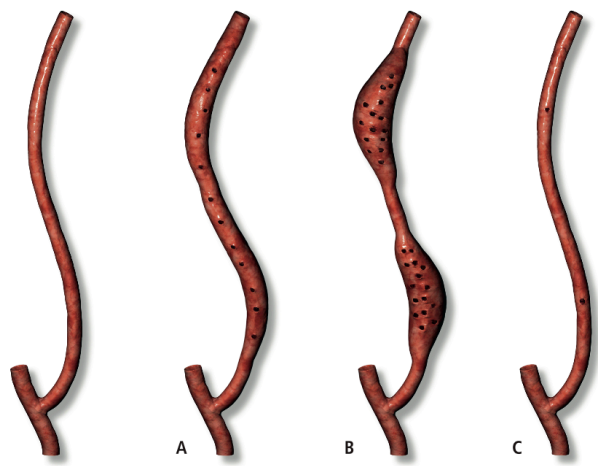

Figure 2.1 A. Rope-ladder technique B. Area technique C. Buttonhole technique

\section{Rope-ladder technique}

The rope-ladder technique is the predominant cannulation method used in the United States, Europe and the Netherlands. For every dialysis two new sites are chosen for needle placement to allow good healing of the puncture wound, and thus avoid complications. The whole access length is used for cannulation, with a minimum of $2-3 \mathrm{~cm}$ between the tip of the arterial and venous needle, at least $3 \mathrm{~cm}$ from the anastomosis, and avoiding the previous sites. The rope-ladder technique results in a moderate vessel dilatation over a long vein segment ${ }^{15}$.

The venous needle is placed in the direction of the blood flow (antegrade). Arterial needle placement can be antegrade or retrograde (against the direction of the blood flow). The arterial needle in either direction will not increase the risk of recirculation as long as the access blood flow is greater than the blood pump flow ${ }^{4,14,16-20}$. Bevel position and flipping of needles is a controversial issue. Both bevel up and bevel down 
cannulation are acceptable until further studies can demonstrate risk/benefits of either technique ${ }^{9,13,21}$. Based on assessment of the vascular access the dialysis nurse chooses the unique angle of insertion for the dialysis needle. Generally, the angle of insertion for AVF is 25 degree (Figure 2.2), and for AVG 45 degree ${ }^{4}$. Some vascular access is shallow or deeper so another angle can be used. Cannulation of AVG is different than AVF, the graft is tougher than autogenous vessels. Only a few publications concerning access handling and the outcome of specific cannulation techniques advise the rope-ladder technique for the cannulation of $\mathrm{AVGs}^{4,18,22}$, to avoid AVG disintegration and the formation of pseudo-aneurysms. Rotation of cannulation sites is needed to avoid pseudo-aneurysm formation.

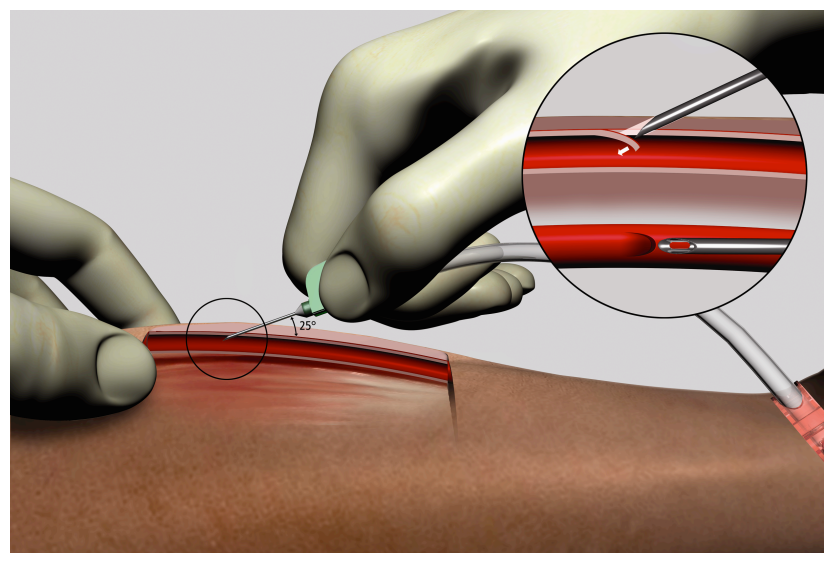

Figure 2.2 Insertion of the dialysis needle

AVF cannulation requires the use of a tourniquet ${ }^{4,18}$. For needle insertion it is important to provide stabilisation of the skin and the vascular access. The vessel should be anchored between thumb and finger to prevent movement. By compressing nerve endings when pulling the skin taut, it is possible to interrupt the "pain-to-brain" sensation for approximately 20 seconds making cannulation less painful ${ }^{13,23}$. There are several published descriptions ${ }^{13,18,24}$ how to insert the dialysis needles, such as the three-point technique were the thumb and forefinger of the non-needle hand are placed on either side of the fistula to eliminate rolling, preventing a sidewall infiltrate, as well as serving as a guide when threading the needle. The ' $\mathrm{L}$ ' cannulation technique ${ }^{24}$ holds the thumb and index finger as an ' $\mathrm{L}$ '. The thumb holds the skin taut over the VA. Until now, best cannulation practice has not been determined ${ }^{20}$.

To ensure proper needle placement, a normal saline flush should be performed before connecting the needles to the blood pump and starting the pump. Blood return alone is not enough to assure good needle placement. One option to check for proper needle placement is the use of "wet" needles. The needle is purged of air and the 
saline in the attached syringe is used to flush the needle. If infiltration has occurred, the injection of normal saline is less harmful to the surrounding AVF tissue. The wet needle also prevents the risk for a blood spray or spill as may occur if dry needles are used for cannulation and the caps are opened to "bleed out" the air from the needle. The opening of the needle is a risk for blood exposure to the dialysis team and patients. For these reasons, use of a flushed needle is a safer technique, in particular for the initial AVF cannulation. This option should be considered as part of the dialysis unit's cannulation policy and procedures ${ }^{4}$.

The needle should be taped with caution, at the same angle or one similar to the angle of insertion. An improper rotation of the needle or taping procedure can cause an infiltration. Special care must be taken with deep oedematous AVGs because the needles are more prone to shift after the cannulation ${ }^{18}$.

\section{Area technique}

There may be some vascular accesses were the rope-ladder technique is difficult to employ, primarily due to the limited length of the vascular access, or a complicated cannulation route. In this case there will be repeated cannulation in the same area of the vascular access. With this area cannulation technique it is evidence- based that there are more aneurysm formations and stenosis on the frequently cannulated spot $^{15}$. The smaller the chosen puncture area, the larger the circumscribed dilatation. Also the skin gets thinner which leads to longer bleeding times after the needles are removed. Other reasons for using the area technique may be the fear of the nurse for miscannulation and patient preference, because this technique is less painful. Although it is not preferable, the area technique is very often used.

\section{Buttonhole technique}

Another cannulation technique - whith renewed interest in Europe and USA - is the buttonhole ${ }^{25}$ (constant-site) technique. As far as we know the buttonhole technique is exclusively used for autogenous fistulae.

The buttonhole technique is not new, and has been used in Europe for more than 25 years. Twardowski et al. were the first in the USA to publish the experience with the buttonhole technique ${ }^{26}$. They had one patient who had a very limited area for puncture so that a constant-site of insertion became a matter of necessity. They observed that the puncture was less painful, was accomplished quickly and without complications. In the course of 6 months another 16 patients used it successfully. In 1984, Krönung ${ }^{15}$ compared the rope-ladder, area and buttonhole technique and found that the area puncture caused mostly aneurysm formation and the buttonhole showed no aneurysm formation.

The buttonhole method requires inserting the needles each time at exactly the same spot, using the same insertion angle, and the same depth of penetration for each consecutive dialysis ${ }^{27-29}$. In this way a scar tissue tunnel track is formed that is very 
similar with a pierced earring hole. The cannulation sites should be selected carefully in an area without aneurysms and with a minimum of $5 \mathrm{~cm}$ between the tips of the needles. This puncture technique is developed in two time periods. In the first period one arterial and one venous buttonhole is created. It takes approximately 6 to 10 sessions to create a scar tissue tunnel track preferably by one single nurse. In the second period, after a good puncture route is established, the fistula can be punctured with a dull edged needle. Dull edged needles are rounded on the top and do not have a sharp cutting edge, like traditional dialysis needles, to prevent damaging the scar tissue tunnel. After a good puncture route has been created, the dull bevel of the needle can be easily inserted into the established tunnel and opens the vessel flap at the end of the tunnel. The needle should slide in with low resistance. After the tunnel has been formed, any staff member can puncture the fistula.

Up to now, for a successful buttonhole technique, the fistula should be cannulated by the same experienced staff for at least 2 weeks, using sharp needles, until the track is established. This could be a drawback of the technique. Toma et al. ${ }^{30}$ developed a new method to create the fixed puncture route for the buttonhole In this method, after the hemodialysis session, a newly developed thumbtack-shaped polycarbonate peg is pushed toward the access vessel along the same path as the puncture needle that has just been removed. At the beginning of the next dialysis, the peg is removed and a dull puncture needle is inserted along the track already formed by the peg left in place. These steps are repeated at each hemodialysis session for 14 days or six sessions. Thereafter, the vascular access is achieved at hemodialysis sessions by inserting a dull needle through the established puncture route. The tip of the peg is rounded and dull so as not to pierce the vessel even if the tip reaches the vessel wall. Marticorana et al. ${ }^{31}$ described a simple method to create a buttonhole by leaving the polyurethane catheter of a hemodialysis needle indwelling for 10 days after the initial cannulation. After each dialysis the catheter was flushed, and dressed with an antibacterial ointment and gauze. Dialysis was carried out via the catheter during that time. After day 10 , the catheter was removed, the tunnel track covered with an antibacterial dressing and the tunnel track was cannulated with a dull buttonhole needle at the next dialysis.

With the increase of the number of AVFs, this buttonhole technique is becoming known as a viable cannulation option and can contribute to the cannulating ease of self-cannulating patients ${ }^{32}$. It is well established that self-cannulation extends the life expectancy of the autogenous $\operatorname{AVF}^{33,34,35}$, is associated with fewer complications ${ }^{4,32-35}$ and the process is more comfortable for the patient ${ }^{28,32}$.

Some authors have reported inflammation and infection in their buttonhole patient population $^{26,36}$ and, therefore, consideration for stringent cleansing of the sites both pre- and post-dialysis is encouraged.

Each cannulation technique demands its own specific skills. There are major differences between the buttonhole and rope-ladder technique like the exact insertion angle versus a different insertion angle of cannulation, scab removal versus 
avoiding scab removal, and using the same cannulators until the tunnel of the buttonhole is formed. Although there are publications of hemodialysis cannulation techniques, best practices have not been determined.

\section{Needle removal}

The technique of needle removal is as important as that of cannulation, to protect the access from damage and to facilitate proper hemostasis. The needle should be removed at approximately the same angle as it was inserted ${ }^{4,13,18}$. Pressure to the puncture site should not been applied until the needle has been completely removed, to prevent damage of the vascular access.

When an access is cannulated, there are two holes that are created from each needle, one through the skin (external) and another through the blood vessel wall (internal). It is important to remember that both holes must be compressed when needles are removed in order to ensure that bleeding stops from both sites ${ }^{4,13,18}$. If the site into the blood vessel wall is not covered adequately, there will be leakage of blood into the tissues causing infiltration and hematoma formation. This can put the access at risk for difficult cannulation, limitation of cannulation sites, and access failure due to increased pressure or stenosis formation. Therefore, two fingers should be used to hold each site, one covering each hole. Pressure should be strong enough to prevent bleeding, but not so strong as to occlude bloodflow. Not using two fingers per site may be one of the reasons for breakthrough bleeding ${ }^{4,13,18}$. In general, prosthetic grafts require a longer time to achieve hemostasis than $\mathrm{AVF}^{22}$.

Use of clamps to assist hemostasis should be discouraged. When clamps are used, they should only be applied to a mature access with an adequate flow, monitored closely, and should be used only if flow can still be palpated in the AVF or AVG while the clamp is in place 9 .

Bandage/ dressing should be applied to the cannulation sites, but may not be taped around the limb. After the dressing is applied, stethoscope auscultation is used to check access patency. The patient should be taught to remove dressings within $24 \mathrm{hrs}$.

\section{Selection of dialysis needles}

Dialysis needles are available as a sharp or a blunt needle (Figure 3). A sharp dialysis needle is a tube with a razor edged cutting blade extending diametrically across its forward end. The blade has a generally " $V$ " shape with a pair of razor sharp cutting edges converging forwardly from opposite sides of the tube and terminating in a needle-sharp point. Blunt needles are rounded on the top and do not have a sharp, cutting edge like traditional needles. Needles have a silicone coating for optimum insertion, and low flow resistance. Two specific embodiments are described: an allstainless-steel version; and a plastic version with a sharp or a blunt mandrin, which is 
removed after cannulation. Both needles are available as a sharp or a blunt needle. Generally these needles are used in 14 to18 gauge sizes (Table 2.1).

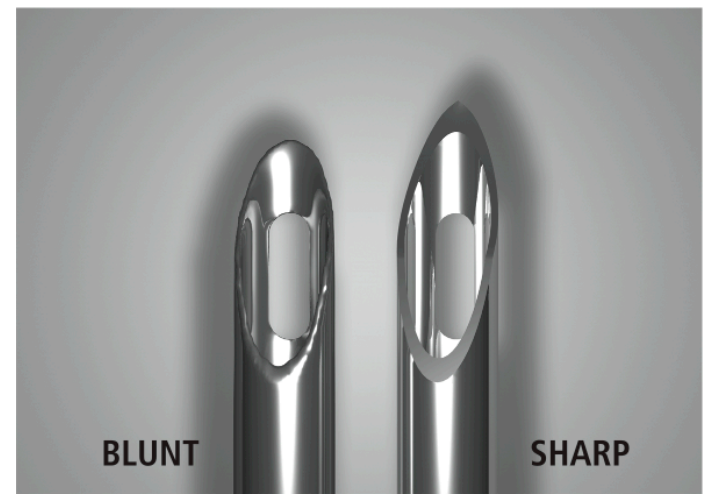

Figure 2.3 Buttonhole needle versus regular needle

Needle selection for the initial cannulation is critical. One method used to select the appropriate needle size is a visual and tactile examination. This examination allows the cannulators to determine which needle gauge would be most appropriate, based on the size of the vessels of the fistula. The vein size is compared to the needle size with and without a tourniquet around the upper arm. If the needle is larger than the diameter of the vein with the applied tourniquet, it may cause infiltration with cannulation. The needle size should be equal or smaller than the vein size (without tourniquet). It is important to match needle gauge to blood flow rate (Table 2.1). If the arterial pressure falls below 200 to $250 \mathrm{mmHg}$, the needle size should be increased (i.e., a smaller gauge number should be used) ${ }^{4}$.

Table 2.1 Recommended gauges for the stated BFR settings. Larger needles, when feasible will reduce pre-pump arterial pressure and increase delivered blood flow.

\begin{tabular}{|l|l|}
\hline Blood Flow Rate (BFR) & Needle Gauge \\
\hline$<300 \mathrm{ml} / \mathrm{min}$ & 17 gauge $(1.5 \mathrm{~mm})$ \\
\hline $300-350 \mathrm{ml} / \mathrm{min}$ & 16 gauge $(1.6 \mathrm{~mm})$ \\
\hline$>350-450 \mathrm{ml} / \mathrm{min}$ & 15 gauge $(1.8 \mathrm{~mm})$ \\
\hline$>450 \mathrm{ml} / \mathrm{min}$ & 14 gauge $(2.0 \mathrm{~mm})$ \\
\hline
\end{tabular}

The arterial needle should always have a back eye to maximize the flow from the access and reduce the need for rotation of the needle ${ }^{4}$. The lengths of the needles are available in $2.0 \mathrm{~mm}$ to $3.2 \mathrm{~mm}$, and may be altered by the dialysis staff in order to reach, for instance, deep accesses such as those found in the upper arm of an obese 
patient. Before placing dialysis needles, it is important for the dialysis nurse to understand the anatomy of the access and its effect on adequacy. Thereby, it is of great importance that the nurse has knowledge of the different cannulation techniques with their morphological consequences ${ }^{15}$.

\section{Hemodynamics of the dialysis needles}

Patients with end- stage renal disease usually, spend 3-5 hrs, three times a week, on hemodialysis treatment, with one to two needles inserted into the vascular access. The needles influence the hemodynamics of the access in different manners: micro trauma of the puncture, and changes in access blood flow velocity and pattern ${ }^{37}$.

The 'inflow' needle takes the blood from the patient to the dialysis machine, and the 'outflow' needle transports it back to the vascular access. Suction of the blood by the inflow needle causes a turbulent flow around this needle. Furthermore, in low-flow accesses, the majority of the access inflow is removed by the inflow needle, which results in a temporary decrease in flow velocity in the access segment between the both needles. Such a decrease in flow velocity could predispose to a hypercoagulable state and decrease in wall shear stress with a possible influence on intimal hyperplasia development ${ }^{38-40}$. Intimal hyperplasia is based on the response to injury hypothesis, in which endothelial and smooth muscle cell injury results in a migration of smooth muscle cells and myofibroblasts from the media to the intima. These cells proliferate to form the lesion of intimal hyperplasia. When about $20 \%$ of the smooth muscle cells have migrated from the media to the intima, have proliferated and deposited extracellular matrix, compromising 60 to $80 \%$ of the intimal cross-sectional area it can be stated that intimal hyperplasia is present ${ }^{39}$.

The 'outflow' needle jets the blood stream towards against the vessel wall. In in-vitro models, where the needle was oriented parallel to the long axis of a polytetrafluoroethylene (PTFE) graft, the velocity at the tip of the needle was $350 \mathrm{~cm} / \mathrm{s}$ with a needle flow of $300 \mathrm{ml} / \mathrm{min}$, reaching a velocity of $80 \mathrm{~cm} / \mathrm{s}$, some $6 \mathrm{~cm}$ downstream the needle, which approaches the velocity of normal graft flow ${ }^{37}$. The National Kidney Foundation guidelines ${ }^{4}$ suggest puncturing the AVF under a 25 degree $^{\circ}$ angle, with the purpose to align the needles parallel to the vessel wall. However, in daily practice the needles usually do not have a parallel orientation and are oriented towards one vessel wall ${ }^{40,41}$. The high-velocity jet 'hurts' the wall. This leads to endothelial denudation and, potentially may decrease nitric oxide production, which is known as a protective factor for the development of intimal hyperplasia ${ }^{42}$. It has been suggested, that the jet flow is a related factor towards the development of intimal hyperplasia ${ }^{42,43}$. Downstream of the outflow needle, where the jet entries the particles of the 'normal' flow in the vascular access, it creates a region of flow instability and turbulence. At the jet boundary regions, high-shear forces can be observed $^{43}$. Under high wall shear rates direct platelet activation occurs ${ }^{37}$. The platelets produce platelet-derived growth factor (PDGF) and other cytokines that 
create a proinflammatory enviroment downstream at the venous anastomosis ${ }^{43}$. Von Willebrand factor is also activated in high wall shear stress and contributes to the development of fibrin-platelet thrombi on PTFE surfaces. Fibrin deposition increases with rising shear rate in the presence of von Willibrand factor ${ }^{44,45}$. Thus needle jet creates conditions for the formation of thrombi and intimal hyperplasia ${ }^{40}$. There are still very little data on the real impact of the needles on vascular access complications. 


\section{References}

1. Tordoir J, Canaud B, Haage P, Konner K, Basci A, Fouque D, Kooman J, Martin-Malo A, Pedrini L, Pizzarelli F, Tattersall J, Vennegoor M, Wanner C, ter Wee P, Vanholder R. EBPG on Vascular Access. Nephrol Dial Transplant 2007;22 Suppl 2:ii88-117.

2. Hayes J. The role of nurses in maintenance of vascular access function. EDTNA/ERCA J 1998;XXIV:9-12.

3. Pisoni RL, Young EW, Dykstra DM, Greenwood RN, Hecking E, Gillespie B, Wolfe RA, Goodkin DA, Held PJ. Vascular access use in Europe and the United States: results from the DOPPS. Kidney international 2002;61:305-316.

4. NFK-K/DOQI. Clinical practice guidelines for vascular access: update July 2006. American Journal of Kidney Disease 2006;48:187-277.

5. Saran R, Dykstra DM, Pisoni RL, Akiba T, Akizawa T, Canaud B, Chen K, Piera L, Saito A, Young EW. Timing of first cannulation and vascular access failure in haemodialysis: an analysis of practice patterns at dialysis facilities in the DOPPS. Nephrol Dial Transplant 2004;19:2334-2340.

6. Tordoir JH, Mickley V. European guidelines for vascular access: clinical algorithms on vascular access for haemodialysis. EDTNA/ERCA journal (English ed 2003;29:131-136.

7. Lazarides MK, Staramos DN, Panagopoulos GN, Tzilalis VD, Eleftheriou GJ, Dayantas JN. Indications for surgical treatment of angioaccess-induced arterial "steal". Journal of the American College of Surgeons 1998;187:422-6.

8. Miles AM. Upper limb ischemia after vascular access surgery: differential diagnosis and management. Seminars in dialysis 2000;13:312-315.

9. Clinical Educators Network nursing recommendations for management of vascular access in hemodialysis patients. The CANNT Journal 2006;16 suppl 1.

10. Centers for Disease Control and Prevention. Recommendations for preventing transmission of infections among chronic hemodialysis patients. . Morbidity and Morality Weekly Report 2001;50:1314.

11. Kaplowitz LG, Comstock JA, Landwehr DM, Dalton HP, Mayhall CG. Prospective study of microbial colonization of the nose and skin and infection of the vascular access site in hemodialysis patients. Journal of clinical microbiology 1988;26:1257-1262.

12. Sawyer J, Febbraro S, Masud S, Ashburn MA, Campbell JC. Heated lidocaine/tetracaine patch (Synera, Rapydan) compared with lidocaine/prilocaine cream (EMLA) for topical anaesthesia before vascular access. British journal of anaesthesia 2009;102:210-215.

13. Ball LK. Improving arteriovenous fistula cannulation skills. Nephrol Nurs J 2005;32:611-617.

14. Suriti K, Suraj A. Principles of office anesthesia: Part II. Topical anesthesia. . American Family Physician 2002;66:91-97.

15. Krönung G. Plastic deformation of Cimino fistula by repeated puncture. Dial Transplant 1984;13:635638

16. Ozmen S, Kadiroglu AK, Ozmen CA, Danis R, Sit D, Akin D, Yilmaz ME. Does the direction of arterial needle in AV fistula cannulation affect dialysis adequacy? Clinical nephrology 2008;70:229-232.

17. Hartigan MF. Vascular access and nephrology nursing practice: existing views and rationales for change. Advances in renal replacement therapy 1994;1:155-162.

18. Brouwer D. Cannulation camp: Basic needle cannulation training for dialysis staff Dialyses and Transplantation 1995:606-612.

19. Brouwer D. Needle placement is paramount to achieving effective dialysis and preserving vascular accesses. Nursing Journal 2005;32:225-227.

20. English DJ. Retrograde arterial needle placement improves dialysis adequacy. Nephrol Nurs J 2005;32:224.

21. Unnikrishnan S, Huynh TN, Brott BC, Ito $\mathrm{Y}$, Cheng $\mathrm{CH}$, Shih AM, Allon M, Anayiotos AS. Turbulent flow evaluation of the venous needle during hemodialysis. Journal of biomechanical engineering 2005;127:1141-1146.

22. Brouwer DJ, Peterson P. The arteriovenous graft: how to use it effectively in the dialysis unit. Nephrology news \& issues 2002;16:41-4, 6, 8-9.

23. National Institutes of Health.The Gate theory of pain. 1997.

24. Fistula First. National vascular improvement initiative. http://www.fistulafirst.org/ 
25. Bhatia NP, Nkang AE, Walsh KB, Baker AJ, Ashwath N, Midmore DJ. Successful seed germination of the nickel hyperaccumulator Stackhousia tryonii. Ann Bot 2005;96:159-163.

26. Twardowski Z, Kubara H. Different sites versus constant sites of needle insertion into arteriovenous fistulas for treatment by repeated dialysis. . dialysis transplantation 1979;8:978-980.

27. Twardowski ZJ. Constant site (buttonhole)method of needle insertion for hemodialysis. Dial Transplant 1995;24:559-576.

28. Ball LK. The buttonhole technique for arteriovenous fistula cannulation. Nephrol Nurs J 2006;33:299304.

29. Peterson P. Fistula cannulation: the buttonhole technique. Nephrol Nurs J 2002;29:195.

30. Toma S, Shinzato T, Fukui H, Nakai S, Miwa M, Takai I, Maeda K. A timesaving method to create a fixed puncture route for the buttonhole technique. Nephrol Dial Transplant 2003;18:2118-2121.

31. Marticorena RM, Hunter J, Cook R, Kashani M, Delacruz J, Petershofer E, Macleod S, Dacouris N, McFarlane PA, Donnelly SM, Goldstein MB. A simple method to create buttonhole cannulation tracks in a busy hemodialysis unit. Hemodialysis international 2009;13:316-321.

32. Verhallen AM, Kooistra MP, van Jaarsveld BC. Cannulating in haemodialysis: rope-ladder or buttonhole technique? Nephrol Dial Transplant 2007;22:2601-2604.

33. Hakim R, Himmelfarb J. Hemodialysis access failure: a call to action. Kidney international 1998;54:1029-1040.

34. Perera GB, Mueller MP, Kubaska SM, Wilson SE, Lawrence PF, Fujitani RM. Superiority of autogenous arteriovenous hemodialysis access: maintenance of function with fewer secondary interventions. Annals of vascular surgery 2004;18:66-73.

35. Huber TS, Carter JW, Carter RL, Seeger JM. Patency of autogenous and polytetrafluoroethylene upper extremity arteriovenous hemodialysis accesses: a systematic review. J Vasc Surg 2003;38:1005-1011.

36. Marticorena RM, Hunter J, Macleod S, Petershofer E, Dacouris N, Donnelly S, Goldstein MB. The salvage of aneurysmal fistulae utilizing a modified buttonhole cannulation technique and multiple cannulators. Hemodialysis international 2006;10:193-200.

37. Malik J, Tuka V, Tesar V. Local hemodynamics of the vascular access for hemodialysis. Kidney \& blood pressure research 2009;32:59-66.

38. Lemson MS, Tordoir JH, Daemen MJ, Kitslaar PJ. Intimal hyperplasia in vascular grafts. Eur J Vasc Endovasc Surg 2000;19:336-350.

39. Van Tricht I, De Wachter D, Tordoir J, Verdonck P. Hemodynamics and complications encountered with arteriovenous fistulas and grafts as vascular access for hemodialysis: a review. Annals of biomedical engineering 2005;33:1142-1157.

40. Tuka V, Wijnen E, van der Sande FM, Tordoir JH. Dialysis needle hemodynamics in arterio-venous fistulae: a technical report. The journal of vascular access 2009;10:157-159.

41. Ortega JM, Small Wt, Wilson TS, Benett WJ, Loge JM, Maitland DJ. A shape memory polymer dialysis needle adapter for the reduction of hemodynamic stress within arteriovenous grafts. IEEE transactions on bio-medical engineering 2007;54:1722-1724.

42. Huynh TN, Chacko BK, Teng X, Brott BC, Allon M, Kelpke SS, Thompson JA, Patel RP, Anayiotos AS. Effects of venous needle turbulence during ex vivo hemodialysis on endothelial morphology and nitric oxide formation. Journal of biomechanics 2007;40:2158-2166.

43. Roy-Chaudhury P, Kelly BS, Zhang J, Narayana A, Desai P, Melham M, Duncan H, Heffelfinger SC. Hemodialysis vascular access dysfunction: from pathophysiology to novel therapies. Blood purification 2003;21:99-110.

44. Kroll MH, Hellums JD, Mclntire LV, Shafer Al, Moake JL. Platelets and shear stress. Blood 1996;88:1525-1541.

45. Cho JS, Ouriel K, DeWeese JA, Green RM, Chen GY, Stoughton J. Thrombus formation on polytetrafluoroethylene surfaces: the importance of von Willebrand factor. Cardiovascular surgery (London, England) 1995;3:645-651. 
Type of hemodialysis vascular access cannulation and practice patterns 
34 Chapter 2 


\section{Chapter 3}

\section{Implementation of a vascular access quality program improves vascular access care}

M. M. van Loon, W. van der Mark, N. Beukers, C. de Bruin, P.J. Blankestijn, R.M. Huisman, J.J. Zijlstra, F.M. van der Sande, J.H.M. Tordoir 


\section{Abstract}

\section{Introduction}

In the Netherlands an access quality improvement plan (QIP) was introduced by vascular access coordinators (VAC) with the aim to decrease vascular access-related complications by preemptive intervention of malfunctioning accesses.

\section{Methods}

A vascular access QIP was established in 24 centers (46\% of all Dutch facilities) and a structural multidisciplinary vascular access meeting was instituted.

In these centers, including 2300 patients, a protocol for enhancement of fistula creation and access surveillance program was implemented, with instruction of physicians and nurses, and rounds to discuss complications and evaluate vascular access interventions. The number and type of vascular access, permanent catheters, thrombosis rates and number of interventions were evaluated at the start and end of the study period.

\section{Results}

After the surveillance program, the number of autogenous arteriovenous fistulas (AVFs) had increased significantly from $69 \%$ to $77 \%(P<0.01)$, while the use of temporary subclavian vein catheters declined (34 vs. $11 \%)(P<0.01)$, with a substantially higher percentage of jugular vein catheters (from $23 \%$ to $35 \%$ ). Interventional treatment of malfunctioning accesses by percutaneous transluminal angioplasty (PTA) (from 0.39 to 0.50 patient/year; $P<0.001$ ) and surgical revisions (from 0.06 to 0.12 per patient/year; $P<0.001$ ) also increased.

\section{Conclusion}

These data demonstrate that a vascular access QIP resulted in placement of more autogenous AVFs, increased number of PTAs and surgical interventions. These findings suggest that a vascular access care QIP is worthwhile to improve dialysis patients' care and access morbidity. 


\section{Introduction}

Preservation of vascular access is critical in the successful management of hemodialysis patients. An adequately functioning access is a prerequisite to dialyse effectively, and therefore of vital importance for the hemodialysis patient. In 2006 in the Netherlands 5259 patients with end-stage renal disease (ESRD) rely on renal replacement therapy, of which 3907 patients depend on hemodialysis. As in most other countries, the number of patients with cardiovascular co-morbidities, diabetes mellitus and older age continues to increase, which makes the creation and maintenance of a well functioning vascular access more difficult. Vascular access complications continue to be a leading cause for hospitalization and morbidity in patients with ESRD. These complications have a negative effect on the quality of life of dialysis patients and may have a major impact on mortality.

To improve quality of life, the Kidney Disease Outcome Quality Initiative (K/DOQI) clinical practice guidelines for Vascular Access (update 2006) recommended an increased use of autogenous arteriovenous fistulas (AVFs) and prevention of access dysfunction by surveillance and preemptive intervention ${ }^{4}$. The reason for this is the longevity and fewer complications of AVFs as compared with grafts and central vein catheters.

The Dialysis Outcomes and Practice Pattern Study (DOPPS) estimated an $80 \%$ autogenous AVF rate in Europe compared to $24 \%$ in the USA ${ }^{5}$. In the Netherlands overall, $61 \%$ of the prevalent hemodialysis patients were dialyzed through an $\mathrm{AVF}^{6}$. Although the necessity of structural vascular access management has been recognized, there is a substantial variation among individual facilities in the Netherlands (52 dialysis facilities) concerning the care of the vascular access. Most of the dialysis facilities have no uniform vascular access surveillance program, education and information for caregivers and patients and database to register access creation, surveillance and intervention rates.

The aim was to improve the quality of vascular access care by implementing a quality improvement program (QIP). The program was meant to: firstly increase awareness and commitment to vascular access of all parties involved, and secondly to monitor outcome parameters, to quantify the effectiveness of the initiative.

\section{Methods}

For the vascular access program 27 dialyses facilities (three academic dialysis centers, 21 dialysis centers in general hospitals and three other centers) representing more than $50 \%$ of all dialysis facilities in the Netherlands were randomly selected and split into three regions.

A taskforce group was created including representatives of the nephrologists, radiologists, and vascular surgeons together with three nurses trained as vascular 
access coordinators (VACs). This taskforce defined standardized procedures and developed multidisciplinary protocols for the construction, maintenance and intervention of the vascular access all based on internationally accepted quality standards (K/DOQI). The QIP included two steps. The first step was meant to improve awareness and commitment of all parties involved, i.e. nephrologists, radiologists, vascular surgeons and dialysis staff. The QIP consisted of an analysis of the baseline situation, defining targets for improvement (summarized in an advisory report), organizing regular meetings, and institution of an education program and of an access surveillance program, which included physical examination, monitoring pressures and access flow. For the management of the QIP each dialysis department was asked to identify a Vascular Access Nurse (VAN), interested in being a key member for the execution of the program. Because the QIP could only be achieved if there was an integrated multidisciplinary approach to vascular access care, every centre was asked to identify a nephrologist, surgeon and interventional radiologist from their staff who could participate in the program. The VAN was the key member in the improvement program, with the purpose of streamlining the communication between the dialysis unit, the involved physicians and the VACs. The VAC regularly visited the dialysis centers with the purpose to guide the center in the program.

In the second step of the QIP prospective monitoring of outcome variables including type of access in incident patients, surgical and radiological interventions, thrombosis rate and central venous catheter was performed.

\section{Statistical analysis}

A comparison between baseline data at the start of the study and data at the end of implementation of the QIP was performed. Data were analysed by SPSS 12.0. A Pvalue less then 0.01 is considered significant.

\section{Results}

During a 3-year period, 27 (51\%) of the Dutch dialysis facilities, including more than 2300 patients, participated in the vascular access QIP. In all centers an advisory rapport was completed and, with support of the VACs, the program was established. In 24 centers (89\%) it was possible to perform a final report/measurement. In three centers the time since program initiation was too short to evaluate the effects.

\section{Surveillance program}

During the vascular access improvement program, in $88 \%$ of the centers vascular access monitoring protocols (at baseline 33\%) were introduced and implemented. At the end of the program in $91 \%$ of the centers, complete clinical examination was 
performed before each cannulation. This was a substantial improvement from baseline: inspection and palpation in $62 \%$, and auscultation in $21 \%$ of the centers. Registration of venous and/or arterial pressures during hemodialysis treatment at normal dialyser flow was common. To monitor the vascular access function during hemodialysis, $88 \%$ of the centers used the ultrasound dilution technique (at baseline $58 \%$ ). All of the hemodialysis centers established structural multidisciplinary evaluation meetings (at baseline $79 \%$ ). In $67 \%$ of the centers multidisciplinary predialysis care was instituted including education, preservation of veins, pre-operative vein mapping, early fistula creation and a follow up for fistula maturation (at baseline $21 \%)$.

\section{Education}

In $88 \%$ of the centers an integrated continuous education program on vascular access care has been established, which improves the knowledge and technical skills of the dialysis staff (at baseline 33\%). All centers have developed a variety of teaching methods for patients and their family/caregivers including videos, written instructions and meetings to improve quality of care and outcomes of vascular accesses (at baseline $87 \%)$.

\section{Outcome parameters}

The baseline period included 14 months of follow up, and the intervention period was 12 months. The number of newly created autogenous AVFs in incident patients increased significantly, from $69 \%$ to $77 \%(P<0.01)$, with $54 \%$ forearm, and $23 \%$ upper arm AVFs $(P<0.01)$ (Figure 3.1). The use of AVFs among prevalent patients increased from $61 \%$ to $64 \%(P<0.01)$ (Figure 3.2$)$. During the program the percentage of nontunneled subclavian vein catheters decreased from $34 \%$ to $11 \%(P<0.01)$, while nontunneled catheters in the jugular vein increased from $11 \%$ to $21 \%(P<0.01)$ (Figure 3.3). A significant greater percentage of the patients were using tunneled central vein catheters from $22 \%$ to $34 \%(P<0.01)$ instead of non-tunneled catheters ( 78 vs. $66 \%$ ) (Figure 3.3).

Interventional treatment of malfunctioning accesses by PTA increased from 0.39 to 0.50 interventions per patient/year $(P<0.001)$ (Table 3.1$)$, as well as surgical intervention (from 0.06 to 0.12 per patient/year; $P<0.001$ ) (Table 3.2). At the start of the program most centers did not have an adequate registration of vascular access problems. At the end of the program all centers did have adequate registration and the prevalence of arteriovenous graft (AVG) thrombosis could be calculated to be 0.41 per patient year. 


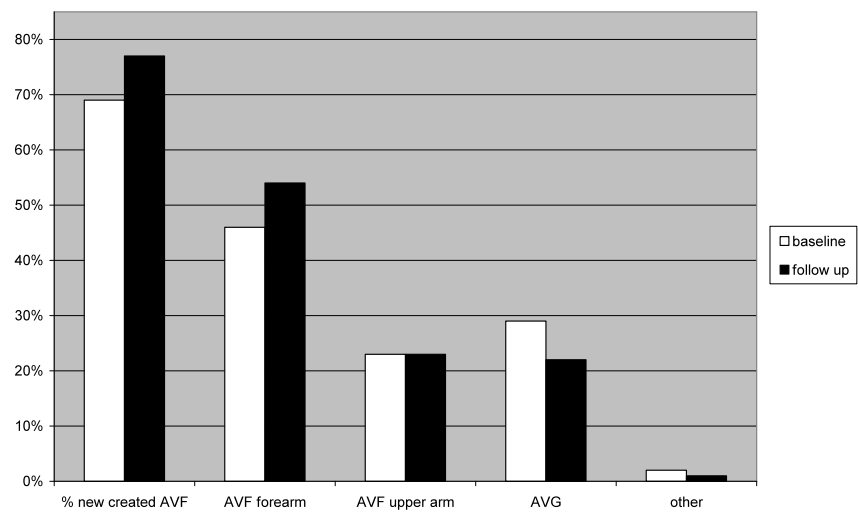

Figure 3.1 Vascular access creation.

AVF: arteriovenous fistula: AVG: arteriovenous graft

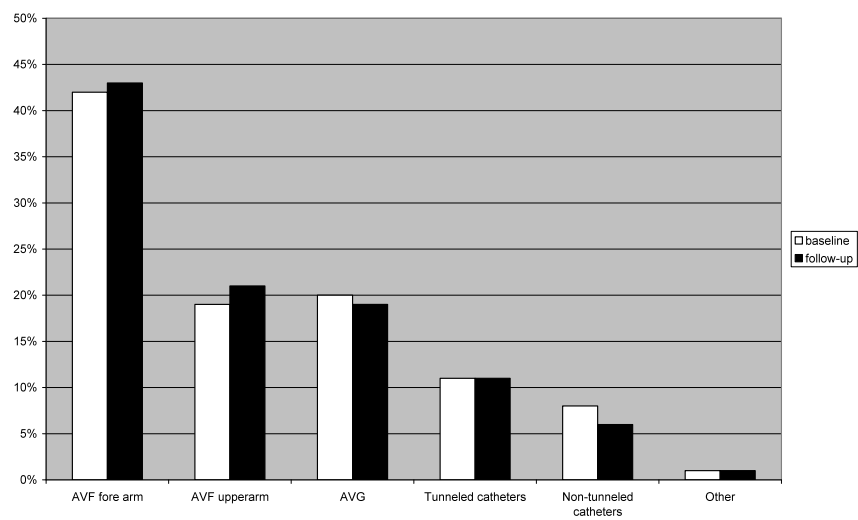

Figure 3.2 Vascular access use among prevalent hemodialysis patients. AVF: arteriovenous fistula: AVG: arteriovenous graft

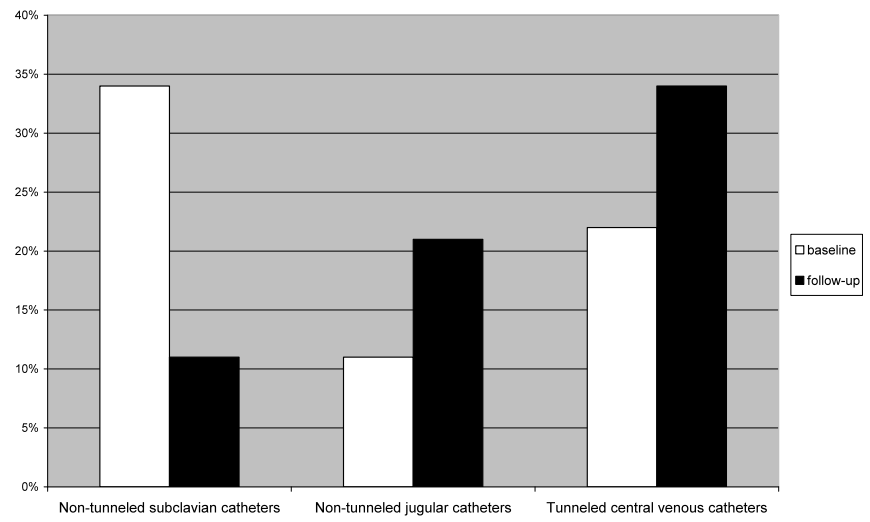

Figure 3.3 Catheter use among hemodialysis patients. 
Table 3.1 Interventional treatment by radiology

\begin{tabular}{lcc}
\hline & Base line & Follow-up \\
\hline A-V Fistula & 1244 & 1355 \\
A-V Graft & 408 & 390 \\
Angiography combined with PTA & 638 & 869 \\
Interventions per patient/year & 0.39 & $0.50^{*}$ \\
\hline
\end{tabular}

$* P<0.001$

Table 3.2 Surgical Interventional treatment

\begin{tabular}{lcc}
\hline & Base line & Follow-up \\
\hline A-V Fistula & 1040 & 1136 \\
AVF revisions per patient/year & 0.06 & $0.12^{*}$ \\
A-V Graft & 344 & 313 \\
AVG revisions per patient/year & 0.16 & 0.21 \\
\hline
\end{tabular}

$* P<0.001$

\section{Discussion}

To the best of our knowledge this is one of the largest initiatives, in terms of number of participating centers and patients, meant to improve quality of vascular access care. The present study shows that introducing and implementing a QIP led firstly to more awareness and commitment with those involved in the care of vascular access and secondly that this was translated in an improvement of some aspects of quality of care.

The introduction of a vascular access QIP resulted in placement of significantly more autogenous AVFs in incident patients, and led to a small increase of fistula use among prevalent patients. The latter can be explained by the number of primary failures and the short observation period. The percentage of PTAs and surgical interventions also increased, indicating early diagnosis of significant stenosis by an anticipating surveillance program.

Various studies have reported a decline in thrombosis rate for AVG after implementation of a vascular access surveillance program, if coupled with a program of elective stenosis correction ${ }^{1,2,9-14}$. Summarizing the described results in mentioned studies AVG thrombosis rates of $<0.5$ per patient/year should be possible. The AVG thrombosis rate of 0.41 per patient/year in this study underlines these findings. Although the program was not designed to investigate the effects of outcomes on patency rate and vascular access quality, the results appear promising. Although the thrombosis rate decreased, the number of tunneled jugular vein catheters increased at the expense of catheters inserted through the subclavian vein route and nontunneled catheters. This development is in line with the recommendations of K/DOQI and helps to diminish catheter-related infections and central vein obstruction ${ }^{4}$. On the 
other hand we could not establish a decrease in the total number of central vein catheters, as recently have been shown by Asif et al. were the implementation of a QIP reduced the use of tunneled catheters ${ }^{17}$.

At the start of the program there was a substantial variation among individual facilities in the Netherlands concerning the care of the vascular access. To improve vascular access care and outcomes it is essential to implement the recommendations of the K/DOQI Clinical Practical Guidelines for Vascular Access and European Guidelines on vascular access ${ }^{3,4,15}$. Because of the multidisciplinary character of vascular access care it was a prerequisite to develop an integrated multidisciplinary approach in all participating facilities. The vascular access quality program focused on establishing pre-dialysis care, implementing access surveillance to detect problems in an early stage, and an education program for patient and their family and caregivers as well as dialysis staff. The update $\mathrm{K} / \mathrm{DOQ}$ guidelines published in $2006^{4}$ underline the importance of a multidisciplinary approach to vascular access related problems both in pre-dialysis and in hemodialysis patients in preventing malfunctioning fistulas. Mishler et al. also showed that a dedicated outpatient vascular access center decreased the number of hospitalizations and dialysis treatments ${ }^{8}$. In addition, the increase in number of AVFs is in agreement with the K/DOQI guidelines ${ }^{3,4}$.

The importance and value of the VACs in this project were to realize changes in vascular access care in the studied dialysis centers by developing, implementing, coordinating and managing the process of vascular access surveillance, stimulating and motivating the multidisciplinary taskforces related to surveillance, and streamline communication and evaluation between professionals involved in vascular access care.

The implementation of such a vascular access QIP is time demanding, and cost consuming. To continue the program and study the effects of the investments and efforts, it is required to measure and communicate the effects of this approach. Therefore it is a crucial factor and prerequisite for individual centers to have a standardized database system to collect prospective data about procedures and complications. These data make it possible to monitor and evaluate outcomes and if necessary make adjustments to the process related to vascular access $3,4,5,7,15$.

Although we did not investigate the impact of a QIP on healthcare costs, McCarley et al. did show the cost effectiveness of an access flow based surveillance program ${ }^{16}$. They calculated a reduction in the number of thrombosis rates in both AVGs and AVFs, which had a beneficial effect on patient comfort and healthcare costs.

The vascular access QIP has shown to be successful. It has been the first step towards a wide standardized and uniform approach of vascular access care, based on international quality standards. The data revealed an important contribution to the process of continuous quality improvement, especially with regard to development and implementation of quality instruments. The next step is to establish a continuous process of evaluation of outcome parameters. For the future a challenge will be to 
continue the program and measure the impact of this quality improvement initiative from a patient perspective.

In conclusion, the data from this study demonstrate that implementation of a vascular access QIP results in placement of more autogenous AVFs in incident patients, increased number of PTAs and surgical interventions. These findings suggest that a vascular access care program is worthwhile to improve dialysis patients' care and access morbidity. 


\section{References}

1. Fistula First. National Vascular Access Improvement Initiative. December 6, 2005.

2. McGill RL, Marcus RJ, Healy DA, Brouwer DJ, Smith BC, Sandroni SE. AV fistula rates: changing the culture of vascular access. J Vasc Access 2005;6:13-17.

3. NKF-K/DOQI: Clinical practice guidelines for vascular access: Update 2000. Am J Kidney Dis 2001;37: S137-S181.

4. NKF-K/DOQI: Clinical practice guidelines for vascular access: Update July 2006. Am J Kidney Dis 2006; 48:S187-S277.

5. Pisoni RL, Young EW, Dykstra DM, Greenwood RN, Hecking E, Gillespie B, Wolfe RA, Goodkin DA, Held PJ. Vascular access use in Europe and the United States: results from the DOPPS. Kidney Int 2002;61:305-316.

6. Haemodialysis vascular access and fistula surveillance methods in The Netherlands

7. R Ezzahiri, MS Lemson, PJEHM Kitslaar, KML Leunissen, JHM Tordoir Nephr Dial Transplant 1999;14:2110-2115.

8. Random Sample (DOPPS) versus Census-Based (Registry) Approaches to Kidney Disease Research Friedrich K. Port, Robert A. Wolf, Philip J.Held, EricW. Young. Blood Purif 2003;21:85-88.

9. Mishler R, Sands JJ, Ofsthun NJ, Teng M, Schon D, Lazarus JM. Dedicated outpatient vascular access center decreases hospitalization and missed outpatient dialysis treatments. Kidney Int 2006; 69;393-398.

10. Pisoni RL, Young EW, Mapes DL, Keen ML, Port FK. Vascular access use and outcomes in the U.S., Europe, and Japan: results from the Dialysis Outcomes and Practice Patterns Study. Nephrol News Issues 2003;17:38-43.

11. Schwab S, Oliver M, Suhocki P, McCann R. Hemodialysis arteriovenous access: Detection of stenosis and response to treatment by vascular access blood flow. Kidney Int 2001;59:358-362.

12. Valj K. Prophylactic angioplasty: Is it worthwhile?; in Gray RJ, Sands JJ (eds): Dialysis Access: A Multidisciplinary Approach. Philadelphia, Lippincott Williams \& Wilkins, 2002:153-156.

13. Sands J, Jabyac P, Miranda C, Kapsick B. Intervention based on monthly monitoring decreases hemodialysis access thrombosis. ASAIO J 1999;45:147-150.

14. Smits JH, van der Linden J, Hagen EC, Modderkolk-Cammeraat EC, Feith GW, Koomans HA, van den Dorpel MA, Blankestijn PJ. Graft surveillance: Venous pressure, access flow or the combination? Kidney Int. 2001;59:1551-1558.

15. Allon M, Bailey R, Ballard R, Deierhoi MH, Hamrick K, Oser R, Rhynes VK, Robbin ML, Saddekni S, Zeigler ST. A multidisciplinary approach to haemodialysis access: Prospective evaluation. Kidney Int 1998;53:473-479.

16. Bakran A, Mickley V, Passlick-Deetjen J, Management of the Renal patient. Clinical Algorithms on Vascular Access for Haemodialysis 2003.

17. McCarley P, Wingard RL, Shyr Y, Pettus W, Hakim R, Ikizler TA. Vascular access blood flow monitoring reduces access morbidity and costs. Kidney Int 2001;60:1164-1172.

18. Asif A, Gautam C, Merrill D, Cipleu CD, Bri P. Conversion of tunneled hemodialysis catheter-consigned patients to arteriovenous fistula. Kidney Int 2005;67:2399-2406. 
Implementation of a vascular access quality program improves vascular access care 
$46 \mid$ Chapter 3 


\section{Chapter 4}

Cannulation and vascular access related complications in hemodialysis: factors determining successful cannulation

M.M. van Loon, A.G.H. Kessels, F.M. van der Sande, J.H.M. Tordoir 


\section{Abstract}

\section{Background}

Little is known about cannulation of the vascular access, such as number of successful cannulation procedures, frequency of complications caused by cannulation, and vascular access failure.

\section{Methods}

Incident patients were followed six months, from the first successful cannulation with two needles - both used for the hemodialysis treatment. Data included patient characteristics, comorbidities, and medication. Vascular access characteristics included: type of vascular access and location, vein diameter assessed by Duplex ultrasound, length of cannulation route, and maturation period. Longitudinal data were collected by dialysis nurses, using identical questionnaires and a standardized method to register data from each dialysis session.

\section{Results}

Among 10 Dutch dialysis facilities, clinical data from 120 patients were collected from June 2005 to March 2007. The use of autogenous arteriovenous fistulae (AVF) $(P<0.001)$ and limited length of cannulation route $(P<0.003)$, negatively affect the outcome of cannulation and complications such as use of single needle dialysis and central vein catheters (CVC). Previous use of CVC and single needle hemodialysis were significant predictors for vascular access failure $(P<0.0001)$.

\section{Conclusion}

The present study demonstrated that during the first 6 months of a newly placed vascular access a great number of cannulation-related complications such as miscannulation, use of CVC and single needle dialysis are encountered. Despite the fact that guidelines recommended the AVF as the preferred vascular access, cannulation-related complications can lead to increased morbidity. The length of the cannulation route positively correlates with successful cannulation. Therefore, adjusted cannulation techniques might be indicated to improve vascular access outcome 


\section{Introduction}

A well functioning vascular access is a prerequisite for successful dialysis treatment. Over the past two decades, the dialysis population has undergone profound changes. The creation and maintenance of vascular access has become more challenging due to cardiovascular comorbidities and diabetes mellitus, which negatively influence the quality of the vessels for vascular access construction, resulting in vascular access complications and even failure.

There is little known about the influence of repeated cannulation on the quality of the vascular access, risk of complications, and access failure. Ideally, a permanent vascular access should be easily accessible and suitable for long-term use with minimal risk of cannulation complications and need for temporary central vein catheter (CVC).

It is reasonable to assume that complications caused by cannulation, such as haematoma, infection and aneurysm formation, lead to morbidity, hospitalisation, access revision and loss of the access. Besides that, the cannulation can be painful and burdensome for the patient, which has a negative impact on the quality of life.

In the Dialysis Outcomes and Practice Patterns Study (DOPPS) ${ }^{1}$, early cannulation of newly placed vascular access was not associated with an increased risk of vascular access failure. Only if AVFs were first cannulated within 14 days of creation, there was a significant, detrimental effect on subsequent AV fistula survival. However in this study, no information on the number of successful/failed cannulations and minor - or major cannulation -related complications were provided.

To prevent cannulation-related complications it is important to gain insight into, and identify factors that may be related to difficult and complicated cannulations.

Therefore, a prospective observational study of incident patients with a newly created AVF and arteriovenous grafts (AVGs) was performed, from the first cannulation with a 6 months follow up. The aim of the study was primarily to investigate predictors for unsuccessful cannulation, time to cannulation complications, vascular access failure, and secondarily to identify factors that may be associated with cannulation-related complications.

\section{Methods}

\section{Study design}

This prospective observational study evaluated the complications caused by cannulation and the clinical consequences in newly created vascular accesses in incident patients. The patients were followed from the first cannulation with a follow up time of six months. Clinical data were collected from 1 June 2005 to 1 March 2007 in 10 Dutch dialysis facilities. The study protocol was approved by the Medical Ethical Committee of the University Hospital Maastricht. 
Data included patient characteristics, comorbidities, and medication. Vascular access characteristics included: type of vascular access, location, a single measurement of vein diameter ( 6 weeks after access creation) by Duplex ultrasound (Aloka 5500, Tokyo, Japan), maturation time, and length of the cannulation route. The technique of cannulation route measurement was standardized in all centers and carried out by an experienced dialysis nurse. After placement of a tourniquet around the upper arm, the usable length of the vein for cannulation was measured with standard tape lint and length expressed in centimetres.

All centers used the rope ladder method for cannulation, where the whole access length of the vascular access is used for cannulation. Needle insertion was as much as possible standardized, with antegrade insertion of the outflow needle, the inflow needle inserted antegrade in AVFs, and retrograde in AVGs. In both groups, the needle position was bevel-up. The dialyser flow was in all patients $250-350 \mathrm{ml} / \mathrm{min}$.

During the study period data were collected by dialysis nurses, using identical Case Record Forms (CRF) and a standardized method to register these data from each dialysis session. A CRF was used to register relevant parameters for cannulation practice, like: number of cannulations per hemodialysis session; access flow measurements using ultrasound dilution technique (Transonic Systems, Inc Ithaca, USA) and the need for CVC insertion if the vascular access was not accessible because of hematoma or other reasons.

\section{Outcome definitions}

Duplex ultrasound at 6 weeks was used to determine the diameter of vein. The length of usable vein traject was determined by physical examination. In most patients the decision for first time cannulation was made by an experienced dialysis nurse, with in some patients also inspection by the vascular surgeon or nephrologist.

An access flow of $>500 \mathrm{~m} / \mathrm{min}$ with a vein diameter of $>4 \mathrm{~mm}$ was determined as a mature fistula ${ }^{2}$. Functional patency started when a vascular access had been successfully used for hemodialysis treatment for the first time ${ }^{3}$. A cannulation procedure was judged as successful if the dialysis nurse was able to insert two needles, both used for the hemodialysis treatment, without miscannulation. Miscannulation is defined as the need to insert more than one needle per arterial or venous connection. Complications means the need for temporary CVC or single needle hemodialysis ${ }^{4}$.

\section{Statistical Analysis}

Statistical analysis was performed using SPSS software for Windows (SPSS release12.0, SPSS Inc, Chicago, IL, USA). Results were expressed as mean \pm standard deviation (SD). All analyses were performed for the AVF and AVG groups separately. Kaplan-Meier analysis was used to investigate the vascular access survival without miscannulation and complications. Univariate and multivariate analysis were determined with the Cox 
regression analysis, to examine independent variables of significance. Variables were entered into a stepwise forward analysis. For all comparisons, the level of significance was set to $P<0.05$.

\section{Results}

\section{Patients}

A total of 120 incident hemodialysis patients with first vascular access were included. The demographics and medical history of the patients are outlined in Table 4.1 and 4.2. The mean age was 67 years \pm 13.5 (SD) (range $21-90 \mathrm{yrs}$ ), $37 \%$ of the patients were female $(n=45)$. The mean follow-up time was 155 days (range 13 to 199 days) and was completed in $83 \%$ of patients. Twenty-one patients $(18 \%)$ were lost to follow up due to the following reasons: seven death $(6 \%)$, one successful kidney transplantation $(0.8 \%)$, six vascular accesses failures $(6 \%)$, and seven patients started hemodialysis at a non participating facility (5.8\%).

Table 4.1 Patient characteristics in AVF and AVG.

\begin{tabular}{|c|c|c|c|c|}
\hline Characteristics & $n$ & AVF & AVG & $P$ \\
\hline & 120 & $89(74 \%)$ & $31(26 \%)$ & \\
\hline Gender & & & & 0.70 \\
\hline Female & 45 & $33(37 \%)$ & 12 (39\%) & \\
\hline Male & 75 & $56(63 \%)$ & $19(61 \%)$ & \\
\hline Age (y) & & & & 0.13 \\
\hline $21-60$ years & 34 & $27(36 \%)$ & $7(21 \%)$ & \\
\hline $61-75$ years & 47 & $32(35 \%)$ & $15(48 \%)$ & \\
\hline$>75$ & 39 & $30(30 \%)$ & $9(31 \%)$ & \\
\hline Causes of ESRD & & & & 0.65 \\
\hline Glomerulonephritis & 14 & $10(11 \%)$ & $4(13 \%)$ & \\
\hline Interstitial nephritis & 8 & $5(7 \%)$ & $3(10 \%)$ & \\
\hline Cystic kidney diseases & 2 & $2(2 \%)$ & - & \\
\hline Other congenital/hereditary kidney diseases & 1 & $1(1 \%)$ & - & \\
\hline Renal vascular diseases & 30 & $22(25 \%)$ & $8(26 \%)$ & \\
\hline Diabetes mellitus & 27 & $19(21 \%)$ & $8(26 \%)$ & \\
\hline Other multisystem diseases & 15 & $13(15 \%)$ & $2(6 \%)$ & \\
\hline Other / Unknown & 23 & $17(19 \%)$ & $6(19 \%)$ & \\
\hline Vintage on hemodialysis & & & & 0.32 \\
\hline $0 \mathrm{mo}$ & 65 & $49(55 \%)$ & $16(52 \%)$ & \\
\hline 1 to $6 \mathrm{mo}$ & 41 & $29(33 \%)$ & $12(39 \%)$ & \\
\hline 6 to $12 \mathrm{mo}$ & 11 & $9(10 \%)$ & $2(7 \%)$ & \\
\hline$\geq 12 \mathrm{mo}$ & 3 & $2(2 \%)$ & $1(3 \%)$ & \\
\hline Body Mass Index ${ }^{a}$ & & & & 0.30 \\
\hline$\leq 30 \mathrm{~kg} / \mathrm{m}^{2}$ & 94 & $71(80 \%)$ & $23(75 \%)$ & \\
\hline$>30 \mathrm{~kg} / \mathrm{m}^{2}$ & 25 & $18(20 \%)$ & $7(23 \%)$ & \\
\hline Tobacco use & & & & 0.73 \\
\hline Yes & 19 & $15(17 \%)$ & $4(13 \%)$ & \\
\hline No & 101 & 74 (83\%) & 27 (87\%) & \\
\hline
\end{tabular}

\footnotetext{
${ }^{a}$ Values were missing for some patients. AVF: arteriovenous fistula; AVG: arteriovenous graft
} 
Table 4.2 Patient comorbidity and medication in AVF and AVG.

\begin{tabular}{lrrrr}
\hline & $n$ & AVF & \multicolumn{1}{c}{ AVG } & $P$ \\
\hline Medical history & & & & \\
$\quad$ Peripheral arterial obstructive disease & 16 & $9(10 \%)$ & $7(23 \%)$ & $\mathbf{0 . 0 8}$ \\
$\quad$ Coronary artery disease & 38 & $26(29 \%)$ & $12(39 \%)$ & $\mathbf{0 . 5 4}$ \\
$\quad$ Cerebrovascular disease & 21 & $13(15 \%)$ & $9(29 \%)$ & $\mathbf{0 . 1 2}$ \\
$\quad$ Diabetes mellitus & 45 & $28(31 \%)$ & $17(55 \%)$ & $\mathbf{0 . 0 2}$ \\
$\quad$ Hypertension & 50 & $36(40 \%)$ & $14(45 \%)$ & $\mathbf{0 . 6 4}$ \\
Medication & & & & \\
$\quad$ Use of calcium antagonist & 36 & $29(33 \%)$ & $9(29 \%)$ & $\mathbf{0 . 7 1}$ \\
$\quad$ Use of anticoagulants & 36 & $22(25 \%)$ & $14(45 \%)$ & $\mathbf{0 . 0 3}$ \\
$\quad$ Use of platelet aggregation inhibitor & 38 & $26(29 \%)$ & $12(39 \%)$ & $\mathbf{0 . 3 4}$ \\
$\quad$ Use of EPO & 111 & $84(94 \%)$ & $27(87 \%)$ & $\mathbf{0 . 1 8}$ \\
\hline
\end{tabular}

AVF: arteriovenous fistula; AVG: arteriovenous graft

\section{Vascular access}

The type of the vascular access placed was $74 \%$ AVFs and $26 \%$ AVGs. AVFs were first cannulated within 119 days (range 7-637 ds), and AVGs were cannulated within 70 days (range 3-524 days). The mean diameter for the AVF was $5.4 \mathrm{~mm}$ (range 2.4$17 \mathrm{~mm}$ ) and for the AVG $5.5 \mathrm{~mm}$ (range 4-10 mm). Furthermore the mean length of the AVF cannulation route was $13 \mathrm{~cm}$ (range 2-28 cm) and the mean AVG cannulation route was $23 \mathrm{~cm}$ (range 10-38 cm), (Table 3.3 ).

During the follow up only 11 patients (9\%) had uncomplicated cannulations with two needles for every hemodialysis treatment. In 61 patients (51\%) miscannulation occurred during the first three dialysis sessions. The mean frequency of miscannulation for patients with AVFs was two times higher than AVGs.

Forty-nine patients $(41 \%)$ used a CVC $(n=20)$ or had a single needle $(n=29)$ dialysis during the follow up period, because the vascular access was not accessible for two needles. 94\% of these patients had an AVF. The median duration of CVC dependence was 11 days for the AVF group, and 1.5 days for the AVG group. $(P<0.010)$. At six months $93 \%(n=83)$ of the patients with an AVF, and $97 \%(n=30)$ of patients with an AVG were able to dialyze with a permanent vascular access.

\section{Factors associated with successful cannulation}

The outcome of successful cannulation in the AVG group was significantly better compared with the AVF group (Figure 4.1). By separate analysis for AVF and AVG, no distinct significant predictors for AVFs were found, while AVG creation in the dominant arm was associated with successful cannulation. $(P<0.02)$. 
Table 4.3 Comparison of vascular access characteristics between the AVF and AVG group.

\begin{tabular}{|c|c|c|c|}
\hline Characteristics & AVF & AVG & $P$ \\
\hline \multicolumn{4}{|l|}{ Access placement } \\
\hline Forearm vascular access & $50(56 \%)$ & $29(94 \%)$ & \\
\hline Upper arm vascular access & $39(44 \%)$ & $2(6 \%)$ & \\
\hline Vascular access in dominant arm & & & 0.11 \\
\hline No & $69(76 \%)$ & $28(90 \%)$ & \\
\hline Yes & $20(22 \%)$ & $3(10 \%)$ & \\
\hline Length of the cannulation route ${ }^{a}$ & & & 0.001 \\
\hline 0 to $7 \mathrm{~cm}$ & $13(15 \%)$ & $0(0 \%)$ & \\
\hline 7 to $14 \mathrm{~cm}$ & $36(40 \%)$ & $2(6 \%)$ & \\
\hline$>14 \mathrm{~cm}$ & $40(45 \%)$ & $29(92 \%)$ & \\
\hline Access diameter (duplex)* & & & 0.13 \\
\hline $2-4 m m$ & $16(18 \%)$ & $6(19 \%)$ & \\
\hline $4-6 \mathrm{~mm}$ & $22(25 \%)$ & $20(65 \%)$ & \\
\hline$>6 \mathrm{~mm}$ & $10(11 \%)$ & $3(10 \%)$ & \\
\hline Maturation time (weeks) & & & 0.001 \\
\hline $0-3$ wks & $1(1 \%)$ & $10(32 \%)$ & \\
\hline $3-6$ wks & $16(18 \%)$ & $7(23 \%)$ & \\
\hline $6-12$ wks & $39(44 \%)$ & $9(29 \%)$ & \\
\hline$>12$ wks & $33(37 \%)$ & $5(16 \%)$ & \\
\hline Access blood flow (Transonic Systems $\left.{ }^{\circledR}\right)^{*}$ & & & 0.10 \\
\hline$<500 \mathrm{ml} / \mathrm{min}$ & $17(19 \%)$ & $3(10 \%)$ & \\
\hline$>500 \mathrm{ml} / \mathrm{min}$ & $55(62 \%)$ & $22(71 \%)$ & \\
\hline
\end{tabular}

* Values were missing for some patients; ${ }^{a}$ Consistent by reporting standards of Sideway et al. ${ }^{17}$; AVF: arteriovenous fistula; AVG: arteriovenous graft.

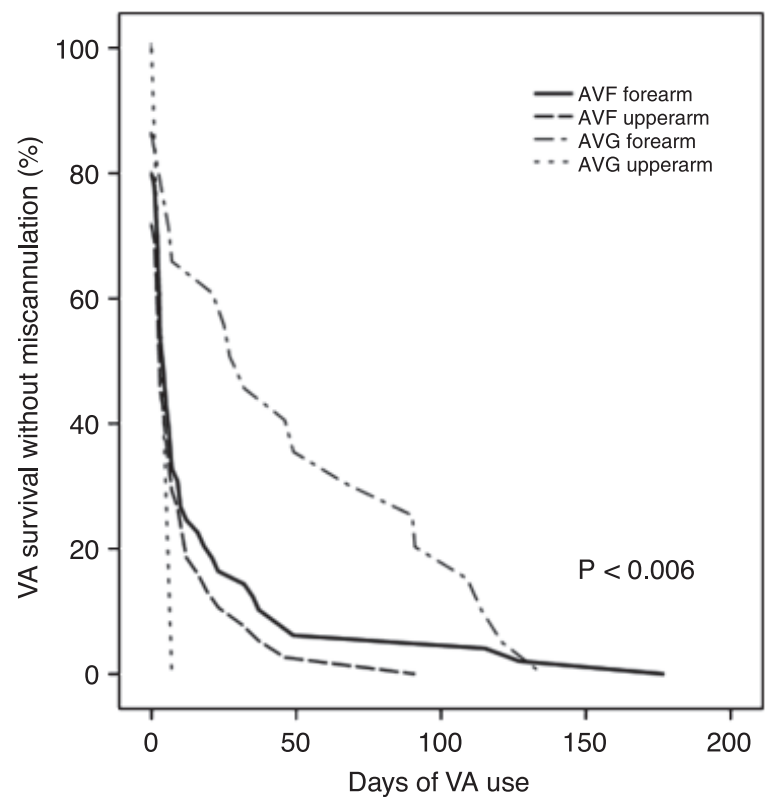

Figure 4.1 Outcome without miscannulation for each type of vascular access. AVF: arteriovenous fistula; AVG: arteriovenous graft. 


\section{Factors associated with CVC dependence or single needle dialysis}

Univariate analysis showed that the type of vascular access $(P<0.001)$ was associated with CVC dependence or single needle dialysis. Figure 4.2 demonstrates that AVGs in the forearm had fewer complications than other forms of accesses.

Univariate analysis (Table 4.4 and 4.5), showed for patients with an AVF, that female gender $(P<0.02)$ and limited length of cannulation route $(P<0.003)$ (Figure 4.3$)$ were significant determinants for CVC dependence or single needle dialysis. When these variables were placed into a multivariate regression analysis model, only the limited length of cannulation route was a single predictive variable $(P<0.002)$.

For both, the AVF and AVG, no association was seen between access flow of $>500 \mathrm{ml} / \mathrm{min}$ and cannulation-related complications.

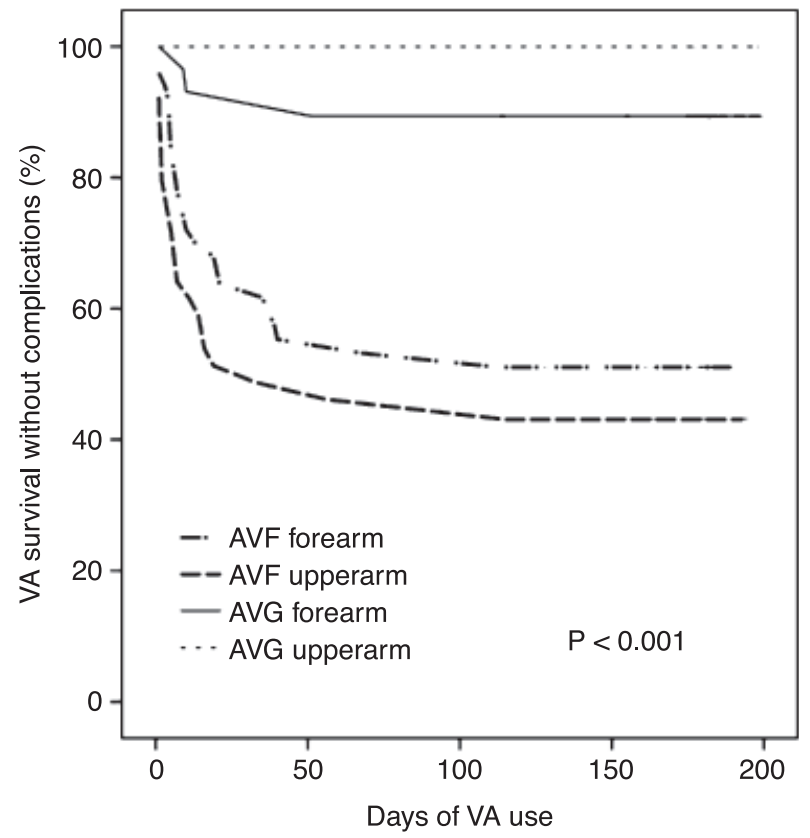

Figure 4.2 Complications like use of central venous catheters or a single needle dialysis in relation to type of vascular access. AVF: arteriovenous fistula; AVG: arteriovenous graft. 


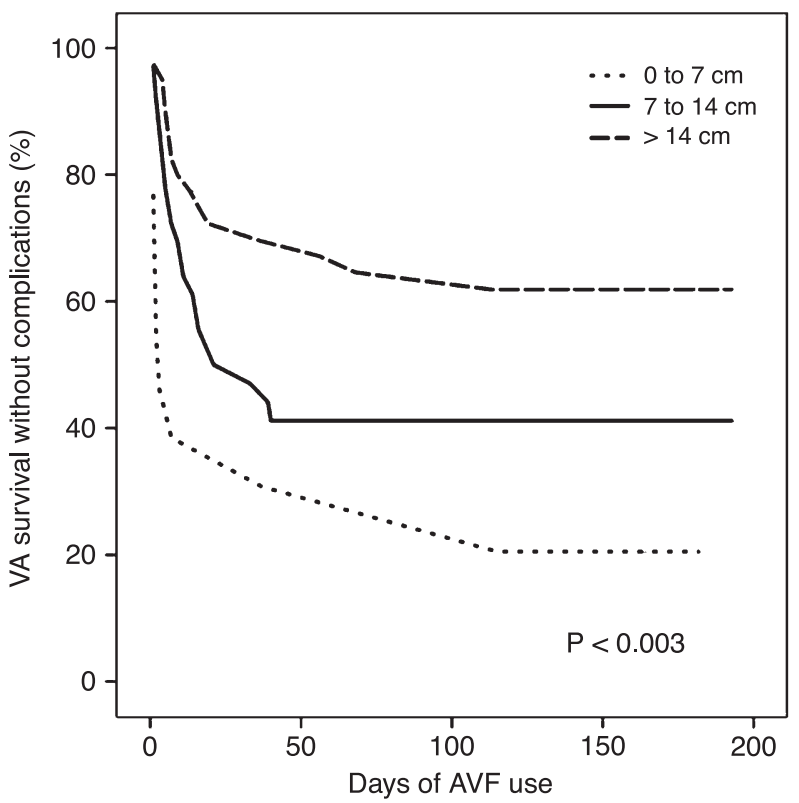

Figure 4.3 Survival without complications like use of central venous catheters or a single needle dialysis in relation to length of cannulation route of the AVF. AVF: arteriovenous fistula.

Table 4.4 Univariate hazard ratio of demographics and comorbidities for cannulation-related complications in the AVF, and AVG group.

\begin{tabular}{llccc}
\hline Characteristics & AVF & $95 \% \mathrm{Cl}$ & AVG & $95 \% \mathrm{Cl}$ \\
\hline Gender (ref = male) & 1.82 & $1.07-3.07$ & 0.70 & $0.17-2.80$ \\
Age (ref = 660 y) & 1.52 & $0.77-3.00$ & 0.58 & $0.05-6.48$ \\
Causes of ESRD (ref = DM) & & & & \\
$\quad$ Glomerulonephritis & 1.09 & $0.48-2.48$ & 0.84 & $0.87-8.09$ \\
$\quad$ Interstitial nephritis & 0.41 & $0.09-1.81$ & 0.65 & $0.06-3.63$ \\
$\quad$ Cystic kidney/other kidney diseases & 0.71 & $0.31-1.61$ & 0.60 & $0.10-6.31$ \\
$\quad$ Diabetes mellitus & 0.86 & $0.40-1.87$ & 0.35 & $0.03-3.42$ \\
$\quad$ Other /Unknown & 1.00 & $0.45-2.21$ & 0.28 & $0.03-2.75$ \\
Vintage on hemodialysis (ref=>6mnd) & 2.30 & $1.10-4.82$ & 7.29 & $0.63-84.0$ \\
Body Mass Index (ref =<30) & 1.33 & $0.67-2.62$ & 7.52 & $0.68-83,1$ \\
Tobacco use (ref = no) & 0.75 & $0.33-1.68$ & 0.04 & $0.001-678$ \\
Comorbidities (ref = no) & & & & \\
$\quad$ Diabetes mellitus & 0.84 & $0.44-1.61$ & 1.66 & $0.15-18.3$ \\
$\quad$ Hypertension & 0.98 & $0.87-1.10$ & 1.20 & $0.74-1.94$ \\
$\quad$ Peripheral arterial obstructive disease & 0.99 & $0.87-1.12$ & 0.15 & $0.06-88.2$ \\
$\quad$ Coronary artery disease & 0.94 & $0.67-1.32$ & 1.44 & $0.31-6.60$ \\
$\quad$ Cerebrovascular disease & 0.88 & $0.37-2.08$ & 1.25 & $0.11-13.8$ \\
Medication (ref = no) & & & & \\
$\quad$ Use of calcium antagonist & 1.01 & $0.91-1.12$ & 1.29 & $0.87-1.03$ \\
$\quad$ Use of anticoagulants & 1.79 & $0.97-3.29$ & 2.79 & $0.25-30.9$ \\
$\quad$ Use of platelet aggregation inhibitor & 0.84 & $0.44-1.61$ & 0.02 & $0.01-311$ \\
$\quad$ Use of EPO & 0.80 & $0.19-3.30$ & 0.04 & $0.01-6.92$ \\
\hline
\end{tabular}

\footnotetext{
*Values were missing for some patients; AVF $n=89$ AVG $n=31$; Ref = reference.
} 
Table 4.5 Univariate hazard ratio of vascular access characteristics for cannulation-related complications in the AVF, and AVG group.

\begin{tabular}{lllll}
\hline Characteristics & AVF & $95 \% \mathrm{Cl}$ & AVG & $95 \% \mathrm{Cl}$ \\
\hline Length cannulation route $(\mathrm{ref}=\leq 10 \mathrm{~cm})$ & 0.46 & $0.25-0.83$ & 21.1 & $0.01-9.40$ \\
Access diameter* $(\mathrm{ref}=\leq 4 \mathrm{~mm})$ & 1.98 & $0.47-2.06$ & 31.7 & $0.01-20.2$ \\
Maturation time $(\mathrm{ref}=\leq 6 \mathrm{wks})$ & 1.25 & $0.58-2.69$ & 2.28 & $0.20-25.2$ \\
Vascular access on dominant side $(\mathrm{ref}=\mathrm{no})$ & 0.64 & $0.30-138$ & 6.20 & $0.53-72.3$ \\
\hline
\end{tabular}

* Values were missing for some patients; AVF: arteriovenous fistula; AVG: arteriovenous graft; AVF $n=89$ AVG $n=31 ;$ Ref $=$ reference.

\section{Factors associated with vascular access failure}

In the group with AVF failure univariate analysis showed that patients with previous CVC dependence or single needle dialysis $(P<0.0001)$ were associated with vascular access failure.

In the group with AVG failure the univariate analysis showed that patients with peripheral arterial obstructive disease (PAOD) $(P<0.005)$, and previous CVC dependence or single needle dialysis $(P<0.005)$ were significant predictive factors. In the multiple regression model, patients with PAOD $(P<0.02)$ were associated with AVG failure (data not shown).

\section{Discussion}

The present study demonstrated that, during the first 6 months of newly placed vascular accesses, a great percentage of incident patients encounter cannulationrelated complications such as miscannulation (31\%), use of single needle dialysis (33\%) and CVC use (22\%). The percentage of miscannulation as well as cannulationrelated complications were significantly higher in patients with AVFs compared to AVGs. Furthermore, we found that cannulation-related complications were eventually associated with vascular access failure.

To our knowledge only the DOPPS ${ }^{5,6}$ study reported on the effect of CVC use on vascular access outcome in patients starting hemodialysis with a permanent vascular access. The previous use of a CVC was associated with detrimental consequences for a subsequent successful AVF. The Kidney Disease Outcome Quality Initiative (K/DOQI) clinical practice guidelines for Vascular Access and the European Best Practice Guidelines (EBPG) ${ }^{7}$ recommended AVF as the preferred vascular access for hemodialysis patients. The major advantage of AVF over AVG is better survival and lower complication rate compared to grafts, once they have successfully matured. Despite these benefits, AVFs may have disadvantages compromising functional patency. This is consistent with our data, where we found that AVFs were associated with more cannulation-related complications, leading to placement of CVCs. Graft implantation may have certain advantages over AVFs, for example in older patients 
with a limited life expectancy and the need for timely access. Several studies ${ }^{9-13}$ have found a relationship between maturation time and vascular access survival, although in our study maturation time was not associated with cannulation-related complications.

In patients with an AVF, female gender was a significant factor for having more cannulation-related complications. In addition, female gender has been reported to be a predictor for AVF failure ${ }^{7}$. Conceivably, women have smaller sized arteries and veins, prohibiting successful fistula creation.

The finding that length of the cannulation route is a defining success factor is consistent with previous reports. Krönung et al. found that repeated cannulation in a small circumscribed area may cause damage to the vessels, and development of stenoses and aneurysm ${ }^{14}$. Sideway et al. ${ }^{23}$ reported standards in which the length of the usable vein was measured and scored preoperatively with duplex ultrasound, discriminating the vein lengths to more than $14 \mathrm{~cm}, 7$ to $14 \mathrm{~cm}$, and less than $7 \mathrm{~cm}$. Another study described ${ }^{12}$ that accessible vein segments need to be more than $10 \mathrm{~cm}$ long to allow for rotation of needle sites and sufficient distance between the needles. Based on our results, we suggest a cannulation route of more than $10 \mathrm{~cm}$, as an optimal criterion, which is associated with a minimum of complications.

Our study has some limitations. Although, in the participating centers, there were minor differences in cannulation practice concerning the type of needle, needle direction, and position, this may influence the occurrence of cannulation-related complications. However, there were no significant differences in complication percentages between dialysis facilities.

Although cannulation practice patterns may affect the outcome, the patient characteristics, comorbidities, and vascular access characteristics were focused on as independent factors.

The present dialysis population often exhibits short length of vein segments, which may result in unsuitability for the conventional rope ladder technique. The updated $\mathrm{K} / \mathrm{DOQI}^{7}$ guidelines recommend the use of the buttonhole technique to decrease cannulation-related complications. This method uses needle insertion at a constant location and angle with similar depth of penetration.

In conclusion, this study shows that the incidence of cannulation-related complications in newly placed vascular accesses is high. Despite the fact that guidelines ${ }^{7,8}$ recommend the use of an AVF for all incident and prevalent hemodialysis patients, our study shows that cannulation-related complications in AVFs are an underestimated problem, and may seriously affect the outcome of the vascular access. Our data emphasize the need to improve cannulation practices and to initiate implementation of other needling techniques, like the buttonhole technique to diminish the number of cannulation complications. Prospective studies are needed to make a careful consideration of the pros and cons of the different cannulation techniques. 


\section{References}

1. Saran R, Dykstra DM, Pisoni R, Akibi T, Akizawa T, Canaud B, Chen K, Piera L, Saito A, Young E. Timing of first cannulation and vascular access failure in hemodialysis: an analysis of practice patterns at dialysis facilities in the DOPPS. Nephrol Dial Transplant 2004;19:2334-2340.

2. Singh $\mathrm{P}$, Robbin $\mathrm{ML}$, Lockhart $\mathrm{ME}$, Allon $\mathrm{M}$. Clinically immature 6 arteriovenous hemodialysis fistulas: effect of US on salvage. Radiology 2008;246:299-305.

3. Sidawy AN, Gray R, Besarab A, Henry M, Ascher E, Silva M Jr, Miller A, Scher L, Trerotola S, Gregory RT, Rutherford RB, Kent KC. Recommended standards for reports dealing with arteriovenous hemodialysis accesses. J Vasc Surg 2002;35:603-610.

4. Lee T, Barker J, Allon M. Needle infiltration of arteriovenous fistulas in hemodialysis patients: Risk factors and consequences. Am J Kidney Dis 2006;47:1020-1026.

5. Pisoni RL, Young EW, Mapes DL, Keen ML, Port FK. Vascular access use and outcomes in the U.S., Europe, and Japan: results from the DOPPS. Nephrol News Issues 2003;17:38-43.

6. Rayner HC, Pisoni RL, Gillespie BW, Goodkin DA, Akiba T, Akizawa T, Saito A, Young EW, Port FK; Dialysis Outcomes and Practice Patterns Study. Creation, cannulation and survival of arterio-venous fistulae, data from the DOPPS. Kidney Int 2003;63:323-330.

7. KDOQI clinical practice guidelines and clinical practice recommendations for vascular access 2006. Am J Kidney Dis 2006;48 (Suppl 1):S176-322.

8. Tordoir J, Canaud B, Haage P, Konner K, Basci A, Fouque D, Kooman J, Martin-Malo A, Pedrini L, Pizzarelli F, Tattersall J, Vennegoor M, Wanner C, ter Wee P, Vanholder R. EBPG on vascular access. Nephrol Dial Transplant 2007;22:ii88-ii117.

9. Brunori G, Ravani P, Mandolfo S, Imbasciati E, Malberti F, Cancarini G, Fistula maturation: doesn't time matter at all? Nephrol Dial Transplant 2005;20:684-687.

10. Feldman HI, Joffe M, Rosas SE, Burns JE, Knauss J, Brayman K. Predictors of successful arteriovenous fistula maturation. Am J Kidney Dis 2003;42:1000-1012.

11. Lok CE, Allon M, Moist L, Oliver MJ, Shah H, Zimmerman D. Risk equation determining unsuccessful cannulation events and failure to maturation in arteriovenous fistulas (REDUCE FTM I). J Am Soc Nephrol 2003;17:3204-3212.

12. Robbin L, Chamberlain N, Lockhart M, Gallichio M, Young C, Deierhoi M, Allon M. Hemodialysis arteriovenous fistula maturity: US Evaluation. Radiology 2002;225:59-64.

13. Saran R., Dykstra, DM., Wolfe RA, Gillespie B, Held PJ, Young EW: Association between vascular access failure and the use of a specific drugs: the Dialysis Outcomes and Practice Patterns Study (DOPPS). Am J Kidney Dis 2002;40:1255-1263.

14. Krönung G. Plastic deformation of Cimino fistula by repeated puncture. Nephrol Dial Transplant 1984; 13:635-638 
Cannulation and vascular access-related complications in hemodialysis 
$60 \mid$ Chapter 4 


\section{Chapter 5}

Cannulation practice patterns in hemodialysis vascular access: predictors for unsuccessful cannulation

M.M. van Loon, A.G.H. Kessels, F.M. van der Sande, J.H.M. Tordoir 


\section{Abstract}

\section{Background}

Little is known about the relationship of cannulation practices in dialysis facilities with the frequency of failed cannulations, complications, and subsequent vascular access failure.

\section{Methods}

In an observational study the incidence of miscannulations and related complications were observed. Patient characteristics, comorbidities, and vascular access characteristics like type of vascular access, were correlated with the occurrence of cannulation-related complications. In addition, the cannulation technique and practice patterns like needle direction, tourniquet use, and years of experience of the dialysis nurse were registered.

\section{Results}

During the study period, $37 \%$ of patients with autogenous arteriovenous fistulas (AVFs), and $19 \%$ of patients with arteriovenous grafts (AVG) had more than 10 miscannulations. Cannulation-induced hematoma resulted in single-needle and catheter dialysis in $40 \%$ of the patients. The use of central venous catheters (CVC) and single needle dialysis were significant predictors of vascular access failure $(P<0.0001)$.

\section{Conclusion}

This study demonstrated a high incidence of unsuccessful cannulation procedures and cannulation-related complications necessitating catheter and single needle dialysis. The type and location of vascular access is significantly related to the occurrence of unsuccessful and complicated cannulation. 


\section{Introduction}

A well-functioning vascular access is a prerequisite for successful hemodialysis treatment. An ideal vascular access delivers adequate blood flow for dialysis, has excellent patency with low complication rates, and allows repetitive and easily cannulation with two needles. The Kidney Disease Outcomes Quality Initiative (K/DOQI) guidelines ${ }^{1}$ on vascular access, recommended the autogenous arteriovenous fistula (AVF) as the preferred vascular access, because they show better survival and lower complication rates compared to arteriovenous grafts (AVGs) and central venous catheters (CVCs).

The K/DOQI ${ }^{1}$ have registered the rule of $6 \mathrm{~s}$, which define that a good functioning access has a flow of approximately $600 \mathrm{ml} / \mathrm{min}$, is less than $6 \mathrm{~mm}$ below the surface of the skin, has a minimum diameter of $6 \mathrm{~mm}$, and can be easily cannulated. However, with the changing demographics of the end-stage renal disease (ESRD) population, it is difficult to create and maintain a vascular access which can meet these criteria.

The maintenance of the vascular access not only depends on the quality of the blood vessels, and the surgical technique used, but also on the way in which the vascular access is handled, in particular is cannulated. Cannulation of the vascular access is a basic but essential part of the hemodialysis treatment. A chronic hemodialysis patient needs at least 312 needle insertions per year. Dialysis staff needs to be competent with cannulation, especially with newly created vascular accesses. Cannulation practice is partly based on theory, practical guidelines, and experience. The dialysis staff finds it difficult to determine which method is best for cannulating the vascular access. Little is known about the influence of repeated cannulation on the quality of the vascular access, the risk of complications, and vascular access failure.

To gain more insight into cannulation-related problems, it is important to identify factors that may be associated with difficult and complicated cannulation. The aim of this study was to identify, in both AVF and AVG, which characteristics of the cannulation practice, i.e. type of needle used, needle direction and position, cannulation technique, ease of cannulation, tourniquet use, and years of experience of the dialysis nurse, predict the time to unsuccessful cannulation, cannulation-related complications, and vascular access failure.

\section{Methods}

\section{Study design}

This prospective, observational study of newly created AVFs and AVGs evaluated the complications caused by cannulation, and the clinical consequences of failed cannulation. The patients were followed from the first cannulation of the vascular access, with a minimal follow-up time of six months. Clinical data were collected from 
1 June 2005 to 1 March 2007 in 10 Dutch dialysis facilities. Baseline data included patient characteristics, co morbidities, and medication. Vascular access characteristics included: type of vascular access, location, vein diameter, as assessed by Duplex ultrasound (Aloka 5500, Tokyo, Japan), access flow measurement using ultrasound dilution technique (Transonic Ithaca, USA), maturation period and length of the cannulation route. The cannulation route is measured by the dialysis nurse while using placement of a tourniquet around the upper arm and measuring the usable length of the vein for cannulation with standard tape lint. Length is expressed in centimetres.

During the study period data were collected by dialysis nurses, using identical Case Record Forms (CRF) and a standardized method was used to register these data from each dialysis session. A 16-item CRF was used to register relevant parameters for cannulation practice i.e. inspection for hematoma caused by cannulation, redness, swelling, auscultation by using the stethoscope, type of needle used, needle direction and position, cannulation technique, number of necessary cannulations, ease of cannulation, tourniquet use and years of experience of the dialysis nurse. CVC insertion was registered if the vascular access was not accessible because of hematoma or other reasons. Exclusion criteria were vascular access failure, successful renal transplantation or death.

The Study protocol was approved by the Medical Ethical Committee of the Maastricht University Medical Centre.

\section{Outcome definitions}

Duplex ultrasound at six weeks was used to determine the diameter of vein. The length of usable vein was determined by physical examination. The decision when to perform the first-time cannulation was made by an experienced dialysis nurse.

An access flow of $>500 \mathrm{~m} / \mathrm{min}$ with a vein diameter of $>4 \mathrm{~mm}$ was determined as a mature fistula ${ }^{2}$. Functional patency started when a vascular access had been successfully used for hemodialysis treatment for the first time $^{3}$. A cannulation procedure was judged as successful if the dialysis nurse was able to cannulate two needles, both used for the hemodialysis treatment, without miscannulation. Miscannulation is defined as the need to insert more than one needle per arterial or venous connection, because of the impossibility to use the previously inserted needle(s) for dialysis. A subcutaneous hematoma of the vascular access is defined as an abnormal localized infiltration of blood caused by needle cannulation ${ }^{4}$.

\section{Statistical analysis}

Differences in cannulation practice variables for AVF and AVG were tested with the Chi-square test. Difference in the duration of CVC use was tested with the MannWhitney test. One of the aims of this study was to investigate which characteristics of cannulation practice could predict the length of time before unsuccessful cannulation, cannulation-related complications and vascular access failure. For each of these 
variables, a univariate Cox regression analysis was performed. To determine independent risk factors, all univariate significant variables (entry $P$-value $=0.05$ ) were included in a stepwise forward multivariate Cox regression analysis.

For all comparisons, the level of significance was set to $P<0.05$. Statistical analysis was performed using SPSS software for Windows (SPSS release12.0, SPSS Inc, Chicago, IL, USA). Results are expressed as mean \pm standard deviation (SD).

\section{Results}

\section{Patients}

A total of 158 incident chronic hemodialysis patients with newly created vascular accesses were included at the start of the study. Twenty-nine patients (18\%) were lost to follow up due to the following reasons: 11 death $(6.9 \%)$, one successful kidney transplantation $(0.6 \%), 10$ vascular access failure $(6.3 \%)$, and seven patients started hemodialysis at a non- participating facility (4.6\%).

Patients' demographics and medical history are outlined in Table 5.1 and 5.2. The mean age was 66.2 years \pm 13.5 (SD) (range $21-90 \mathrm{yrs}$ ), $37 \%$ of the patients were female ( $n=59)$. The mean follow-up time was 155 days (range 2 to 199 days).

\section{Vascular access}

The type of the vascular access placed was $70 \%$ AVFs and $30 \%$ AVGs. The mean time to first cannulation in all patients was 100 days (range 1-822 days). AVFs were first time cannulated within a mean of 115 days and AVGs were cannulated within a mean of 66 days. At first cannulation the mean diameter of AVFs and AVGs were similar and was $5.5 \mathrm{~mm}$. Furthermore the mean length of the AVF cannulation route was $13 \mathrm{~cm}$ and the mean AVG cannulation route was $24 \mathrm{~cm}$ (Table 5.3) All patients were being cannulated using the rope-ladder technique, where the whole access length of the vascular access was used for cannulation. Table 5.4 shows the cannulation practice for AVFs and AVGs. Sonographic-guided cannulation of the vascular access was used in $4 \%$ of patients.

Figure 5.1 shows the incidence of miscannulation in the AVF and AVG group. During the period of research study $37 \%$ of patients with AVFs, and $19 \%$ of patients with AVGs had more than 10 miscannulations.

As shown in Figure 5.2 there was a major difference in the incidence of hematoma between AVF and AVG which is also depended on location (upper arm vs. forearm) of the vascular access.

The median duration of temporary CVC dependence was 17 days for the AVF group, and 8.5 days for the AVG group $(P<0.01)$. The need for single needle dialysis in the AVF 
and AVG group was in $41 \%$ and $8 \%$ of patients respectively. For CVC use these percentages were $31 \%$ and $12 \%$ respectively.

At six months $89 \%$ of the patients with an AVF, and $96 \%$ of patients with an AVG were able to dialyze through their vascular access.

Table 5.1 Comparison of demographics and comorbidities of the study population, between the AVF and the AVG, with their $P$-value.

\begin{tabular}{|c|c|c|c|c|}
\hline Characteristics & $\begin{array}{c}n \\
158 \\
\end{array}$ & $\begin{array}{c}\text { AVF } \\
110(70 \%) \\
\end{array}$ & $\begin{array}{c}\text { AVG } \\
48(30 \%)\end{array}$ & $P$ \\
\hline Gender & & & & 0.70 \\
\hline Female & 59 & $40(36 \%)$ & $19(40 \%)$ & \\
\hline Male & 99 & $70(64 \%)$ & $29(60 \%)$ & \\
\hline Age $(y)$ & & & & 0.13 \\
\hline 21 - 60 years & 49 & $39(36 \%)$ & $10(21 \%)$ & \\
\hline $61-75$ years & 61 & $38(35 \%)$ & $23(48 \%)$ & \\
\hline$>75$ & 48 & $33(30 \%)$ & $15(31 \%)$ & \\
\hline Causes of ESRD & & & & 0.65 \\
\hline Glomerulonephritis & 18 & $14(13 \%)$ & $4(8 \%)$ & \\
\hline Interstitial nephritis & 12 & $7(6 \%)$ & $5(10 \%)$ & \\
\hline Cystic kidney diseases & 4 & $2(2 \%)$ & $2(4 \%)$ & \\
\hline Other congenital/hereditary kidney diseases & 2 & $2(2 \%)$ & $0(0 \%)$ & \\
\hline Renal vascular diseases & 38 & $28(26 \%)$ & $10(21 \%)$ & \\
\hline Diabetes mellitus & 32 & $23(21 \%)$ & $9(19 \%)$ & \\
\hline Other multisystem diseases & 17 & $13(12 \%)$ & $4(8 \%)$ & \\
\hline Other /Unknown & 35 & $21(19 \%)$ & $14(29 \%)$ & \\
\hline Vintage on hemodialysis & & & & 0.32 \\
\hline $0 \mathrm{mo}$ & 75 & $53(48 \%)$ & $22(46 \%)$ & \\
\hline 1 to $6 \mathrm{mo}$ & 48 & $36(33 \%)$ & $12(25 \%)$ & \\
\hline 6 to $12 \mathrm{mo}$ & 14 & $10(9 \%)$ & $4(8 \%)$ & \\
\hline$\geq 12 \mathrm{mo}$ & 21 & $11(10 \%)$ & $10(21 \%)$ & \\
\hline Body Mass Index ${ }^{a} *$ & & & & 0.30 \\
\hline$<18.5 \mathrm{~kg} / \mathrm{m}^{2}$ & 6 & $2(2 \%)$ & $4(9 \%)$ & \\
\hline $18.5-24.9 \mathrm{~kg} / \mathrm{m}^{2}$ & 71 & $51(46 \%)$ & $20(43 \%)$ & \\
\hline $25-34.9 \mathrm{~kg} / \mathrm{m}^{2}$ & 52 & 37 (34\%) & $15(32 \%)$ & \\
\hline$>30 \mathrm{~kg} / \mathrm{m}^{2}$ & 28 & $20(18 \%)$ & $8(17 \%)$ & \\
\hline Tobacco use & & & & 0.73 \\
\hline Yes & 22 & $16(14 \%)$ & $6(12 \%)$ & \\
\hline No & 136 & $94(86 \%)$ & $42(88 \%)$ & \\
\hline
\end{tabular}

* Values were missing for some patients; AVF: arteriovenous fistula; AVG: arteriovenous graft; ${ }^{a}$ Body mass index consistent with the World Health Organization definition (Hubbard vs. 2000). 
Table 5.2 Comparison of medical history of the study population between the AVF and the AVG, with their $P$-value.

\begin{tabular}{lcccc}
\hline & $n$ & AVF & AVG & $P$ \\
\hline Medical history & & & & \\
$\quad$ Peripheral arterial obstructive disease & 18 & $10(9 \%)$ & $8(17 \%)$ & $\mathbf{0 . 1 8}$ \\
$\quad$ Coronary artery disease & 46 & $29(26 \%)$ & $17(35 \%)$ & $\mathbf{0 . 5 2}$ \\
$\quad$ cerebrovascular disease & 25 & $14(13 \%)$ & $11(23 \%)$ & $\mathbf{0 . 1 2}$ \\
$\quad$ Diabetes mellitus & 36 & $34(31 \%)$ & $22(46 \%)$ & $\mathbf{0 . 7 4}$ \\
$\quad$ Hypertension & 52 & $38(35 \%)$ & $14(29 \%)$ & $\mathbf{0 . 0 4}$ \\
Medication & & & & \\
$\quad$ Use of calcium antagonist & 47 & $35(32 \%)$ & $12(25 \%)$ & $\mathbf{0 . 0 9}$ \\
$\quad$ Use of anticoagulants & 57 & $32(29 \%)$ & $25(52 \%)$ & $\mathbf{0 . 0 0 6}$ \\
$\quad$ Use of platelet aggregation inhibitor & 51 & $31(46 \%)$ & $20(65 \%)$ & $\mathbf{0 . 1 0}$ \\
Use of EPO & 149 & $105(95 \%)$ & $44(92 \%)$ & $\mathbf{0 . 3 6}$ \\
\hline
\end{tabular}

AVF: arteriovenous fistula; AVG: arteriovenous graft.

Table 5.3 Comparison of vascular access characteristics between the AVF and AVG group.

\begin{tabular}{|c|c|c|c|}
\hline Characteristics & AVF & AVG & $P$ \\
\hline \multicolumn{4}{|l|}{ Access placement } \\
\hline Forearm vascular access & $58(53 \%)$ & $38(47 \%)$ & \\
\hline Upper arm vascular access & $52(47 \%)$ & $10(53 \%)$ & \\
\hline Vascular access in dominant arm & & & 0.35 \\
\hline No & $82(75 \%)$ & $38(79 \%)$ & \\
\hline Yes & $28(25 \%)$ & $10(21 \%)$ & \\
\hline Length of the cannulation route ${ }^{a} *$ & & & 0.001 \\
\hline 0 to $7 \mathrm{~cm}$ & $15(14 \%)$ & $0(0 \%)$ & \\
\hline 7 to $14 \mathrm{~cm}$ & $45(41 \%)$ & $3(6 \%)$ & \\
\hline$>14 \mathrm{~cm}$ & 49 (45\%) & $44(92 \%)$ & \\
\hline Access diameter * & & & 0.009 \\
\hline $2-4 \mathrm{~mm}$ & $20(18 \%)$ & $7(15 \%)$ & \\
\hline $4-6 m m$ & $27(25 \%)$ & $33(69 \%)$ & \\
\hline$>6 \mathrm{~mm}$ & $15(14 \%)$ & $5(10 \%)$ & \\
\hline Maturation time (weeks) & & & 0.03 \\
\hline $0-3$ wks & $3(3 \%)$ & $15(31 \%)$ & \\
\hline $3-6$ wks & $22(20 \%)$ & $12(25 \%)$ & \\
\hline $6-12$ wks & $48(44 \%)$ & $13(27 \%)$ & \\
\hline$>12$ wks & $37(34 \%)$ & $8(17 \%)$ & \\
\hline Previous accesses & & & 0.03 \\
\hline No & 89 (81\%) & 31 (65\%) & \\
\hline Yes & $21(19 \%)$ & $17(35 \%)$ & \\
\hline
\end{tabular}

Values were missing for some patients; ${ }^{\text {a }}$ Consistent by reporting standards (Sideway et al).

AVF: arteriovenous fistula; AVG: arteriovenous graft. 
Table 5.4 Cannulation characteristics in percentages, in the AVF and AVG group, and forearm and upper arm.

\begin{tabular}{|c|c|c|c|c|}
\hline Cannulation Practice & AVF forearm & AVF upper arm & AVG forearm & AVG upper arm \\
\hline \multicolumn{5}{|l|}{ Type of needle used } \\
\hline Metal & 67 & 50 & 97 & 85 \\
\hline Catheter & 33 & 50 & 3 & 15 \\
\hline \multicolumn{5}{|l|}{ Needle Gauche } \\
\hline 14 gauche & 12 & 4 & 0 & 0 \\
\hline 15 gauche & 52 & 52 & 92 & 90 \\
\hline 16 gauche & 36 & 44 & 8 & 10 \\
\hline \multicolumn{5}{|l|}{ Needle position } \\
\hline Bevel up & 74 & 80 & 93 & 82 \\
\hline Bevel down & 26 & 20 & 7 & 18 \\
\hline \multicolumn{5}{|l|}{ Axis rotation needle } \\
\hline Yes & 13 & 11 & 34 & 24 \\
\hline No & 87 & 89 & 66 & 76 \\
\hline \multicolumn{5}{|l|}{ Direction arterial needle } \\
\hline Antegrade & 83 & 90 & 34 & 35 \\
\hline Retrograde & 17 & 10 & 66 & 65 \\
\hline \multicolumn{5}{|l|}{ Tourniquet use } \\
\hline Yes & 86 & 82 & 4 & 30 \\
\hline No & 14 & 18 & 96 & 70 \\
\hline \multicolumn{5}{|c|}{ Sonographic guided cannulation } \\
\hline Yes & 5 & 5 & 1 & 1 \\
\hline No & 95 & 95 & 99 & 99 \\
\hline \multicolumn{5}{|c|}{ Experience dialyses nurse } \\
\hline$<3$ yrs & 23 & 21 & 21 & 21 \\
\hline$\geq 3$ yrs & 77 & 79 & 79 & 79 \\
\hline
\end{tabular}

AVF: arteriovenous fistula; AVG: arteriovenous graft; $A V F, n=110$ AVG, $n=48$.

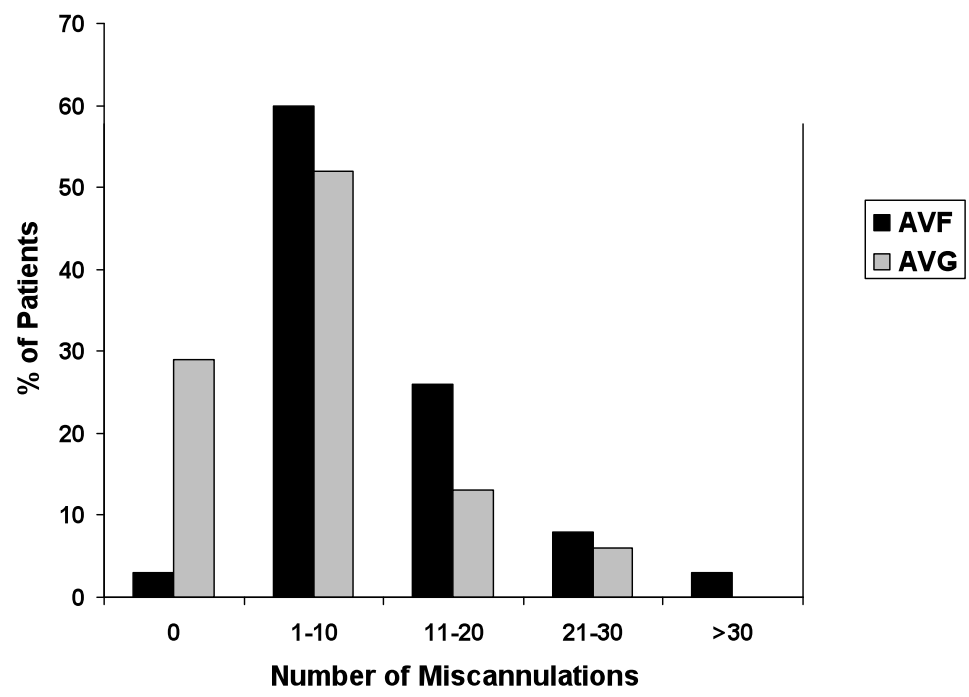

Figure 5.1 The distribution of frequencies of miscannulation in the AVF and AVG group. 


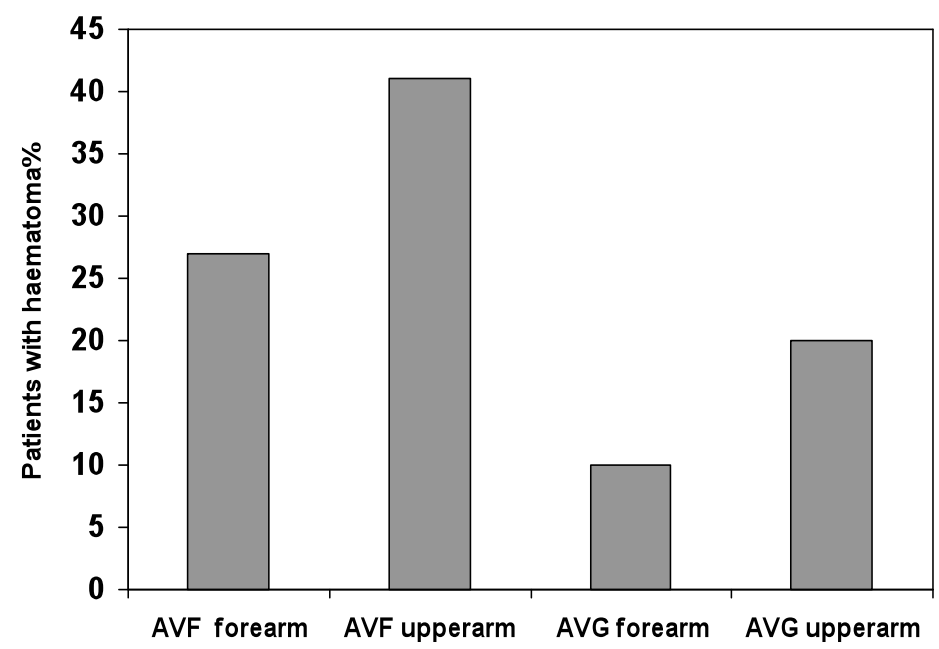

Figure 5.2 The distribution of frequencies of hematoma in the AVF and AVG group.

\section{Factors associated with successful cannulation}

Univariate analysis for patients with an AVG found arterial needle direction retrograde (needle point down, against the direction of the bloodflow) $(P<0.0009)$ to be a significant factor for successful cannulation. For patients with an AVF, no predictors were found to be associated with successful cannulation.

For both AVFs and AVGs, no significant influence of the experience of the dialysis nurse on unsuccessful cannulation was observed.

\section{Factors associated with CVC dependence or single needle dialysis}

Univariate analysis for patients with an AVF, showed hematoma $(P<0.0001)$ and arm swelling $(P<0.004)$ to be significant determinants for CVC usage and single needle dialysis (Table 5.5). In the multiple regression model only the presence of hematoma $(P<0.0001)$ was predictive of the need for central catheter or single needle dialysis For the AVG group, the univariate analysis found the following variables to be significant for CVC dependence or single needle dialysis; variation in vascular access sound by using the stethoscope $(P<0.01)$, hematoma $(P<0.003)$, swelling $(P<0.0009)$, and the direction of the arterial needle (antegrade ) $(P<0.003)$ (Table 5.4).

The multivariate regression model, showed antegrade arterial needle direction $(P<0.007)$ as single predictor for cannulation-related complications. 
Table 5.5 Univariate hazard ratio of cannulation practice characteristics for cannulation-related complications in the AVF and AVG group.

\begin{tabular}{lcccc}
\hline Characteristics & AVF & $95 \% \mathrm{Cl}$ & AVG & $95 \% \mathrm{Cl}$ \\
\hline Type of needle used (metal needles vs. catheter needles) & 0.65 & $0.34-1.24$ & 0.36 & $0.04-3.08$ \\
Needle Gauche (16 gauche vs. 14 and 15 gauche) & 1.51 & $0.89-2.54$ & 3.34 & $0.41-27.0$ \\
Needle position (bevel-down vs. bevel-up) & 0.43 & $0.15-1.22$ & 0.04 & $0.000-208$ \\
Axis rotation needle (yes vs. no) & 0.75 & $0.29-1.92$ & 0.90 & $0.31-2-59$ \\
Direction arterial needle (antegrade vs. retrograde) & 0.79 & $0.19-3.30$ & 0.007 & $0.0001-0.74$ \\
Tourniquet used (yes vs. no) & 1.62 & $0.71-3.70$ & 1.02 & $0.31-3.39$ \\
Experience dialyses nurse ( $\geq 3 y r$ vs. <3yr) & 0.93 & $0.44-1.95$ & 0.60 & $0.68-5.45$ \\
Changing vascular access sound by stethoscope (yes vs. & 1.12 & $0.48-2.62$ & 5.84 & $1.20-28.4$ \\
no) & & & & \\
Hematoma (yes vs. no) & 1.74 & $1.42-2.13$ & 1.79 & $1.15-2.79$ \\
Swelling (yes vs. no) & 1.23 & $1.05-1.43$ & 1.63 & $1.16-2.29$ \\
Accessflow* $\geq 600 \mathrm{ml} / \mathrm{min}$ vs. $<600 \mathrm{ml} / \mathrm{min}$ ) & 0.61 & $0.31-1.17$ & 2.99 & $0.37-23.9$ \\
\hline
\end{tabular}

* Values were missing for some patients; AVF: arteriovenous fistula; AVG: arteriovenous graft; AVF $n=110$ AVG $n=48$

\section{Factors associated with vascular access failure}

In the group with subsequent AVF failure the univariate analysis found cannulationrelated complications $(P<0.0001)$ resulting in CVC and single needle dialysis to be a significant factor. In the group with AVG failure the univariate analysis showed that patients with cannulation-related complications $(P<0.005)$, an irregular vascular access sound $(P<0.04)$, and antegrade arterial needle direction $(P<0.04)$ as significant factors.

In the multiple regression model, arterial needle direction $(P<0.006)$, and previous cannulation-related complications $(P<0.0001)$ were predictors for AVG failure.

\section{Discussion}

In this study with newly placed vascular accesses, we observed a high incidence of unsuccessful cannulation procedures, and cannulation-related complications resulting in use of CVC and single needle dialysis, which occurs more frequently in autogenous AVFs.

Hematoma formation occurred more frequently in AVFs compared with grafts. For both AVF and AVG, hematoma formation as a result of unsuccessful cannulation was a significant predictor for the need of CVC and single needle dialysis. Needle infiltration into the tissues may result in a temporary inability to use the vascular access until the hematoma disappears, which may account for the great amount of temporary CVCs used in this study. Lee et al. ${ }^{4}$ showed similar results, and found a relatively high rate of needle infiltration which was more common in older patients with new fistulas, resulting in prolongation of CVC dependence for more than three months. In this 
study, cannulation-related complications that resulted in use of CVC or single needle dialysis, were also associated with vascular access failure, for both AVF and AVG.

Cannulation of a newly created vascular access demands specific clinical knowledge, behaviour and skills. Several studies have highlighted the importance of staff experience on vascular access outcomes ${ }^{5,6}$. The DOPPS data found that each $20 \%$ increase in the number of experienced staff nurses (nurses who had worked in dialysis $>3$ years) was associated with an $11 \%$ reduction in AVF failure ( $R R=0.89 ; P<0.05)$, and $8 \%$ reduction in AVG failure $(R R=0.92 ; P<0.01)$. In this study, the years of experience of the dialysis nurse were shown to have no significant role on successful cannulation practice, cannulation- related complications or vascular access failure. In the Netherlands, vascular access cannulation is delivered by registered and well-trained dialysis nurses, and complex, difficult vascular accesses are usually cannulated by staff with expert skills. The cannulation skills of dialyses staff according to the years of experience, is difficult to estimate.

Physical examination prior to cannulation, is a basic skill for vascular access assessment $^{1,7-10}$. One aspect of the examination is stethoscope auscultation of vascular sounds. In this study, an alteration in vascular access sound has shown to be predictive for cannulation-related complications and AVG failure. This feature suggests that analysis of vascular sounds may be useful in determining pending AVG failure.

Retrograde arterial needling was the single predictor affecting the successful cannulation outcome of AVGs. Placement of the arterial needles has been a controversial subject. In the literature ${ }^{11-13}$ an antegrade and retrograde direction of the arterial needle has been recommended. A recent study found no difference in needle direction, regarding hemodialysis efficacy ${ }^{14}$. However, besides the chance of successful cannulation, the retrograde needle direction is associated with less cannulation-related complications and AVG failure. The cannulation of the AVF proved to be more problematic, and predictive factors regarding cannulation practices of AVFs, can not yet be determined.

Our study showed that sonographic imaging of the vascular access is rarely used to facilitate cannulation. There may be several reasons for this: the availability of the device, time-consuming, and technically challenging practice. The additional value of these sonographic devices for cannulation practice has still to be proved.

This study has some limitations. First, although patient characteristics, comorbidities, and vascular access characteristics may affect the outcome, it was the practice patterns were focused on, as independent factors. Furthermore, as this is an observational, non-randomized study, comparison of patient groups with a specific factor could be biased. We allowed for this by performing a multivariate analysis adjusting for confounders.

It is a well-known fact that many unintended faults caused by healthcare givers, are not reported. This may be due to a culture of fear in healthcare which holds perfect 
performance as an ideal and imposes blame and shame for those who fail to meet these requirements.

We showed, that miscannulation of vascular accesses, particular in AVFs, occurs frequently and has serious consequences for the hemodialysis patient, leading to CVC and single needle dependence and even vascular access failure. This study also indicates that, although the quality of the vascular access is of paramount importance, cannulation practice patterns are of great influence.

There is a need to improve cannulation practice, and to conduct more studies on this subject in the future. The data also underline the importance for awareness, of the complexity of the cannulation practice given today's population, with patients of increasing age. Therefore, a high level of expertise of the dialysis staff is required.

Continued education and training of the dialysis staff towards theoretical knowledge and cannulation skills, especially for cannulation of new AVFs, is essential and may be beneficial in minimizing miscannulation and cannulation-related complications and improve vascular access outcome ${ }^{15}$. A feature of cannulation skills is to be able to make a balanced choice in choosing which is the most suitable cannulation technique for every specific vascular access. In some cases it may be beneficial to use an alternative cannulation technique such as the buttonhole method ${ }^{16,17}$.

Furthermore, to improve the quality of vascular access cannulation, a sonographic device may increase the success of difficult and complicated cannulation procedures. Comparative studies are needed to determine the value of sonographic-guided cannulation. 


\section{References}

1. National Kidney Foundation. KDOQI Clinical Practice Guidelines and Clinical Practice Recommendations for 2006 Updates: Vascular Access. American Journal Kidney Disease 2006;48 (S1):S1-S322.

2. Singh $\mathrm{P}$, Robbin $\mathrm{ML}$, Lockhart $\mathrm{ME}$, Allon $\mathrm{M}$. Clinically immature 6 arteriovenous hemodialysis fistulas: effect of US on salvage. Radiology 2008;246:299-305.

3. Sidawy AN, Gray R, Besarab A, Henry M, Ascher E, Silva M Jr, Miller A, Scher L, Trerotola S, Gregory RT, Rutherford RB, Kent KC. Recommended standards for reports dealing with arteriovenous haemodialysis accesses. Journal Vascular Surgery 2002;35:603-610

4. Lee T, Barker J, Allon M. Needle infiltration of arteriovenous fistulas in haemodialysis patients: Risk factors and consequences. American Journal of Kidney Disease 2006;47:1020-1026.

5. Robbin L, Chamberlain N, Lockhart M, Gallichio M, Young C, Deierhoi M, Allon M. Hemodialysis Arteriovenous Fistula Maturity: US Evaluation. Radiology 2002;225:59-64.

6. Pile C. Hemodialysis vascular access: how do practice patterns affect outcomes? Neprology Nursing Journal 2004;31:305-308.

7. Ball L. Improving arteriovenous fistula cannulation skills Nephrology Nursing Journal 2005;32:611-617.

8. Tordoir J, Mickley V. Management of the Renal patient: Clinical Algorithms on Vascular Access for Haemodialysis EDTNA ERCA 2003;29:131-136.

9. King B, Miller D. .Hemodialysis Special interest group networking session: improving vascular access cannulation skills. Nephrology Nursing Journal 2004;31:688

10. Van Waeleghem JP, Elseviers M, De Vos JY; Research Board of EDTNA/ERCA. EDTNA/ERCA vascular access recommendations for nephrology nurses EDTNA/ERCA Journal 2004;30:97-105.

11. Brouwer J. Cannulation camp: Basic needle cannulation training for dialysis staff. Dialyses and Transplantation 1995;606-612.

12. Brouwer D. Needle placement is paramount to achieving effective dialysis and preserving vascular accesses. Nursing Journal 2005;32: 225-227

13. English DJ. Retrograde arterial needle placement improves dialysis adequacy Nephrology Nursing Journal 2005;32:224.

14. Ozmen S, Kemal Kadiroglu A, Akgul Ozmen C, Danis R, Sit D, Akin D, Yilmaz M. Does the direction of arterial needle in AV fistula cannulation affect dialysis adequacy? Clin Nephrol. 2008;70:229-232.

15. Hugh C, Rayner HC, Pisoni RL, Gillespie BM, e.a. Creation, cannulation and survival of arterio-venous fistulae, data from the DOPPS. Kidney International 2003;63:323-330.

16. Besarab A, Ravani P, Spergel LM, Roy-Chaudhury P, Asif A. The native arteriovenous fistula in 2007 Research needs. Journal of Nephrology: 2007;20:668-673.

17. Murcutt G. Buttonhole cannulation: should this become the default technique for dialysis patients with native fistulas? Summary of the EDTNA/ERCA journal club discussion Autumn 2007 Journal of Renal Care 2008;34:101-108. 


\section{Chapter 6}

Buttonhole needling of hemodialysis arteriovenous

fistulas results in less complications and interventions compared to the rope-ladder technique

M.M. van Loon, T. Goovaerts, A.G.H. Kessels, F.M. van der Sande, J.H.M. Tordoir 


\section{Abstract}

\section{Background}

The rope-ladder puncture technique, with cannulation along the whole vessel traject, has been very common in hemodialysis patients with autogenous arteriovenous fistula (AVF). Today's dialysis population with AVF may exhibit difficult cannulation, because of a short vein length or complicated cannulation route. An alternative needling possibility is the buttonhole technique, which inserts needles at exactly the same location during every dialysis session. The present study was conducted to investigate the effect of both cannulation techniques on the incidence of vascular access complications.

\section{Methods}

A total of 75 prevalent hemodialysis patients with autogenous AVF using the buttonhole technique were compared with 70 patients using the rope-ladder technique. The following parameters were registered: hematoma occurrence, redness, swelling, aneurysm formation, the use of sharp or dull needles, miscannulations, interventions. Needling pain and fear of puncture were assessed using a Verbal Rating Scale (VRS). Duration of follow-up was nine months.

\section{Results}

Patients in the buttonhole group had more unsuccessful cannulations, compared with the rope-ladder method $(P<0.0001)$ but the frequency of hematoma $(P<0.0001)$ and aneurysm formation $(P<0.0001)$ was less. In addition, intervention such as angioplasty $(P<0.0001)$, was higher in patients using the rope-ladder technique. A negative outcome of the buttonhole technique was the higher incidence of access infections compared to the rope-ladder method.

\section{Conclusion}

This study showed that the buttonhole method is a valuable technique with few complications like hematoma, aneurysm formation and the need for interventions. However, the infections induced by the buttonhole method should not be underestimated. This underlines the importance of aseptic and correct technique of the buttonhole procedure. 


\section{Introduction}

Adequate vascular access is essential for the successful hemodialysis treatment of patients with end-stage renal disease (ESRD). The Kidney Disease Outcomes Quality Initiative (K/DOQI) guidelines ${ }^{1}$ on vascular access, recommends the autogenous arteriovenous fistula (AVF) as the preferred vascular access for hemodialysis patients, because of both its longevity and a lower complication rate, as compared to arteriovenous grafts (AVGs) and central venous catheters (CVC). This recommendation has led to an increased number of AVFs, created during the past years.

The demographics of the ESRD population is changing which makes the construction of a functioning and usable AVF more difficult as a consequence. Because the anatomy of the superficial veins may differ from patient to patient, the quality and usability after creation of the fistula, is not always predictable. In addition, cannulation of an AVF requires more technical skills than cannulation of an $\mathrm{AVG}^{2}$. Lee et al, have shown a high incidence of needle infiltrations in patients with autogenous $\mathrm{AVF}^{3}$, which resulted in numerous revision procedures, as well as prolongation of CVC dependence for dialysis.

Despite the fact that complications caused by cannulation may seriously affect vascular access outcome ${ }^{3}$, there is little evidence about the influence of the cannulation technique on vascular access outcomes.

Three cannulation techniques are nowadays used: the rope-ladder, with cannulation of the whole access length is the most frequently used technique in Europe and the United States ${ }^{4}$; the area technique with cannulation in the same small vessel area (which may lead to vessel damage and the development of stenosis and aneurysm) ${ }^{5}$ and finally, the constant-site or buttonhole technique, where the needles are inserted at the same spot during every dialysis session. Few studies have compared cannulation techniques, indicating the benefits of the buttonhole method in terms of diminished pain, less miscannulations and reduction of hematoma formation ${ }^{5-7}$. Although there is a growing conviction/belief that buttonhole cannulation has several advantages compared with other techniques, there is no generally accepted method of cannulating the $\mathrm{AVF}^{1}$.

Therefore we conducted a prospective observational study in prevalent hemodialysis patients with an AVF, with the purpose to establish the pros and cons of the ropeladder and buttonhole cannulation techniques respectively, with respect to several outcome parameters like the incidence of miscannulation, cannulation ease, hematoma and aneurysm formation, CVC dependence or single needle dialysis, interventions. In addition evaluation of needle pain and fear associated with both cannulation techniques was evaluated. 


\section{Methods}

\section{Study design}

From 1 January 2007 to 1 November 2007, 145 prevalent hemodialysis patients with an autogenous AVF were included from three different centres and prospectively followed; 75 patients used the buttonhole and 70 patients used the rope-ladder technique. Inclusion criteria were a well-functioning fore - or upper arm AVF, with an access flow of $\geq 500 \mathrm{ml} / \mathrm{min}$, diameter of $\geq 6 \mathrm{~mm}$ and the ability to use the AVF, with cannulation of two needles. For all patients, hemodialysis frequency was three times per week. Data were collected from three dialysis facilities. One centre exclusively used the buttonhole technique and included all prevalent patients with an established tunnel track. The two other centres included all prevalent patients using the ropeladder method. Similar cannulation techniques were already used in these patients, before inclusion into the study.

Baseline data included patient characteristics, comorbidities, and medication. Vascular access characteristics include access type and anatomic location, date of creation, AVF duration, and a single measurement of vein diameter in $\mathrm{mm}$ at inclusion, assessed by Duplex ultrasound (Aloka 5500, Tokyo, Japan). During the study period, it was standard practice to monitor the AVF once per three months, using the ultrasound dilution technique (Transonic systems inc ${ }^{\circledR}$ Ithaca, NY).

Longitudinal data were administered, using Case Record Forms (CRF) and a standardized method to register data from each dialysis session. The following variables were registered: cannulation technique, inspection for hematoma, redness, swelling and aneurysm, auscultation, use of local anesthesia, sharp or dull needles, needle direction and position, number of cannulations, ease of cannulation, and years of experience of the dialysis nurse. During each dialysis session, needling pain was assessed using a Verbal Rating Scale (VRS) 10 point scale (1=no pain, 10=extreme pain $)^{8}$. Of the arterial and venous needles, the highest pain score was recorded. Fear was documented once a week, using the Verbal Rating Scale (VRS) 10 point scale (1=no fear, 10=extreme fear).

The study protocol was approved by the Medical Ethical Committee of the Maastricht University Medical Center.

\section{Fistula cannulation techniques}

Cannulation was performed by, trained skilful dialysis staff with experience in the specific cannulation technique. The cannulation procedure is characterized by a learning curve, and regular practice is needed to achieve skills and competence. Therefore, the dialysis staff is trained by proper education, and clinical training. During clinical training the dialysis nurse will be supervised by a qualified nurse until successful cannulation is demonstrated. 
For the buttonhole as well as the rope-ladder technique, needle insertion was standardized according to a cannulation protocol. In the group of patients with buttonhole cannulation, dull needles are gently inserted at the same spot through an established tunnel track ${ }^{5-7}$. The dull bevel of the needle opens the vessel flap at the end of the tunnel. The tunnel tracks were previously established by a reduced number of nurses (max. 3), cannulating with sharp needles into the exact same spot, using the same insertion angle and the same depth of penetration, and this for at least six sessions. Only one arterial and one venous buttonhole was created.

Subsequently all nurses were allowed to cannulate with dull needles. If there were difficulties placing a dull needle into an established buttonhole, a conventional sharp needle was used.

The skin was disinfected with Chlorhexidine $70 \%$ before and after scab removal from the puncture site according to the K/DOQI guidelines. The scab was removed with a 19 Gauche sharp needle.

In the rope-ladder group, every dialysis session two new sites are chosen for needle placement, with a minimum of $2-3 \mathrm{~cm}$ between the tip of the needles, and avoiding previous sites ${ }^{1}$.

A cannulation procedure was judged as successful if the dialysis nurse was able to cannulate two needles, both used for the hemodialysis treatment, without unsuccessful cannulation. Unsuccessful cannulation is defined as the need to insert more than one needle per arterial or venous connection, because of the impossibility to use the previously inserted needle(s). A subcutaneous hematoma of the AVF is defined as an abnormal localized infiltration of blood caused by needle cannulation. Aneurysm formation is defined as a localised dilatation of the vessel ${ }^{9}$. Signs and symptoms of inflammation such as redness and localized warmth were observed and documented.

A vascular access surveillance program, which included prevention of access dysfunction by surveillance and pre-emptive intervention, was operational at the participating facilities consistent with the K/DOQI guidelines ${ }^{1}$.

\section{Statistical analyses}

Statistical analysis was performed using SPSS software for Windows (SPSS release12.0, SPSS Inc, Chicago, IL, USA). Mann-Whitney test was performed to test differences between the rope-ladder and buttonhole group. Proportions of cannulation practice variables between both groups were tested with the Chi-square test. For all comparisons, the level of significance was set to $P<0.05$. 


\section{Results}

\section{Patients and arteriovenous fistulas}

Baseline data are listed in Table 6.1 and 6.2. The mean age of the patients in the ropeladder group was $65 \mathrm{yrs}$ and $67 \mathrm{yrs}$ in the buttonhole group, respectively. Access characteristics and cannulation characteristics are outlined in Table 6.3 and 6.4. Flow measurement of the AVF, using the ultrasound dilution technique, did not show significant differences between the buttonhole group $(1275 \mathrm{ml} / \mathrm{min}$ range 320-2500 $\mathrm{ml} / \mathrm{min}$ ) and the rope-ladder group (1053 $\mathrm{ml} / \mathrm{min}$ range $281-2400 \mathrm{ml} / \mathrm{min}$ ). For five patients in the buttonhole group, and two patients in the rope-ladder group, it was impossible to measure access flow, due to anatomical reasons (all upper arm AVF). Twenty-one patients (14\%) were lost to follow up due to the following reasons: eight death (5\%), five successful kidney transplantation (3\%), five AVF failure (3\%), and three patients started hemodialysis at a non participating facility (2\%). Mean duration of follow-up was 9 months, covering a total of 13729 dialysis sessions.

Table 6.1 Comparison of demographics and comorbidities of the study population between the ropeladder and buttonhole technique, and their $P$-value.

\begin{tabular}{|c|c|c|c|}
\hline Characteristics & $\begin{array}{c}\text { Rope-ladder } \\
n=70\end{array}$ & $\begin{array}{c}\text { Buttonhole } \\
n=75\end{array}$ & $P$ \\
\hline Gender & & & 0.28 \\
\hline Female & $23(33 \%)$ & $31(41 \%)$ & \\
\hline Male & $47(67 \%)$ & $44(59 \%)$ & \\
\hline Age (y) & & & 0.36 \\
\hline$\leq 60$ years & $22(31 \%)$ & $29(39 \%)$ & \\
\hline$>60$ years & $48(69 \%)$ & $46(61 \%)$ & \\
\hline Causes of ESRD* & & & 0.007 \\
\hline Glomerulonephritis & $14(20 \%)$ & $18(24 \%)$ & \\
\hline Interstitial nephritis & $6(9 \%)$ & - & \\
\hline Cystic kidney diseases & $2(3 \%)$ & $11(14 \%)$ & \\
\hline Other congenital/hereditary kidney diseases & - & $2(4 \%)$ & \\
\hline Renal vascular diseases & $24(34 \%)$ & $15(20 \%)$ & \\
\hline Diabetes mellitus & $11(16 \%)$ & $13(17 \%)$ & \\
\hline Other multisystem diseases & - & $2(3 \%)$ & \\
\hline Other /Unknown & $11(16 \%)$ & $14(18 \%)$ & \\
\hline Vintage on hemodialysis & & & 0.01 \\
\hline 1 to $12 \mathrm{mo}$ & $13(18 \%)$ & $20(27 \%)$ & \\
\hline 1 to 5 years & $51(73 \%)$ & $35(47 \%)$ & \\
\hline$\geq 5$ years & $6(9 \%)$ & $20(27 \%)$ & \\
\hline Body Mass Index ${ }^{*}$ & & & 0.03 \\
\hline$\leq 30 \mathrm{~kg} / \mathrm{m}^{2}$ & $64(91 \%)$ & $58(77 \%)$ & \\
\hline$>30 \mathrm{~kg} / \mathrm{m}^{2}$ & $6(9 \%)$ & $16(21 \%)$ & \\
\hline Tobacco use & & & 0.25 \\
\hline No & $58(83 \%)$ & 67 (89\%) & \\
\hline Yes & $12(17 \%)$ & $8(11 \%)$ & \\
\hline
\end{tabular}

* Values were missing for some patients 
Table 6.2 Comparison of medical history of the study population between the rope-ladder and buttonhole cannulation technique.

\begin{tabular}{lccc}
\hline & $\begin{array}{c}\text { Rope-ladder } \\
n=70\end{array}$ & $\begin{array}{c}\text { Buttonhole } \\
n=75\end{array}$ & $P$ \\
\hline Medical history & & & \\
$\quad$ Peripheral arterial obstructive disease & $7(10 \%)$ & $11(15 \%)$ & 0.39 \\
$\quad$ Coronary artery disease & $56(80 \%)$ & $46(61 \%)$ & 0.46 \\
$\quad$ Cerebrovascular disease & $14(20 \%)$ & $13(17 \%)$ & 0.68 \\
Diabetes mellitus & $15(21 \%)$ & $20(27 \%)$ & 0.46 \\
Hypertension & $15(21 \%)$ & $27(36 \%)$ & 0.08 \\
Medication & & & 0.04 \\
Use of calcium antagonist & $17(24 \%)$ & $7(9 \%)$ & 0.03 \\
Use of anticoagulances & $17(24 \%)$ & $8(11 \%)$ & 0.01 \\
Use of platelet aggregation inhibitor & $26(37 \%)$ & $46(61 \%)$ & 0.02 \\
Use of EPO & $68(97 \%)$ & $60(80 \%)$ & \\
\hline
\end{tabular}

Table 6.3 Comparison of AVF type between the rope-ladder and buttonhole cannulation techniques.

\begin{tabular}{|c|c|c|c|}
\hline Characteristics & $\begin{array}{c}\text { Rope-ladder } \\
n=70\end{array}$ & $\begin{array}{c}\text { Buttonhole } \\
n=75\end{array}$ & $P$ \\
\hline Mean duration of AVF use (mo) & $31(1-109)$ & $44(1-245)$ & 0.74 \\
\hline Access placement & & & 0.14 \\
\hline a. radialis - v. cephalica forearm & $42(60 \%)$ & $36(48 \%)$ & \\
\hline a. ulnaris - v.basilica forearm & $1(1 \%)$ & $1(1 \%)$ & \\
\hline a. brachialis - v.cubiti upper arm & $3(4 \%)$ & $10(13 \%)$ & \\
\hline a. brachialis - v.cephalica upper arm & $14(20 \%)$ & $25(33 \%)$ & \\
\hline a. brachialis - v.basilica upper arm & $10(14 \%)$ & $3(4 \%)$ & \\
\hline Previous accesses & & & 0.02 \\
\hline No & $59(84 \%)$ & $51(68 \%)$ & \\
\hline Yes & $11(16 \%)$ & $24(32 \%)$ & \\
\hline Previous catheter use* & & & 0.30 \\
\hline No & $21(30 \%)$ & $33(44 \%)$ & \\
\hline Yes & $41(59 \%)$ & $39(52 \%)$ & \\
\hline
\end{tabular}

* Values were missing for some patients

\section{Frequency of cannulation events}

Unsuccessful cannulation, defined as the need to insert more than one needle per arterial or venous connection, significantly differed between groups $(P<0.0001)$. Patients in the buttonhole group had more unsuccessful cannulations (Figure 6.1), but less hematoma formation $(P<0.0001)$ (Figure 6.2). Aneurysm formation occurred significantly more often $(P<0.0001)$ in patients using the rope- ladder technique $(67 \%)$ compared to patients using the buttonhole technique (1\%) (Figure 6.3). 
Table 6.4 Comparison of cannulation characteristics in percentages, between the rope-ladder and the buttonhole cannulation techniques.

\begin{tabular}{|c|c|c|}
\hline Cannulation Practice & $\begin{array}{c}\text { Rope-ladder } \\
n=70 \\
6882 \text { dialysis sessions }\end{array}$ & $\begin{array}{c}\text { Buttonhole } \\
n=75 \\
6847 \text { dialysis sessions }\end{array}$ \\
\hline \multicolumn{3}{|l|}{ Type of needle used } \\
\hline Metal sharp & 90 & 44 \\
\hline Metal dull & - & 56 \\
\hline Catheter & 10 & - \\
\hline \multicolumn{3}{|l|}{ Needle Gauche } \\
\hline 14 gauche & - & 7 \\
\hline 15 gauche & 100 & 93 \\
\hline \multicolumn{3}{|l|}{ Needle position } \\
\hline Bevel up & 52 & 99 \\
\hline Bevel down & 48 & 1 \\
\hline \multicolumn{3}{|l|}{ Axis rotation needle } \\
\hline Yes & 6 & 13 \\
\hline No & 94 & 87 \\
\hline \multicolumn{3}{|c|}{ Direction arterial needle } \\
\hline Antegrade & 95 & 76 \\
\hline Retrograde & 5 & 24 \\
\hline \multicolumn{3}{|l|}{ Tourniquet use } \\
\hline Yes & 50 & 73 \\
\hline No & 50 & 27 \\
\hline \multicolumn{3}{|c|}{ Sono graphic guided cannulation } \\
\hline Yes & - & - \\
\hline No & 100 & 100 \\
\hline \multicolumn{3}{|c|}{ Experience dialyses nurse } \\
\hline$<3$ yrs & 41 & 32 \\
\hline$\geq 3 \mathrm{yrs}$ & 59 & 68 \\
\hline
\end{tabular}

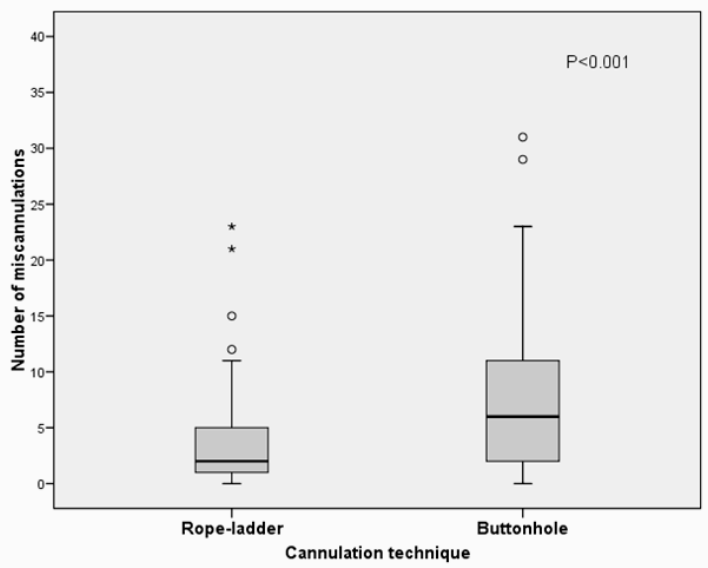

Figure 6.1 Comparison of miscannulations between the rope-ladder and buttonhole cannulation technique. Box indicates $25^{\text {th }}$ and $75^{\text {th }}$ percentiles (thick line is the median value). Capped bars indicate minimum and maximum value including outliers. The mean (SD) number of miscannulations for the rope-ladder technique was 3.7 (4.7), and for the buttonhole technique 8.1 (7.0) . 


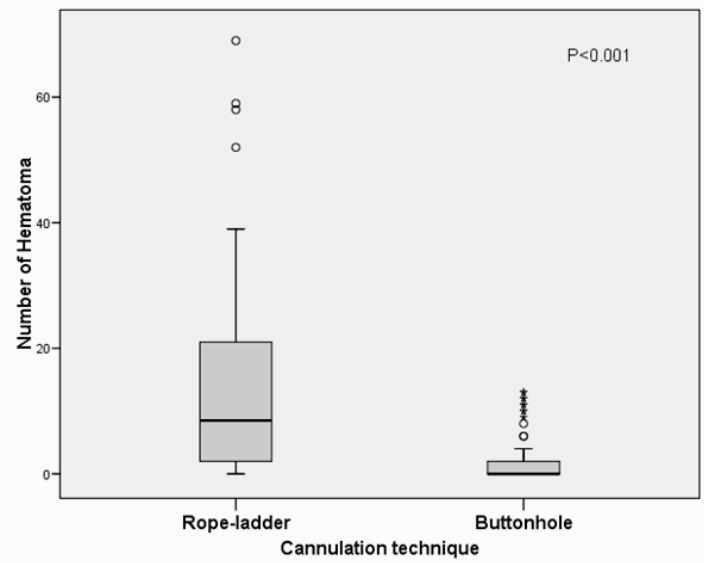

Figure 6.2 Number of hematoma with the rope-ladder and buttonhole cannulation technique. Box indicates $25^{\text {th }}$ and $75^{\text {th }}$ percentiles (thick line is the median value). Capped bars indicate minimum and maximum value including outliers. The mean (SD) number of hematoma for the rope-ladder technique was 14.0 (15.6), and for the buttonhole technique 2.0 (3.7) .

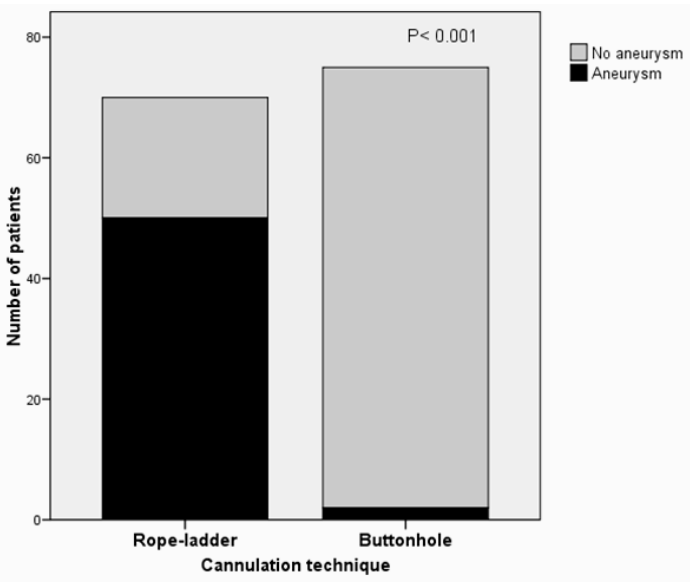

Figure 6.3 The number of patients who experienced an aneurysm.

\section{Comparison of cannulation pain and fear}

The patients average pain and fear score, assessed by the 10 point VRS, is outlined in Table 6.5. Although the mean pain experience level of both groups was mild and not very painful, patients in the buttonhole group experienced more pain $(\mathrm{P}<0.001$ and fear $(P<0.002)$ than patients in the rope-ladder group. However, the need to apply local anesthesia crème (EMLA=Eutectic Mixture of Local Anesthetics) was more 
common in patients with rope-ladder than in patients using the buttonhole technique $(\mathrm{P}<0.001)$ (Table 6.5).

Table 6.5 Pain and fear at the different cannulation techniques assessed by Verbal Rating Scale in the various groups.

\begin{tabular}{lccc}
\hline Cannulation Practice & $\begin{array}{c}\text { Rope-ladder } \\
n=70\end{array}$ & $\begin{array}{c}\text { Buttonhole } \\
n=75\end{array}$ & $P$ \\
\hline Age $(\mathrm{yr})$ & $67(20-90)$ & $65(21-87)$ & 0.49 \\
Gender & & & 0.29 \\
$\quad$ Female & $33(23 \%)$ & $31(41 \%)$ & \\
$\quad$ Male & $67(77 \%)$ & $44(59 \%)$ & $<0.001$ \\
Use of local anesthesia crème & $30 \%$ & $8 \%$ & $<0.001$ \\
Pain score & $1.0(0-5.4)$ & $1.6(0-5.0)$ & $<0.002$ \\
Fear score & $0.38(0-4.1)$ & $0.63(0-8.2)$ & \\
\hline
\end{tabular}

\section{Frequency of access interventions}

During the study period, patients in the buttonhole group required significantly fewer endovascular interventions (angioplasty) 10 out of 75 patients $(P<0.001)$, as compared with patients in the rope-ladder group 41 out of 70 patients $(P<0.001)$ (Table 6.6). The number of thrombectomies $(P=0.81)$, and surgical interventions $(P=0.55)$ were similar in both groups. To maintain the functionality of the AVF, the buttonhole group required 0.2 interventions per patient-year, and patients in the rope-ladder group had 0.8 interventions per patient-year.

Table 6.6 Diagnostic tests and interventions at the different cannulation techniques during nine months.

\begin{tabular}{lccc}
\hline & $\begin{array}{c}\text { Rope-ladder } \\
n=70\end{array}$ & $\begin{array}{c}\text { Buttonhole } \\
n=75\end{array}$ & \\
\hline Patients with diagnostic tests & $\mathbf{2 8}$ & $\mathbf{1 5}$ & $\mathbf{0 . 0 0 4}$ \\
Diagnostic tests & $\mathbf{7 3}$ & $\mathbf{2 4}$ & \\
Duplex & 14 & 11 & \\
Fistulogram & 51 & 10 & \\
MRA & 8 & 3 & $\mathbf{0 . 0 0 1}$ \\
Patients with interventions & $\mathbf{2 1}$ & $\mathbf{6}$ & $\mathbf{0 . 0 0 1}$ \\
Interventions & $\mathbf{4 1}$ & $\mathbf{1 0}$ & $\mathbf{0 . 8 1}$ \\
angioplasty & 35 & 2 & $\mathbf{0 . 5 5}$ \\
thrombectomy & 3 & 1 & $\mathbf{0 . 0 0 1}$ \\
surgical revisions & 3 & 3 & \\
antibiotic treatments because of access & - & 4 & \\
related infections & & & \\
\hline
\end{tabular}

However, for the buttonhole group, antibiotic treatment because of access-related infection was more frequently encountered $(P \leq 0.001)$. In the buttonhole group, intravenous antibiotic treatment was necessary in five patients because of accessrelated infection. Hemoculture results indicated in two patients a gram-positive 
Staphylococcus aureus infection. Two local infections of the buttonhole site were registered, caused by Staphylococcus aureus and Clostridium perfringens. One patient exhibited a gram-negative culture.

No statistically significant difference was seen between the rope-ladder and buttonhole technique, for as well as CVC use $(P=0.08)$, and single needle dialysis $(P=0.08)$ (data not shown).

\section{Discussion}

This study shows that, although the buttonhole technique resulted in more miscannulations, hematoma formation occurred significantly fewer than in the ropeladder group. An explanation for this observation might be that unsuccessful cannulation with dull needles causes less tissue injury compared to sharp needles. Previous studies have shown that complications associated with cannulation were almost eliminated using buttonhole techniques ${ }^{7,10-19}$.

The result of using the rope-ladder technique is only a small dilatation effect over a greater length ${ }^{5}$. We observed a significant number of aneurysms in patients exhibiting the rope-ladder technique. This finding suggests that, although the protocol prescribes to use the rope-ladder method, the dialysis staff in daily practice may use the area technique.

The present data also demonstrate a significantly lower number of angioplasties in the buttonhole group. This finding supports previous studies which have shown that difficult and complicated cannulation is associated with interventions, access thrombosis, and use of central venous catheters as a consequence ${ }^{3}$.

A possible explanation for the lower number of interventions in the buttonhole group might be that the buttonhole procedure causes less vessel damage due to the use of dull needles, which are inserted in exactly the same entry point, compared with the rope-ladder technique, where sharp needles have different angles of insertion, which possibly causes more damage, initiating neointimal hyperplasia development resulting in stenosis. To avoid fistula tromboses, stenosis are treated with pre-emptive angioplasty procedures. A negative outcome of the buttonhole technique was the higher incidence of access infections compared to the rope-ladder method. Similar observations ${ }^{6,20}$ indicate that although infection rates in AVFs are usually low, the buttonhole cannulation may induce infections. A possible explanation for this observation could be an inappropriate application of the disinfection protocol by the nursing staff and/or the frequently intermittent use of sharp instead of dull needles. Indeed, in the busy in-centre dialysis facility, in order to gain time, nurses did not always respect the contact time of the disinfecting agent, and scabs were in some cases not removed properly.

As soon as a bouncing effect was felt and the vessel flap could not be opened immediately with a dull needle, nurses preferred to 're'cannulate with a sharp needle, 
which was successful in most cases. However, the latter may result in a faulty track cannulation, which can damage and infect the cannulation site. A reinforced disinfection protocol has been implemented, where the scabs and surrounding skin are generously soaked with the disinfecting agent. The importance of thorough scab removal has been highlighted again, together with the advocacy to use dull needles. In addition, the role of primary cannulators has been created. Only the latter are allowed to use sharp needles, after unsuccessful cannulation with a dull needle. A reduction from $48 \%$ to less than $10 \%$ use of sharp needles has subsequently been observed with a dramatically improved infection rate in the following months (data not shown).

Surprisingly, the average pain score in patients using the rope-ladder technique was less compared to patients with the buttonhole method. This is not consistent with other studies ${ }^{5-7,13}$ in which patients did score less pain with the buttonhole technique. An explanation for this finding might be, the fact that other studies have compared pain sensation of both techniques in the same individual patient. In the present study the individual patient was using only one technique, and therefore can not experience and judge the effect of the other technique. The application of local anesthesia crème in the rope-ladder group might also have influenced the pain score.

Our study has limitations, as it was an observational, non-randomised study, with a comparison of patient groups and nursing teams, so that a specific factor could have been biased. Each cannulation technique demands its own specific skill, therefore patients had to be included from three different centers.

Some prognostic factors like; vintage on hemodialysis, BMI and previous accesses are not equal distributed between the rope-ladder and buttonhole group. Only based on these factors the buttonhole group should have worse outcomes. The rope-ladder technique requires a cannulation route of more than $10 \mathrm{~cm}$ to allow for rotation of needle sites and sufficient distance between the needles. This is not necessary for the buttonhole, which is a clear advantage for this technique.

Cannulation of the AVF in the today's population is more difficult and challenging than ever. This study showed that the buttonhole method is a valuable technique with few complications like hematoma, aneurysm formation and the need for interventions. The frequency of cannulation-related complications was significantly lower in the buttonhole technique compared with the rope-ladder method. In addition we may postulate that the buttonhole technique is suitable for self-cannulating patients, and also deserves a place in dialysis facilities with the possibility to cannulate the patient not only by a small group of nurses. Infections induced by the buttonhole method should not be underestimated, and underline the importance of aseptic and correct technique of the buttonhole procedure.

Successful access cannulation requires a high level of awareness and skills of the dialysis nurse, and frequent monitoring, evaluation and education of the needling technique is mandatory to guarantee that patients will receive the highest quality of care. 


\section{References}

1. NFK-KDOQI clinical practice guidelines and clinical practice recommendations for vascular access: update 2006. Am J Kidney Dis 2006;48(S1):S176-S322

2. Allon $M$, Robbin ML. Increasing a-v fistulas in hemodialysis patients: problems and solutions. Kidney Int 2002;62:1109-1124.

3. Lee T, Barker J, Allon M. Needle infiltration of arteriovenous fistulas in hemodialysis patients: Risk factors and consequences. Am J Kidney Dis 2006;47:1020-1026

4. Ball LK. Improving arteriovenous fistula cannulation skills. Nephrol Nurs J 2005;32:611-617

5. Krönung G. Plastic deformation of Cimino fistula by repeated puncture. Nephrol Dial Transplant 1984; 13:635-638

6. Verhallen AM, Kooistra MP, Jaarsveld van BC. Cannulating in heamodialysis; rope-ladder or buttonhole technique? Nephrol Dial Transplant 2007;22:2601-2604

7. Twardowski ZJ, Kubara H. Different sites versus constant sites of needle insertion into arteriovenous fistulas for treatment by repeated dialysis. Dialyses Transpl 1979;8:978-980

8. Melzack R. The McGill pain questionnaire: major properties and scoring methods. Pain 1975;1:277299.

9. Tordoir J, Mickley V. European guidelines for vascular access: clinical algorithms on vascular access for haemodialysis EDTNA ERCA J 2003;29:131-136.

10. Twardowski ZJ. Constant site (buttonhole) method of needle insertion for hemodialysis. Dial Transplant 1995;24:559-576

11. Twardowski ZJ, Harper G. The buttonhole method of needle insertion takes center stage in attempt to revive daily home hemodialysis. Dialyses Transpl 1995;24:559

12. Toma S, Shinzato T, Fukui H, Nakai S, Miwa M, Takai I, Maeda K. A time saving method to create a fixed puncture route for the buttonhole technique. Nephrol Dial Transplant 2003;18:2118-2121

13. Ball LK. The buttonhole technique for arteriovenous fistula cannulation. Nephrol Nurs J 2006;33: 299-304

14. Goovaerts T. Long-term experience with buttonhole technique of fistula cannulation. Oral communication, Annual dialysis conference, Tampa, Florida, 2005.

15. Peterson P. Fistula cannulation: the buttonhole technique. Nephrol Nurs J 2002;29:195

16. Harper G. The buttonhole technique of fistula access: a personal experience. Home Hemodial Int 1997;1:41-42

17. Murcutt G. Buttonhole cannulation: should this become the default technique for dialysis patients with native fistulas? Summary of the EDTNA/ERCA J club discussion Autumn 2007. J of Renal Care 2008;34:101-108

18. Marticorena RM, Hunter J, Macleod S, Petershofer E, Dacouris N, Donnelly S, Goldstein MB. The salvage of aneurismal fistulae utilizing a modified buttonhole cannulation technique and multiple cannulators. Hemodial Int 2006;10:193-200

19. Ball LK, Treat L, Riffle V, Scherting D, Swift L. A multi-center perspective of the buttonhole technique in the Pacific Northwest. Nephrol Nurs J 2007;34:234-241

20. Doss S, Schiller B, Moran J. Buttonhole cannulation - an unexpected outcome. Nephrol Nurs J 2008; 35:417-419 


\section{Chapter 7}

Surgical techniques to improve cannulation of hemodialysis vascular access

J.H.M. Tordoir, M.M. van Loon, N. Peppelenbosch, A.S. Bode, M. Poeze, F.M. van der Sande 


\section{Abstract}

\section{Background}

Successful access cannulation is of utmost importance for adequate hemodialysis treatment. Upper arm fistulas, obesity and deep or tortuous veins may impair needling and can cause significant complications and inconvienance for the patient. In the ultimate case, cannulation problems lead to temporary central vein catheter use for dialysis or even to irreversible access loss. Surgical access revision may enhance successful cannulation.

\section{Methods}

A systematic literature review of all publications related to hemodialysis vascular access, cannulation complications and treatment was performed.

\section{Results}

A total of 384 publications were identified of which only 17 were related to treatment of cannulation complications in large patient populations. The clinical success rate of surgical intervention with vein elevation or transposition ranges from 85 to $91 \%$. The one year primary and secondary patencies are 60 and $71 \%$ respectively. Lipectomy results in an initial success rate of $100 \%$ with a primary and secondary patency of 71 and $98 \%$, respectively, after one year of follow up.

\section{Conclusion}

Surgical revision to improve hemodialysis vascular access cannulation has a high clinical success rate with good long-term patency. 


\section{Introduction}

Miscannulation of hemodialysis vascular access may cause infiltrations, hematoma formation, infection and aneurysms, and leads to morbidity, hospitalisation, access revision and even loss of the access. Difficult cannulation is painful and burdensome for the patient, which has a negative impact on the quality of life. Recent studies have shown cannulation-related complications in a great percentage (31\%) of incident patients. In addition, alternative access methods, like single- needle cannulation and central vein catheters were needed in these patients, with a potential higher morbidity and mortality rate. Miscannulation and cannulation-related complications are usually seen in autogenous arteriovenous fistula (AVF) but also occur in the arteriovenous graft (AVG). Obesity, female gender and the length of the cannulation route are important factors for the occurrence of cannulation-related complications. In a univariaten analysis of patients with AVF, female gender $(P<0.02)$ and limited length of cannulation route $(P<0.003)$ were significant determinants for the use of catheter or single needle dialysis. Multivariate analysis showed the limited length of cannulation route as the single predictive factor for cannulation problems $(P<0.002)$. Upper arm AVFs exhibit more cannulation problems than forearm AVFs, but the difference is not statistically significant ${ }^{1}$. Ultrasound-guided needling may facilitate successful cannulation of difficult accesses, this technique can be cumbersome to learn by dialysis nurses and extended experience is needed for good outcome.

Surgical access revision may enhance access cannulation and improve fistula outcome. For the description and outcome of the various surgical techniques a literature review was performed.

\section{Methods}

A systematic literature review using a Medline search of English-language publications was performed. Keywords used were: vascular access; hemodialysis; cannulation; complications. For this review in particular, large population-based, randomised studies and meta-analyses were included. Small patient studies and case reports were excluded. A total of 384 studies were identified; 367 studies were excluded for review because of: not meeting the inclusion criteria $(n=214)$; case reports $(n=106)$ and nonEnglish-language publications $(n=47)$. None of the identified studies was randomised or concerned a meta-analysis. Seventeen studies were eligible for review, including various techniques to enhance access cannulation. A test of heterogeneity showed no significant deviation of the different papers from the normal distribution. 


\section{Etiology of miscannulation}

\section{Non-maturation}

Fistula cannulation can be usually performed after successful maturation. A time period of six weeks to three months is sufficient to achieve adequate maturation in most patients. According to the National Kidney Foundation-Kidney Diseases Outcome Quality Initiative (NFK-DOQI) guidelines autogenous AVFs have matured when they fulfill to 3 criteria: a vein diameter of $6 \mathrm{~mm}$; a bloodflow of $600 \mathrm{ml} / \mathrm{minute}$ and a vein depth of less than $6 \mathrm{~mm}^{2}$. These criteria are hardly met with in daily practice. As much as $30-40 \%$ of radiocephalic wrist AVFs and $10-20 \%$ of elbow and upper arm AVFs (brachiocephalic/basilic) fail or do not mature after creation. The reason for nonmaturation is in $90 \%$ of patients a stenotic lesion at the arteriovenous anastomosis or arterial inflow. In addition, large calibre accessory veins may be associated with nonmaturation and cannulation difficulties. In 10 out of 15 patients with radiocephalic arteriovenous fistulas (RCAVFs), the presence of large caliber accessory veins was the only significant predictor for non-maturation $(P=0.01)^{3}$.

\section{Obesity \& deeply located veins}

The number of obese end-stage renal disease patients, who frequently have type 2 diabetes, is continuously increasing. On the one hand, obese and diabetic patients belong to a group with an increased risk of autogenous arteriovenous fistula placement failure due to advanced arteriosclerosis and reduced accessibility of forearm vessels because of excessive fat tissue. Moreover, needling of the deeply located veins may be difficult. Up to $50 \%$ of AVFs may fail to mature, primarily because of problems with fistula cannulation. On the other hand, while physical examination usually does not show superficial veins in these patients, Doppler ultrasound vessel imaging may identify well-sized, good quality radial arteries and cephalic veins for fistula creation and these are comparable between obese and nonobese patients ${ }^{4}$.

Still, AVF use for dialysis is less frequent among obese than non-obese patients. This discrepancy may be due to a lower rate of fistula placement in obese patients and a higher primary and secondary failure rate. A prospective study showed that fistula placement was equally likely between obese (body mass index (BMI) $\geq 30 \mathrm{~kg} / \mathrm{m}^{2}$ ) and non-obese $\left(\mathrm{BMl}<30 \mathrm{~kg} / \mathrm{m}^{2}\right.$ ) patients ( 47.4 vs $\left.47.1 \%\right)$. The primary failure rate of AVFs was similar in both groups ( 46 vs $41 \%, P=0.45$ ). Among those AVFs that were usable for dialysis, the secondary survival was worse in obese patients (hazard ratio 2.74; 95\% confidence interval $(\mathrm{Cl}), 1.48-7.90 ; P=0.004)$. Secondary fistula survival in obese versus non-obese patients was 68 vs $92 \%$ at one year, 59 vs $78 \%$ at two years, and 47 vs $70 \%$ at three years. On multivariate survival analysis with age, sex, race, diabetes, coronary artery disease, peripheral vascular disease, fistula location, surgeon, and obesity in the model, obesity was the only significant factor predicting secondary 
fistula failure (hazards ratio 2.93; $95 \% \mathrm{Cl}, 1.44-5.93 ; P=0.004)$. Long-term fistula survival is worse in obese than non-obese patients, owing to a higher secondary failure rate. Access failure in obese patients may be due to needling difficulties resulting in cannulation-related complications ${ }^{5}$.

In a large retrospective study, 1486 hemodialysis patients were included. Using body mass index $(\mathrm{BMI})<30 \mathrm{~kg} / \mathrm{m}^{2}$ as reference, obesity did not emerge as a factor in predicting vascular access revisions or failures. An increased risk of AVF failure to mature was found only in the highest BMI quartile $\left(>35 \mathrm{~kg} / \mathrm{m}^{2}\right)(A O R 3.66[95 \% \mathrm{Cl}$ 1.27-10.55], $P=0.017)$. Peripheral vascular disease was independently associated with an increased risk of AVF failure (AOR $2.78[95 \% \mathrm{Cl} 1.01-7.63], P=0.047$ ) and AVG failure (AOR 1.65 [95\% Cl 1.03-2.64], $P=0.036$ ). Obesity was not associated with increased AVF or AVG revision rates or failure and only associated with poorer AVF maturity at the highest BMI quartile ${ }^{6}$.

\section{Short vein segment and/or tortuosity}

Vein anatomy may differ widely among patients, which implies a variety of accessible vein segments after access creation. In some patients, meandering veins may lead to difficult (mis)cannulation with greater chance on hematoma. Radio/brachiocephalic AVFs may develop stenosis and subsequently obstruction the site of side branches. Usually, a short vein segment remains available for cannulation. However, this segment may be unsuitable for two-needle dialysis. Further, short vein segments result in a higher percentage of miscannulation and complications ${ }^{7}$.

\section{Surgical techniques to enhance cannulation}

\section{Vein elevation \& transposition.}

If the flow and size of the fistula are adequate, subcutaneous elevation or transposition is an ideal procedure. The vein can be directly superficialised under the wound (Figure 7.1A-C), or tunnelled to a more favourable location for needling if required. It is important to avoid placing the vein under tension and disconnection with re-formation of the anastomosis may be required.

The fistula elevation procedure (FEP) is a simple superficialisation procedure where the fistula is surgically exposed, mobilized, and elevated into a more superficial position for the purpose of facilitating AV fistula cannulation. The FEP procedure can be performed in one or two-staged operation (second operation between four and nine weeks after fistula creation to allow for vein maturation). A longitudinal incision is made some distance away from the fistula vein, running from the wrist to the proximal forearm in the patients with a RCAVF and from the antecubital fossa to the proximal upper arm in patients with a BCAVF. The fistula is mobilized along the length of the incision. It is important to be aware that skin incision directly over the vein may result in excessive scar tissue, which hampers future access needling. Tributaries are 
ligated with fine silk sutures and divided. The subcutaneous fat is than approximated beneath the fistula with interrupted 3-0 Vicryl suture, thereby elevating the fistula to a superficial position. The skin is closed over the fistula with a running subcuticular 4-0 Vicryl suture ${ }^{8-10}$.

A

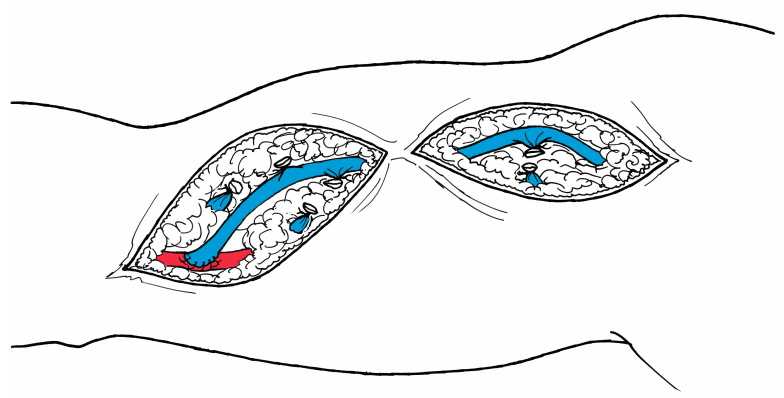

B
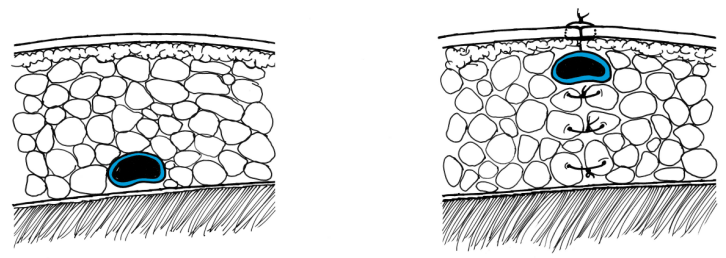

C
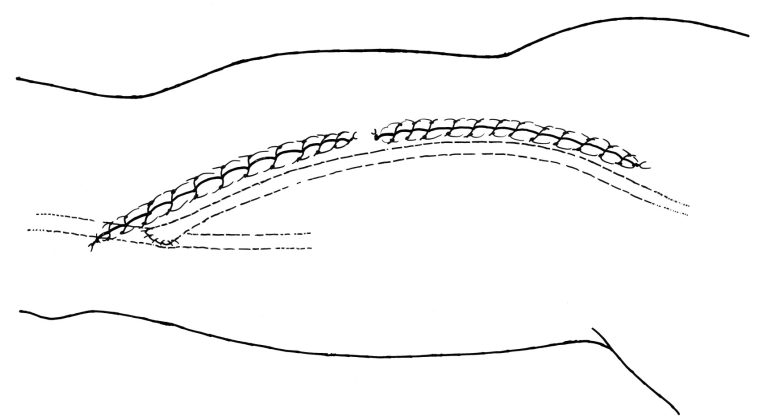

Figure 7.1A-C. Schematic drawing of the elevation technique.

Silva et al. ${ }^{11}$ have described a high maturation and cannulation rate with subcutaneous elevation \& transposition of forearm veins in an one-stage operation. They advocated different surgical techniques, according to the forearm artery and vein location. Of the 89 veins that were of acceptable size and patency, 13 (15\%) were in immediate proximity to the radial artery such that an AVF could be formed through a single incision. Thirty of 89 (33\%) of the veins were located on the dorsal aspect of the forearm and were transposed to the volar aspect for anastomosis to the appropriate 
artery (radial in 26, ulnar in 2, and brachial in 2). The remaining 46 of 89 veins (52\%) were located on the volar aspect of the forearm but were dissected through separate incisions, transposed superficially, and sutured to the appropriate artery (radial in 42, ulnar in 2, and brachial in 2). Successful cannulation and hemodialysis was accomplished in 81 of the 89 AVFs, giving a maturation rate of $91 \%$. Primary patency rates were $84 \%$ at 1 year and $69 \%$ at 2 years for all AVFs.

The two-staged FEP technique has been performed by Weyde et.al. ${ }^{12}$ in 71 obese patients with RCAVFs. In the first stage, an autogenous arteriovenous fistula was created in the wrist region. In the second-stage, which was carried out 10-14 days after fistula formation, an arterialised vein was elevated subcutaneously to enable safe needling. The time span between the two procedures allowed for saving of the vein for a second more proximal anastomosis in the event of initial fistula failure. Sixty-five patients with functioning AVFs underwent the second stage operation, which was successful in 60 patients (85\%). The cause of unsuccessful elevation in four patients was insufficient blood flow through the vein. In one patient, the vein elevation produced a large hematoma that resulted in fistula thrombosis. Primary patency rates were $65 \%$ at 6 months and $59 \%$ at 1 year. Secondary patency rates were $83 \%$ at 6 months and remained steady after a 1-year observation (Figure 7.2A,B).

The largest series of fistula elevation procedures comprise 295 patients. (172 brachiocephalic, 70 brachiobasilic, 46 radiocephalic, 7 superficial femoral vein). FEP was performed if the fistula was considered too deep to cannulate or if nurses were unable to cannulate the fistula. Functional primary patency rates for patients undergoing an adjunctive FEP were $73 \%$ at 6 months, $60 \%$ at 1 year, and $46 \%$ at 2 years. Secondary functional patency rates were $81 \%$ at 6 months, $71 \%$ at 1 year, and $59 \%$ at 2 years. There was no statistical significance in any outcomes based on anatomic site of elevation ${ }^{13}$.
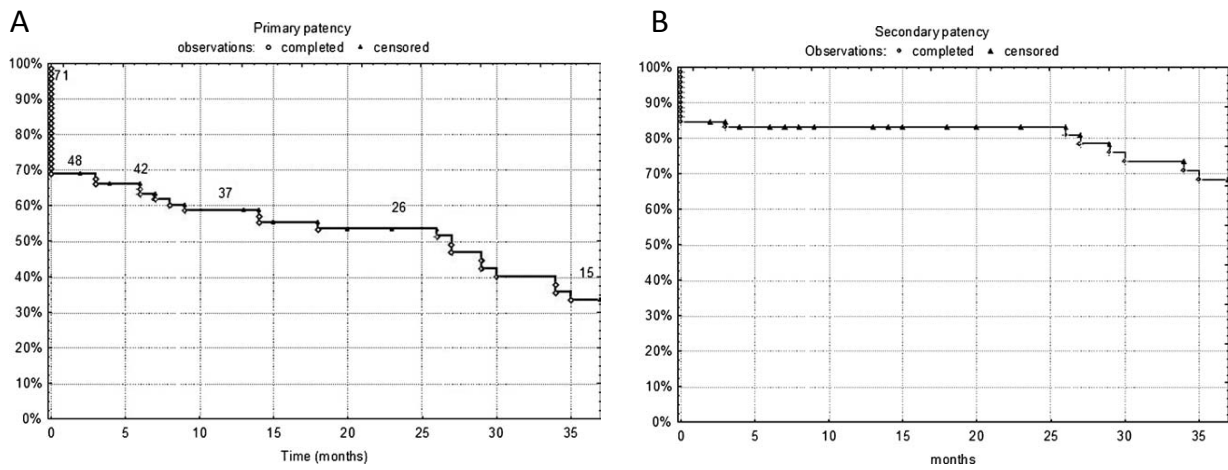

Figure 7.2 A. Results of two-stage elevation technique. Primary patency rates are 65\% (SE 0.056), 59\% (SE 0.059), 53\% (SE 0.061) and 33\% (SE 0.065) at 6, 12, 24, 36 months, respectively. The numbers above the curve represent numbers at risk. B. Results of two-stage elevation technique. Secondary patency rates are $83 \%$ (SE 0.04 ), $83 \%$ (SE 0.04), 80\% (SE 0.05) and 68\% (SE 0.06) at 6, 12, 24, 36 months, respectively ( $\mathrm{SE}=$ standard error). (reproduced from Weyde et al. with permission) 
An alternative technique is subcutaneous transposition of the cephalic vein in the fore- or upper arm, which is done in a two-staged operation. This technique is also possible for a deeply located non-transposed basilic vein after the creation of a brachiocubital (Gracz) fistula. After vein dissection and transsection two $\mathrm{cm}$ proximal of the AV anastomosis, subcutaneous rerouting of the vein with a tunneler along a straight course is performed with subsequently re-anastomosis to the vein stump near to the already existing AV anastomosis.

AVFs that might otherwise have been abandoned because of excessive depth or tortuosity can be successfully salvaged by an adjunctive elevation or transposition procedure and achieve satisfactory long-term functional patency.

\section{Vein stretching \& accessory vein ligation}

Large ( $>50 \%$ of main vein diameter) accessory veins may divert flow from the main vein, making needling more challenging. These tributaries can be ligated under local anaesthesia, through small stab incisions adjacent to the vein. It is best to place the incision a little way from the branch point to avoid ligating or damaging the main vein. A vein hook, as used for phlebectomy, can be used to gently hook up smaller veins and ligate them. This is a straightforward procedure, usually made more accurate by pre-operative duplex mapping.

Beathard et al. ${ }^{14}$ have published on the treatment of fistula non-maturation, including accessory vein ligation. One hundred patients were identified that met the definition of early failure. Arterial, juxta-anastomotic, venous or a combination of stenotic lesions was present in almost all patients. Accessory veins were present in $46 \%$ and in $12 \%$ this was the only lesion present. Angioplasty was performed to treat venous stenosis in $72 \%$ of the cases with a $98 \%$ success rate. Angioplasty of the arterial anastomosis was performed in 38 cases with a $100 \%$ success rate. Accessory vein obliteration was performed in $46 \%$ of the patients with a $100 \%$ success rate. It was possible to initiate dialysis using the fistula in $92 \%$ of the cases. Life-table analysis showed that $84 \%$ were functional at 3 months, $72 \%$ at 6 months, and $68 \%$ at 12 months.

Usually, salvage procedures with endovascular (PTA $=$ Percutaneous Transluminal Angioplasty) and/or surgical procedures result in a high success percentage resulting in blood flow enhancement, vessel adaptation and dilatation and secondary maturation and cannulation ${ }^{15}$.

The surgical technique of vein stretching is similar to vein transposition. The tortuous vein is dissected and side branches ligated. The vein is transected near the AV anastomosis. The excess vein length is trimmed and after subcutaneous rerouting a re-anastomosis to the venous stump with $6 / 0$ polypropylene suture (Prolene ${ }^{\circledR}$ ) is performed. Wound healing with vein ingrowths in the subcutaneous tunnel for a period of 4 to 6 weeks is obligatory, before any needling is started. 


\section{Local vein revision}

Segmental vein stenosis and/or aneurysm may impair cannulation and can be revised by endovascular or surgical means. PTA is the first treatment option for segmental stenosis. As an alternative, vein or graft interposition/patch can augment the area of needling sites.

\section{Lipectomy}

An alternative technique is lipectomy with removal of the subcutaneous fat between the vein and the $\operatorname{skin}^{16}$. Two transverse skin incisions are made over the cephalic vein, $8 \mathrm{~cm}$ apart. The fat is removed over a length of approximately $4 \mathrm{~cm}$ on each side of each incision. The dissection is facilitated by elevation of the skin with hooks. The periadventitial plane is opened and dissected between the fascia superficialis and the anterior surface of the vein. The use of a tourniquet allows for easy bloodless separation of the vein and the fascia. The posterior part of the subcutaneous fatty tissue is dissected medially from the anterior surface of the vein and cut laterally. The anterior part of the subcutaneous fatty tissue is bluntly separated from the skin, with the exception of the most superficial part (1 mm deep). This approximately $4-\mathrm{cm}$-long dissection is performed distally and proximally from each incision site. The tissues were cut medially and laterally $2 \mathrm{~cm}$ from the vein. The fat pad and the underlying fascia are then excised.

In a single-center prospective study 49 consecutive patients underwent lipectomy after creation of a radiocephalic fistula. The mean body mass index was $31 \pm 5.6 \mathrm{~kg} / \mathrm{m}^{2}$. Subcutaneous fatty tissues were removed with two transverse skin incisions under regional anesthesia and preventive hemostasis. Cannulation was first allowed one month later, after clinical and color duplex ultrasound evaluation. Technical success was defined as the ability to remove the fat and to palpate the patent vein immediately under the skin at the end of the operation. Clinical success was defined as the ability to perform at least three consecutive dialysis sessions with two needles. Technical and clinical success rates were $96 \%$ and $94 \%$, respectively. Mean vein depth decreased from $8 \pm 2$ to $3 \pm 1 \mathrm{~mm}$ according to duplex ultrasound imaging. The mean vein diameter increased from $6 \pm 1$ to $8 \pm 2 \mathrm{~mm}$. In one patient, vein tortuosity that was overlooked required conventional repeat tunneling. One extensive hematoma resulted in loss of the fistula. One patient died before the fistula could be used. Primary patency rates were $71 \%$ and $63 \%$ at one and three years, respectively, and secondary patency rates were $98 \%$ and $88 \%$ (Figure 7.3 ). Complications were treated by surgery (7) or by endovascular procedures $(10)^{17}$. 

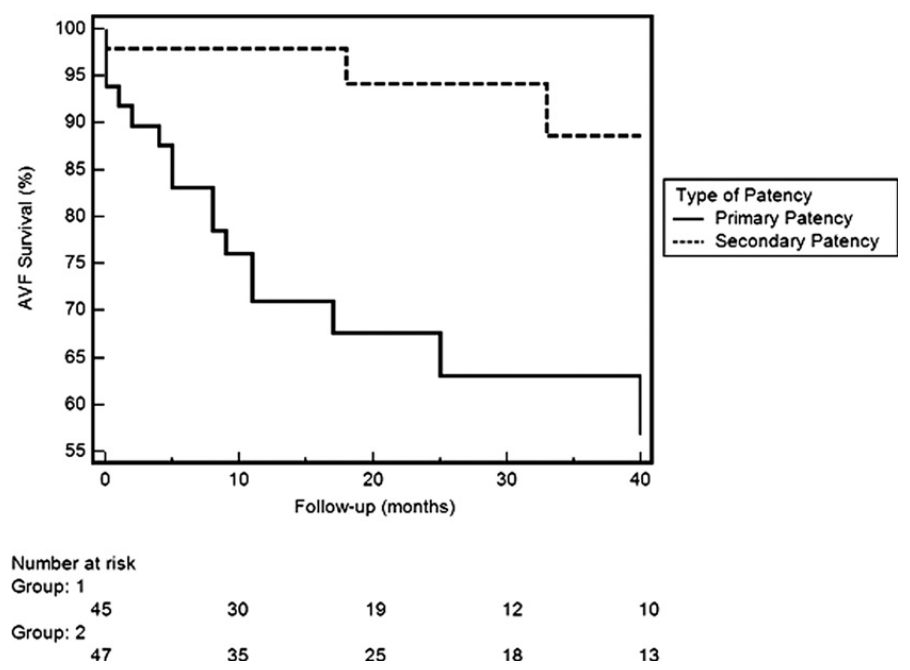

Figure 7.3 Results of lipectomy. Primary patency rates (solid line) are $71 \%$ (SE 0.07), 67\% (SE 0.07) and $63 \%$ ( SE 0.08) at 12,24 and 36 months, respectively. Secondary patency rates (dashed line), are $98 \%$ (SE 0.02), 94\% (SE 0.04), and 88\% (SE 0.07) at 12,24 and 36 months respectively ( $S E=s t a n d a r d$ error). The numbers at the bottom of the graph represent numbers at risk. (reproduced from Bourquelot et al. with permission)

\section{Discussion}

Cannulation difficulties and complications appear in one third of patients with autogenous AVFs and AVGs. In particular, obese patients and patients with upper arm AVFs are at risk for miscannulation. Cannulation problems result in local infiltration, infection and aneurysmatic vein dilatation, which urge the physician to shift to central vein catheter dialysis or even abandonment of the access. Adjustment of the cannulation practice, for instance adding sonography to guide needling of deeply located veins, or changing cannulation technique (buttonhole), may help some patients to overcome difficult cannulation. However, in a great number of patients these changes in practice patterns do not result in a better outcome. Endovascular and/or surgical interventions are therefore helpful to treat cannulation-related complications. Non-matured or stenosed veins are treated by endovascular means as a primary option. Surgical techniques, employing vein elevation/ stretching/ transposition and repositioning are indicated in particular in deeply located or tortuous veins. Alternative techniques like lipectomy are useful to solve cannulation inability in obese patients. In the literature only scarce information on the outcome of surgical revisions has been referenced. However, they show high primary success rate 
and good long-term patencies and amongst the different methods of vein superficialisation or lipectomy the outcomes are comparable.

In conclusion, surgical intervention is useful to enhance cannulation practice in obese patients and difficult accesses. Nephrologists and vascular surgeons should be aware of the possibilities of surgical interventions and may offer these to their dialysis patients with persistent cannulation difficulties and complications. 


\section{References}

1. van Loon MM, Kessels AGH, van der Sande FM, Tordoir JHM. Cannulation practice patterns in haemodialysis vascular access: predictors for unsuccessful cannulation. J Ren Care. 2009;3582-9

2. NFK-KDOQI. Clinical practice guidelines and clinical practice recommendations for vascular access: update 2006. Am J Kidney Dis. 2006;48(Suppl 1):S176-S322

3. Planken RN, Duijm LE, Kessels AG, Leiner T, Kooman JP, Van Der Sande FM, Tordoir JH. Accessory veins and radial-cephalic arteriovenous fistula non-maturation: a prospective analysis using contrastenhanced magnetic resonance angiography. J Vasc Access .2007;8:281-286.

4. Vassalotti JA, Falk A, Cohl ED, Uribarri J, Teodorescu V. Obese and non-obese hemodialysis patients have a similar prevalence of functioning arteriovenous fistula using pre-operative vein mapping. Clin Nephrol. 2002;58:211-214.

5. Kats M, Hawxby AM, Barker J, Allon M. Impact of obesity on arteriovenous fistula outcomes in dialysis patients. Kidney Int. 2007;71:38-43

6. Chan MR, Young HN, Becker YT, Yevzlin AS. Obesity as a predictor of vascular access outcomes: analysis of the USRDS DMMS Wave II study. Semin Dial. 2008;21:274-279.

7. van Loon MM, Kessels AGH, van der Sande FM, Tordoir JHM. Cannulation and vascular access-related complications in hemodialysis: Factors determining successful cannulation. Hemodial Int. 2009;13: 498-504

8. Cull DL, Taylor SM, Carsten CG, Youkey JR, Snyder BA, Sullivan TM, Langan EM. The fistula elevation procedure: a valuable technique for maximizing arteriovenous fistula utilization. Ann Vasc Surg. 2002;16:84-88

9. Weyde W, Krajewska M, Letachowicz W, Klinger M. Superficialization of the wrist native arteriovenous fistula for effective hemodialysis vascular access construction. Kidney Int. 2002; 61:1170-1173

10. Arenas MD, Gil MT, Malek T, Moledous A, Nuñez C, López-Collado M. Superficialization of autologous vascular access: an alternative to the use of vascular prostheses and permanent catheters. Nefrologia. 2009;29:67-70

11. Silva MB Jr, Hobson RW 2nd, Pappas PJ, Haser PB, Araki CT, Goldberg MC, Jamil Z, Padberg FT Jr. Vein transposition in the forearm for autogenous hemodialysis access. J Vasc Surg. 1997;26:981-986.

12. Weyde W, Krajewska M, Letachowicz W, Porazko T, Watorek E, Kusztal M, Banasik M, Golebiowski T, Bartosik H, Madziarska K, Janczak D, Klinger M. Obesity is not an obstacle for successful autogenous arteriovenous fistula creation in haemodialysis. Nephrol Dial Transplant. 2008;23:1318-1322

13. Bronder CM, Cull DL, Kuper SG, Carsten CG, Kalbaugh CA, Cass A, Watkins T, Taylor SM. Fistula elevation procedure: experience with 295 consecutive cases during a 7-year period. J Am Coll Surg. 2008;206:1076-1081

14. Beathard GA, Arnold P, Jackson J, Litchfield T; Physician Operators Forum of RMS Lifeline. Aggressive treatment of early fistula failure. Kidney Int. 2003;64:1487-1494.

15. Voormolen EH, Jahrome AK, Bartels LW, Moll FL, Mali WP, Blankestijn PJ. Nonmaturation of arm arteriovenous fistulas for hemodialysis access: A systematic review of risk factors and results of early treatment. J Vasc Surg. $2009 ; 49: 1325-1336$

16. Roberts C. Saving a brachiocephalic fistula using lipectomy. Nephrol Nurs J. 2005;32:331.

17. Bourquelot P, Tawakol JB, Gaudric J, Natário A, Franco G, Turmel-Rodrigues L, Van Laere O, Raynaud A. Lipectomy as a new approach to secondary procedure superficialization of direct autogenous forearm radial-cephalic arteriovenous accesses for hemodialysis. J Vasc Surg. 2009;50:369-374 
Surgical techniques to improve cannulation of hemodialysis vascular access. 
102 Chapter 7 


\section{Chapter 8}

General Discussion 
104 Chapter 8 


\section{General discussion}

\section{Vascular access quality improvement plan}

Cannulation of the vascular access is a basic but essential part of the hemodialysis treatment. The goal of cannulation is to gain entry to the patients vascular access without causing damage. Poorly performed cannulation can lead to complications such as hematoma, (pseudo) aneurysm formation and infection. Chapter $\mathbf{2}$ describes the precannulation assessment process and the different cannulation techniques. A recent observational study demonstrated that nurses varied in their level of clinical experience and expertise with cannulation ${ }^{1}$. Participants suggested that the lack of proper assessment and hasty cannulation were the reasons for cannulation problems encountered by the dialysis nurses. The organization should provide hemodialysis nurses with adequate education and experiential opportunities, and this may be an important area for improvement. In addition nurses need to demonstrate accountability in identifying knowledge deficits and seek out learning opportunities within the clinical setting. Hayes reported the development and implementation of a structured cannulation program. This implementation led to an improved documentation and a better liaison between nephrologists and vascular surgeons, resulting in fewer access complications ${ }^{2}$.

The necessity of a structural vascular access management has been recognized, however the Dialysis Outcome and Practice Pattern Study (DOPPS) shows a great difference among individual dialysis facilities ${ }^{3}$. In the Netherlands there is also a wide diversity in vascular access management. Most of the dialysis facilities have not yet a uniform vascular access program surveillance, education and information for caregivers and patients. Moreover, a database for registration of access characteristics, surveillance and interventions is lacking.

In chapter $\mathbf{3}$ we demonstrated that the implementation of a vascular access quality improvement plan (QIP), based on national and international guidelines, improves vascular access outcome. In the Netherlands, professionals are more and more confronted with the need to monitor patients.

Guidelines can be successfully implemented only when there is adequate planning an availability of resources, organizational and administrative support, as well as appropriate facilities.

The importance of teamwork and good collaboration for an effective implementation process has been confirmed in earlier studies ${ }^{4,5}$.

Because of the complexity of vascular access care, it is crucial to have a dedicated vascular access nurse who plays a pivotal role and acts as a liaison between the team members and maintains a database to collect prospectively information about vascular access procedures and complications ${ }^{6}$. This makes it possible to evaluate access outcome, and if necessary, make adjustments to the process related to vascular access management. 
Various aspects may affect the implementation of QIP such as existing knowledge, attitude and skills. They should be included in the basic education curriculum of the surgeon, nephrologist and dialysis nurse, and be available to all members of the multidisciplinary team. Studies confirm training and individual skills regarding vascular access to be paramount to both fistula placement and survival ${ }^{7-10}$. Therefore, organizations should provide opportunities to expand the knowledge and skills on vascular access with the goal of the highest quality of vascular access care. This QIP has a proven beneficial effect on patient comfort and healthcare costs ${ }^{11,12}$.

\section{Cannulation technique}

Chapters $\mathbf{4}$ and $\mathbf{5}$ on the outcome of cannulation practice showed that miscannulation appeared in one third of patients with an arteriovenous fistula (AVF) and arteriovenous graft (AVG), of which $51 \%$ occurred during the first 3 dialysis sessions ${ }^{13}$. The mean frequency of miscannulation for patients with AVFs, is 2 times higher than for patients with AVGs, and in particular the upper arm AVFs exhibit more cannulation problems compared to the forearm AVFs. Cannulation of AVGs has advantages over cannulation of AVFs because they are firm and large, and do not roll ${ }^{14}$. Bay reported that nurses, in contrast to physicians, preferred the AVG in the lower arm because of easier cannulation compared with $\mathrm{AVFs}^{15}$.

These findings indicate that cannulation of AVFs may be complex. There are several risk factors which influence cannulation of AVF. Some factors are modifiable and others are not, such as gender, comorbidities like peripheral arterial obstructive disease and the length of the cannulation route.

In order guarantee the continuity of vascular access care, nurses need to attend educational opportunities related to vascular access issues (particularly cannulation). However, in our study the years of professional experience of the dialysis nurse was unrelated to a successful cannulation practice, cannulation-related complications, and vascular access outcome. This is in line with previous studies where years of experience was unrelated to treatment outcomes ${ }^{16,17}$. Still, the other aspects of individual competence of nurses may play a role in the occurrence of cannulationrelated complications and vascular access outcome.

Dialysis nurses ranked difficult cannulation and insufficient access blood flows prohibiting adequate dialysis as their major problems ${ }^{15}$. This shows that cannulation of the vascular access is an important part of the daily clinical practice and therefore basic cannulation skills are mandatory. A high level of performance in cannulation practice requires technical expertise, the ability to think critically, awareness, experience and clinical judgment. In order to reach this goal, the principles and practice of vascular access cannulation should be included in the basic education curriculum of dialysis nurses, and be available as a continuing education based on the latest evidence and guidelines. 
In the Netherlands, all registered nurses, are entitled to enter specialist-training courses, post-basic nurse training e.g. to become a dialysis nurse. Specialist nurse training is aiming at obtaining extra competencies and qualifications on specific professional skills. A substantial theoretical training based on evidence-based best practice guidelines besides clinical training is necessary for such specialist nurse trainings.

In chapter 6 a prospective observational study is described in prevalent hemodialysis patients with an AVF, with the purpose to establish the advantages of the rope-ladder and the buttonhole cannulation techniques.

This study showed that buttonhole cannulation is a valuable technique with only minor complications. A drawback of the buttonhole technique is the higher incidence of infections compared to the rope-ladder method ${ }^{18-21}$. Infection and subsequently sepsis in hemodialysis patients is a leading cause for morbidity and mortality. The use of the buttonhole cannulation technique may increase the risk of infection. The mechanism by which this infection risk is increased is yet unknown. It is well established that uremia itself is associated with impaired immune function ${ }^{22}$. Interaction between systemic and local factors may contribute to the increased infection risk associated with buttonhole cannulation ${ }^{19}$. Local factors may include bacterial colonization, loss of skin integrity, and the frequency of cannulation and needle movement within the needle tracts. However, infection is also a leading complication in patients with AVG and central venous catheters (CVC) for dialysis ${ }^{23-25}$. This is the reason to perform AVF instead of AVG and CVC. The fact that nowadays more AVF in the upper arm are created in the older patient population with usually short vein segments for cannulation has led to a revival of the buttonhole technique, which is suitable for short cannulation segments. Despite its inherent infection risk. The decision to start buttonhole cannulation of AVFs is made to improve cannulation and to reduce associated complications in short vein segment vascular accesses. In most dialysis facilities additional education in using the buttonhole technique is needed to renew experience and to avoid buttonhole related complications.

Various studies have reported that the buttonhole technique contributes to the cannulation ease for self-cannulating patients ${ }^{18,26-28}$, which extends the life expectancy of the $\mathrm{AVF}^{29-32}$. In addition this technique is comfortable for the patient ${ }^{18,29,30,32,33}$. Although the implementation of the buttonhole technique in a busy hemodialysis facility is a great challenge, it deserves a place in dialysis facilities with multiple cannulators $^{34}$. The buttonhole technique requires different skills of the dialysis nurse as compared to the rope-ladder technique ${ }^{35}$. The buttonhole cannulation is not just a variation on the rope-ladder cannulation, but rather, an entirely different way of performing cannulation ${ }^{14}$. Every cannulation technique, including the buttonhole method is characterized by a learning curve. Therefore, successful implementation of the buttonhole technique requires a high level of awareness and skills of the dialysis nurse, frequent monitoring, and a continued evaluation and education of the 
technique. A motivated team, with commitment to make the outcome positive for both patients and staff is of vital importance.

In order to prevent buttonhole complications a strict cannulation protocol should be followed. Literature showed that patients on dialysis have more Staphylococcus aureus on the skin and in the nares than the general population ${ }^{36}$. Therefore, adequate disinfection with respect to the contact time of the disinfecting agent, before and after scab removal, is crucial. Scab removal is often difficult, and must be complete in order to avoid that small scab particles with bacteria, enter the blood. These steps should not be performed hastily. Ball described the 'hubbing' phenomenon that is derived from the needle hub becoming buried in the entrance to the tunnel ${ }^{37}$. Scab formation occurs at the bottom of the concave area and becomes very hard to remove completely. Correct needle placement with approximately $2 \mathrm{~mm}$ of the needle exposed, can prevent the development of large scab formation in the buttonhole sites ${ }^{37}$.

Some nurses prefer to re-cannulate with a sharp needle when cannulation with a blunt needle appears difficult. However, use of sharp needles may damage the created tunnel track, resulting in the formation of faulty tracks. If the blunt needle meets resistance, it must be partly draw withdrawn and with manipulation and changed angle access the vessel ${ }^{38,39}$. In our study the role of primary access nurses was essential for successful creation of the track for performance of difficult cannulations, for highlighting the importance of thorough scab removal and disinfection, together with the advocacy to use dull needles. This led to a dramatically decrease in use of sharp needles with concomitant reduction in infection rate. Caution should be taken to prevent and recognize this complication at an early stage so that adequate treatment can be initiated. Antimicrobial prophylaxis has been studied in patients using the buttonhole technique with favorable results ${ }^{19,35,40,41}$.

In our study there is a lower number of vascular access angioplasties in patients using the buttonhole method. An explanation for this observation might be that cannulation with dull needles causes less vessel wall injury compared to sharp needles. A recent study found intimal changes of the buttonhole puncture segments of AVFs, but none of these caused significant luminal stenosis ${ }^{42}$.

Few studies on needle hemodynamics have been published ${ }^{43-46}$, but the impact of repetitive cannulation in relationship to complications in AVF remains unclear. Krönung published fundamental ideas on how different types of cannulation affect the remodelling of the venous traject of the fistula ${ }^{47}$. He demonstrated that cannulation not only destroys the vein, but is also causing remodelling. If puncture areas are dilated and there is diffuse dilation over the full length of the fistula vein, it can be handled more easily. Further studies are needed to investigate complications at the site of dialysis needles and whether there is a reduced incidence of stenosis requiring interventions with the buttonhole method.

Krönung suggested that not one cannulation method can be recommended, but knowledge of the different cannulation techniques and their consequences is essential 
in avoiding stenosis and aneurysma formation ${ }^{47}$. Nowadays, available literature still does not recommend the routine use of the buttonhole method in all AVFs. To determine the most suitable cannulation technique for the single AVF, it is of vital importance that the type and seriousness of the complications, which occur in the buttonhole technique as well as in the rope-ladder technique, are taken into consideration.

Adjustment of the cannulation practice may help some patients to overcome difficult cannulation. Yet, in a great number of patients these changes in practice do not result in a better outcome and the patient may still be left with a difficult or unpleasant to cannulate vascular access. Patients with painful and difficult cannulations have increased anxiety about their dialysis treatments ${ }^{15}$. Ultimately this may contribute to cannulation phobia and catheter dependence. Bay et al. reported pain during needle insertion as the most common problem for hemodialysis patients ${ }^{15}$. Several studies evaluate pain during AVF cannulation and report that the buttonhole technique reduced cannulation pain compared with the rope-ladder cannulation ${ }^{18,34,39,48,49}$. In our study patients in the buttonhole group experienced more pain. This discrepancy might be due to the fact that other studies compared pain sensation of both techniques in one patient, and in our study the individual patient used only one technique. Therefore, patients could not experience and judge the effect of the other technique. Further studies are needed to define the best cannulation technique with regard to pain.

If safe and successful cannulation is impossible, surgical revision may enhance successful cannulation. Veins, which are tortuous or located in subcutaneous fat, can be adapted by surgical techniques, employing vein elevation, stretching, transposition and repositioning. Alternative techniques like lipectomy and liposuction are useful to solve cannulation inability in obese patients. Chapter 7 reviewed all publications related to cannulation difficulties and complications and the various surgical techniques that may enhance access cannulation and improve fistula outcome. None of the identified studies were randomized or concerned a meta-analysis. In the literature only scarce information on the outcome of surgical revisions has been referenced. Nonetheless, the available studies show a high primary success rate and good long-term patencies amongst the different methods of vein superficialisation and lipectomy. Nephrologists and vascular surgeons should be aware of the possibilities of surgical interventions and may offer these to their dialysis patients with persistent cannulation difficulties and complications. 


\section{Future perspectives}

\section{Vascular access quality improvement plan}

The creation and maintenance of a functional vascular access will remain a great challenge in the dialysis field for the future and will need great commitment, teamwork, and the development of specific expertise. It is of utmost importance to prevent vascular access complications due to the implementation of a vascular access QIP based on international guidelines. Because of the multidisciplinary character of vascular access care, it is a prerequisite to establish a dedicated multidisciplinary approach in every dialysis facility. Individual organizations need to base their decisions not only on published data but also on their own surveillance statistics. It is crucial for individual centers to have a standardized database to collect prospectively data about procedures and complications. These data makes it possible to monitor and evaluate outcomes and if necessary make adjustments to the process related to vascular access.

\section{Cannulation technique}

Another future challenge remains prevention of cannulation-related complications. Today's population shows several characteristics like aging and comorbidities, which make it difficult to create a fistula with an adequate diameter for safe cannulation and sufficient blood flow to permit adequate hemodialysis treatment. This frequently results in inaccessibility and cannulation-related complications after access creation. Our findings support the fact that the cannulation technique used is fundamental, when vessel damage and the possible complications such as infection, aneurysms, and hematoma are to be avoided. However, little attention has been given to the effects of cumulative trauma to the vascular access caused by cannulation. Further clinical studies should investigate the role of experienced cannulators, the effect of needle design to minimise trauma, and the impact of bevel up or bevel down cannulation, and correct needle position.

There is a growing interest in the buttonhole technique. However, the increase in infections related with the buttonhole technique is an issue of concern. This problem merits further investigation into skin preparation before cannulation and after needle removal, the application of antibacterial ointment, several new products on the market like scab removals, and tools for creation of the tunnel track. The ideal way to answer these questions will be randomised controlled trials.

\section{Ultrasound-guided cannulation}

It may be useful to evaluate the value of ultrasound-guided cannulation to determine whether it results in fewer aborted needling cannulations and fewer redirections, in 
patients with a difficult vascular access. If so, it can be incorporated in clinical practice to improve vascular access longevity.

Ultrasound-guided needling may facilitate successful cannulation of difficult accesses, but in our own study it was not frequently used to facilitate cannulation. The need exists for a device and method that can facilitate and simplify the cannulation of the vascular access. To reach this goal, the cooperation of biomedical engineers, scientists and professionals involved in daily clinical practice is necessary to develop a device to improve both the quality and success rate of cannulation.

\section{Cannulation skills}

Nowadays, cannulation of the vascular access requires considerable skills of dialysis nurses. Cannulation is an invasive procedure. Lack of cannulation knowledge and skills creates difficulties and stress for both the dialysis nurse and the patient. Between the needs of the nurse to acquire necessary cannulation skills and the safety and wellbeing of the patient, there may be a 'gap'. Therefore, there may be a need for more training of basic clinical cannulation skills during the curriculum. A variety of new ways of learning such as blended learning can contribute to improve the potential safety of patients. Blended Learning refers to a mix of different learning environments including workbooks, problem-based learning, supervised practice, e-learning, and simulation ${ }^{50}$. Combining face-to-face instruction with computer-mediated instruction. It is possible to use this methodology for both assessment and training of skills and expertise. The principles and practice of cannulation should also be available as continuing education and lifelong learning to reach the highest level of cannulation skills. This approach may help to decrease cannulation-related complications and should be prospectively evaluated in future studies. 


\section{Conclusions of this thesis}

1. The implementation of a vascular access quality improvement plan (QIP) results in placement of significantly more autogenous arteriovenous fistulas in incident patients and an increased number of PTAs and surgical interventions to maintain vascular accesses.

2. During the first 6 months of newly placed vascular accesses, a great percentage of incident patients encounter cannulation-related complications. The use of autogenous AVF and limited length of cannulation route negatively affect the outcome of cannulation and the occurrence of complications such as use of single needle dialysis and CVC.

3. Unsuccessful cannulation procedures and cannulation-related complications result in the use of CVC and single needle dialysis, which occurs more frequently in autogenous AVFs. Hematoma formation as a result of unsuccessful cannulation was a significant predictor for the need of CVC and single needle dialysis.

4. The buttonhole technique has a significantly lower frequency of cannulationrelated complications like hematoma, aneurysm formation and the need for interventions compared to the rope-ladder group. A negative outcome of the buttonhole technique was the higher incidence of access infections compared to the rope-ladder method.

5. Surgical revision to improve hemodialysis vascular access cannulation such as vein superficialisation and lipectomy has a high clinical success rate with good longterm patency. 


\section{References}

1. Wilson B, Harwood L, Oudshoorn A, Thompson B. The culture of vascular access cannulation among nurses in a chronic hemodialysis unit. CANNT J 2010;20:35-42.

2. Hayes J. Prolonging access function and survival, the nurse's role. EDTNA/ERCA journal (English ed 1998;24:7-10.

3. Ethier J, Mendelssohn DC, Elder SJ, Hasegawa T, Akizawa T, Akiba T, Canaud BJ, Pisoni RL. Vascular access use and outcomes: an international perspective from the Dialysis Outcomes and Practice Patterns Study. Nephrol Dial Transplant 2008;23:3219-3226.

4. Berwick DM, Nolan TW. Physicians as leaders in improving health care: a new series in Annals of Internal Medicine. Annals of internal medicine 1998;128:289-292.

5. Grol R, Wensing M, Eccles M. Improving Patient Care - The Implementation of Change in Clinical Practice. Toronto: Elsevier; 2005.

6. Allon M, Bailey R, Ballard R, Deierhoi MH, Hamrick K, Oser R, Rhynes VK, Robbin ML, Saddekni S, Zeigler ST. A multidisciplinary approach to hemodialysis access: prospective evaluation. Kidney international 1998;53:473-479.

7. O'Hare AM, Dudley RA, Hynes DM, McCulloch CE, Navarro D, Colin P, Stroupe K, Rapp J, Johansen KL. Impact of surgeon and surgical center characteristics on choice of permanent vascular access. Kidney international 2003;64:681-689.

8. Huijbregts HJ, Bots ML, Moll FL, Blankestijn PJ. Hospital specific aspects predominantly determine primary failure of hemodialysis arteriovenous fistulas. J Vasc Surg 2007;45:962-967.

9. Dixon BS, Novak L, Fangman J. Hemodialysis vascular access survival: upper-arm native arteriovenous fistula. Am J Kidney Dis 2002;39:92-101.

10. Allon $\mathrm{M}$, Robbin $\mathrm{ML}$. Increasing arteriovenous fistulas in hemodialysis patients: problems and solutions. Kidney international 2002;62:1109-1124.

11. McCarley P, Wingard RL, Shyr Y, Pettus W, Hakim RM, Ikizler TA. Vascular access blood flow monitoring reduces access morbidity and costs. Kidney international 2001;60:1164-1172.

12. Wijnen E, Planken N, Keuter X, Kooman JP, Tordoir JH, de Haan MW, Leunissen KM, van der Sande F. Impact of a quality improvement programme based on vascular access flow monitoring on costs, access occlusion and access failure. Nephrol Dial Transplant 2006;21:3514-3519.

13. Akenji TN, Ntonifor NN, Kimbi HK, Abongwa EL, Ching JK, Ndukum MB, Anong DN, Nkwescheu A, Songmbe M, Boyo MG, Ndamukong KN, Titanji VP. The epidemiology of malaria in Bolifamba, a rural community on the eastern slopes of Mount Cameroon: seasonal variation in the parasitological indices of transmission. Ann Trop Med Parasitol 2005;99:221-227.

14. Ball LK. The buttonhole technique: strategies to reduce infections. Nephrol Nurs J 2010;37:473-477.

15. Bay WH, Van Cleef S, Owens M. The hemodialysis access: preferences and concerns of patients, dialysis nurses and technicians, and physicians. American journal of nephrology 1998;18:379-83.

16. Ericsson KA. Deliberate practice and the acquisition and maintenance of expert performance in medicine and related domains. Acad Med 2004;79:S70-81.

17. Choudhry NK, Fletcher RH, Soumerai SB. Systematic review: the relationship between clinical experience and quality of health care. Annals of internal medicine 2005;142:260-273.

18. Verhallen AM, Kooistra MP, van Jaarsveld BC. Cannulating in haemodialysis: rope-ladder or buttonhole technique? Nephrol Dial Transplant 2007;22:2601-2604.

19. Nesrallah GE, Cuerden M, Wong JH, Pierratos A. Staphylococcus aureus bacteremia and buttonhole cannulation: long-term safety and efficacy of mupirocin prophylaxis. Clin J Am Soc Nephrol 2010;5:1047-1053.

20. Doss S, Schiller B, Moran J. Buttonhole cannulation--an unexpected outcome. Nephrol Nurs J 2008;35:417-419.

21. Birchenough E, Moore C, Stevens K, Stewart S. Buttonhole cannulation in adult patients on hemodialysis: an increased risk of infection? Nephrol Nurs J 2010;37:491-8, 555; quiz 499.

22. Hauser $A B$, Stinghen $A E$, Kato $S$, Bucharles $S$, Aita $C$, Yuzawa $Y$, Pecoits-Filho R. Characteristics and causes of immune dysfunction related to uremia and dialysis. Perit Dial Int 2008;28 Suppl 3:S183-187. 
23. Saran R, Dykstra DM, Pisoni RL, Akiba T, Akizawa T, Canaud B, Chen K, Piera L, Saito A, Young EW. Timing of first cannulation and vascular access failure in haemodialysis: an analysis of practice patterns at dialysis facilities in the DOPPS. Nephrol Dial Transplant 2004;19:2334-2340.

24. Oliver MJ, Rothwell DM, Fung K, Hux JE, Lok CE. Late creation of vascular access for hemodialysis and increased risk of sepsis. J Am Soc Nephrol 2004;15:1936-1942.

25. Polkinghorne KR, McDonald SP, Atkins RC, Kerr PG. Vascular access and all-cause mortality: a propensity score analysis. J Am Soc Nephrol 2004;15:477-486.

26. Lewis C. Let's empower patients with the choice of self-cannulation! Nephrol Nurs J 2005;32:225.

27. Mott S, Moore H. Using 'Tandem hand' technique to facilitate self-cannulation in hemodialysis. Nephrol Nurs J 2009;36:313-316.

28. Peterson P. Fistula cannulation: the buttonhole technique. Nephrol Nurs J 2002;29:195.

29. Hakim R, Himmelfarb J. Hemodialysis access failure: a call to action. Kidney international 1998;54:1029-1040.

30. Huber TS, Carter JW, Carter RL, Seeger JM. Patency of autogenous and polytetrafluoroethylene upper extremity arteriovenous hemodialysis accesses: a systematic review. J Vasc Surg 2003;38:1005-1011.

31. Perera GB, Mueller MP, Kubaska SM, Wilson SE, Lawrence PF, Fujitani RM. Superiority of autogenous arteriovenous hemodialysis access: maintenance of function with fewer secondary interventions. Annals of vascular surgery 2004;18:66-73.

32. Pisoni RL, Young EW, Dykstra DM, Greenwood RN, Hecking E, Gillespie B, Wolfe RA, Goodkin DA, Held PJ. Vascular access use in Europe and the United States: results from the DOPPS. Kidney international 2002;61:305-316.

33. Hashmi A, Cheema MQ, Moss AH. Hemodialysis patients' experience with and attitudes toward the buttonhole technique for arteriovenous fistula cannulation. Clinical nephrology 2010;74:346-350.

34. Ward J, Shaw K, Davenport A. Patients' perspectives of constant-site (buttonhole) cannulation for haemodialysis access. Nephron Clin Pract 2010;116:c123-127.

35. Marticorena RM, Hunter J, Macleod S, Petershofer E, Dacouris N, Donnelly S, Goldstein MB. The salvage of aneurysmal fistulae utilizing a modified buttonhole cannulation technique and multiple cannulators. Hemodialysis international 2006;10:193-200.

36. Kaplowitz LG, Comstock JA, Landwehr DM, Dalton HP, Mayhall CG. Prospective study of microbial colonization of the nose and skin and infection of the vascular access site in hemodialysis patients. Journal of clinical microbiology 1988;26:1257-1262.

37. Ball LK, Mott S. How do you prevent indented buttonhole sites? Nephrol Nurs J 2010;37:427-428, 31.

38. Mott S, Prowant BF. The "touch cannulation" technique for hemodialysis. Nephrol Nurs J 2008;35:6566.

39. Murcutt G. Buttonhole cannulation: should this become the default technique for dialysis patients with native fistulas? Summary of the EDTNA/ERCA Journal Club discussion Autumn 2007. J Ren Care 2008;34:101-108.

40. Lok CE, Stanley KE, Hux JE, Richardson R, Tobe SW, Conly J. Hemodialysis infection prevention with polysporin ointment. J Am Soc Nephrol 2003;14:169-179.

41. Marticorena RM, Hunter J, Cook R, Kashani M, Delacruz J, Petershofer E, Macleod S, Dacouris N, McFarlane PA, Donnelly SM, Goldstein MB. A simple method to create buttonhole cannulation tracks in a busy hemodialysis unit. Hemodialysis international 2009;13:316-321.

42. Hsiao JF, Chou HH, Hsu LA, Wu LS, Yang CW, Hsu TS, Chang CJ. Vascular changes at the puncture segments of arteriovenous fistula for hemodialysis access. J Vasc Surg 2010;52:669-673.

43. Van Tricht I, De Wachter D, Tordoir J, Verdonck P. Hemodynamics and complications encountered with arteriovenous fistulas and grafts as vascular access for hemodialysis: a review. Annals of biomedical engineering 2005;33:1142-1157.

44. Tuka V, Wijnen E, van der Sande FM, Tordoir JH. Dialysis needle hemodynamics in arterio-venous fistulae: a technical report. The journal of vascular access 2009;10:157-159.

45. Huynh TN, Chacko BK, Teng X, Brott BC, Allon M, Kelpke SS, Thompson JA, Patel RP, Anayiotos AS Effects of venous needle turbulence during ex vivo hemodialysis on endothelial morphology and nitric oxide formation. Journal of biomechanics 2007;40:2158-2166.

46. Ortega JM, Small Wt, Wilson TS, Benett WJ, Loge JM, Maitland DJ. A shape memory polymer dialysis needle adapter for the reduction of hemodynamic stress within arteriovenous grafts. IEEE transactions on bio-medical engineering 2007;54:1722-1724. 
47. Krönung G. Plastic deformation of Cimino fistula by repeated puncture. Dial Transplant 1984;13:635638

48. Ball LK. The buttonhole technique for arteriovenous fistula cannulation. Nephrol Nurs J 2006;33:299304.

49. Figueiredo AE, Viegas $A$, Monteiro $M$, Poli-de-Figueiredo CE. Research into pain perception with arteriovenous fistula (avf) cannulation. J Ren Care 2008;34:169-172.

50. Graham $\mathrm{CR}$, in Bonk CJ. Blended learning systems: Definition, current trends, and future directions. San Fransisco: CA: Pfeiffer; 2005. 
116 Chapter 8 


\section{Summary}

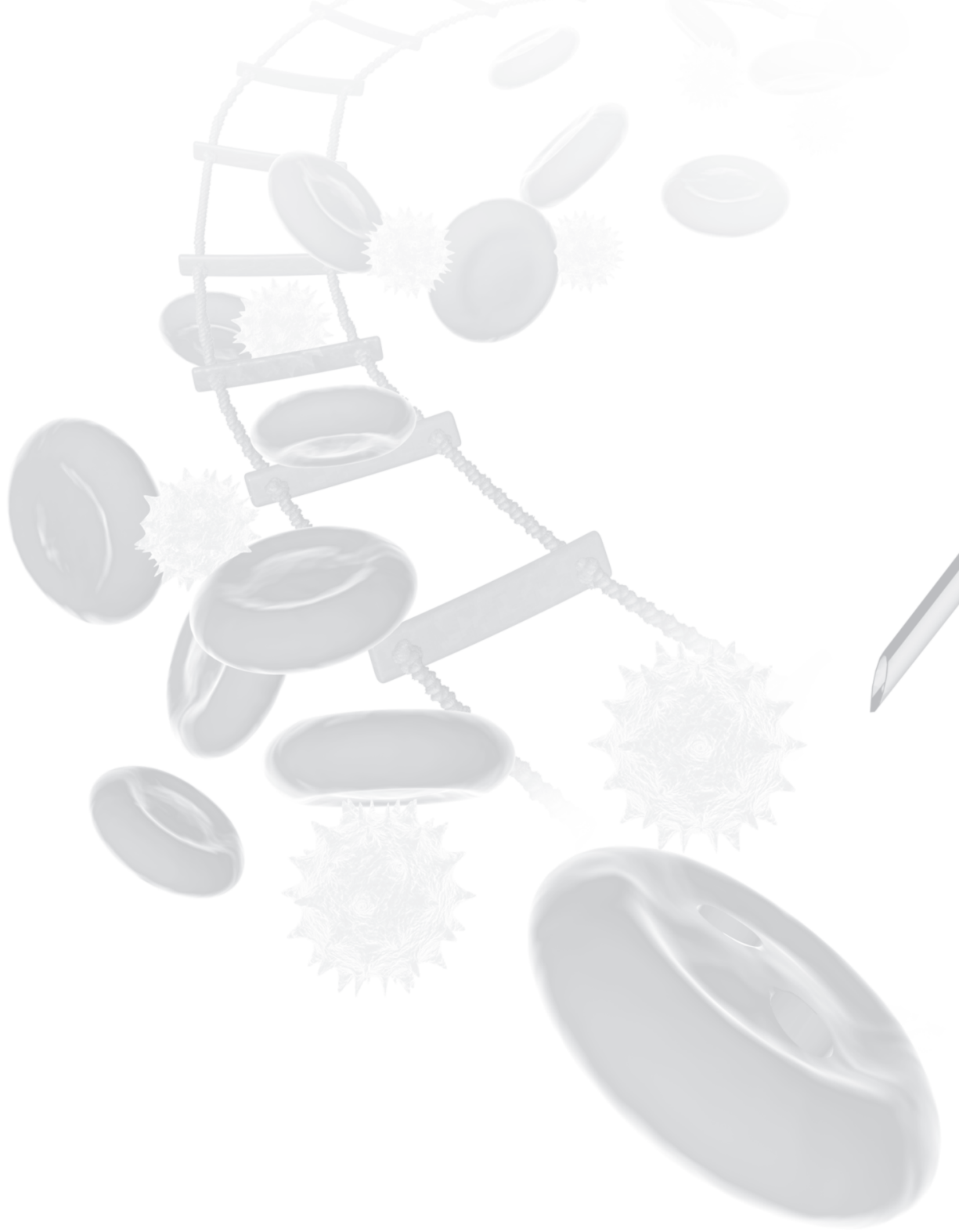




\section{Summary}

Patients with end-stage renal disease can be treated with hemodialysis. To achieve this, a good functional vascular access to the circulation is a prerequisite. Chapter 1 describes the three different types of vascular access: an autogenous arteriovenous fistula (AVF), an arteriovenous graft (AVG), and a central venous catheter (CVC). The AVF is the preferred form of vascular access because of superior patency with low risk of thrombosis and infection. The alternative of the AVF is the AVG using synthetic material, which is associated with a higher risk of thrombosis and infection when compared to the AVF. A CVC is often required for varying intervals when acute access is needed. Long-term CVCs are used in patients without the possibility of creating or maintaining a functional arteriovenous access.

This thesis describes various functional and clinical aspects of vascular accesses for hemodialysis.

The specific aims of this thesis are:

1. To analyse the effect of the implementation of a quality improvement program (QIP) on the quality of vascular access care.

2. To identify predictors for unsuccessful cannulation, time to the occurrence of cannulation complications, and vascular access failure, and to identify factors that may be associated with cannulation-related complications.

3. To analyse characteristics of the cannulation practice predicting the time to unsuccessful cannulation, cannulation-related complications, and vascular access failure in AVFs and AVGs.

4. To compare the so called rope-ladder and buttonhole cannulation techniques with respect to several outcome parameters.

5. To review the various surgical techniques to improve cannulation of the vascular access

Chapter 2 describes the precannulation assessment process and the different cannulation techniques. Assessment of vascular access involves inspection, palpation, and auscultation. It is necessary for vascular accesses to be evaluated prior to every cannulation using these three aspects of nursing care. There are three methods for cannulation of the vascular access; rotation of cannulation sites (rope-ladder), constant site cannulation (buttonhole), or repeated cannulation in a smallcircumscribed area of the vascular access (area technique). The rope-ladder technique is the predominant cannulation method used in the United States, Europe and the Netherlands. For every dialysis two new sites are chosen for needle placement to allow good healing of the previous puncture wound, and therefore avoid complications. The whole access length is used for cannulation, with a minimum of 2-3 $\mathrm{cm}$ between the tip of the arterial and venous needle, at least $3 \mathrm{~cm}$ from the anastomosis, and avoiding the previous sites. The rope-ladder technique results in a 
moderate vessel dilatation over a long vein segment. There are some vascular accesses were the rope-ladder technique is difficult to employ, primarily due to the limited length of the vascular access, or a complicated cannulation route. As a result repeated cannulation in the same area of the vascular access will occur. With this area cannulation technique it is evidence-based that there are more aneurysm formations and stenosis on the frequently cannulated spot. Although it is not preferable, the area technique is still very often used. Another cannulation technique - with renewed interest in Europe and USA - is the buttonhole (constant-site) technique. As far as we know the buttonhole technique is exclusively used for autogenous fistulas. The buttonhole method requires inserting the inflow and outflow needles each time at exactly the same spot, using the same insertion angle, and the same depth of penetration for consecutive dialysis. In this way two scar tissue tunnel tracks are formed quite similar to a pierced earring hole. This puncture technique is developed in two time periods. In the first period one arterial and one venous buttonhole is created. It takes approximately 6 to 10 sessions to create a scar tissue tunnel track that preferably should be done by one single nurse. In the second period, after a good puncture route is established, the fistula can be punctured with a dull edge needle. Dull needles are rounded on the top and do not have a sharp cutting edge, like traditional dialysis needles, to prevent damaging the scar tissue tunnel. After a good puncture route has been created, the dull edged bevel of the needle can be easily inserted into the established tunnel and opens the vessel flap at the end of the tunnel. The needle should slide in with minimal resistance. After the tunnel has been formed, any staff member can puncture the fistula. Needle removal is as important as cannulation, to protect the access from damage and to facilitate proper hemostasis. The needle is removed at approximately the same angle as it was inserted.

Chapter 3 describes the implementation of a vascular access quality improvement program in 24 centers in the Netherlands representing $46 \%$ of all Dutch facilities. The program was meant to decrease vascular access related complications by pre-emptive intervention (surgical or endovascular intervention) of malfunctioning accesses. This study demonstrated that implementation of a quality improvement program results in placement of significantly more autogenous AVFs in incident patients. Although the thrombosis rate decreased, the number of tunneled jugular vein catheters increased significantly at the expense of non-tunneled catheters inserted through the subclavian vein route and non-tunneled catheters. There was also a significantly increased number of percutaneous transluminal angioplasty and surgical interventions for malfunctioning accesses, indicating early diagnosis of significant stenosis by an anticipating surveillance program.

Chapter 4 describes a prospective, observational multicenter study in which we evaluated the complications caused by cannulation and the clinical consequences in newly created vascular accesses. The study demonstrated that a great percentage of 
the incident patients encounter cannulation-related complications such as miscannulation, have the need to single needle dialysis and CVC use. Miscannulation appeared in one third of patients with an AVF and AVG, of whom 51\% occurred during the first three dialysis sessions. The mean frequency of miscannulation for patients with AVFs was 2 times higher than for patients with AVGs. The upper arm AVFs exhibited more cannulation problems compared to the forearm AVFs.

The use of autogenous AVF and a limited length of cannulation route negatively affected the outcome of the cannulation and often resulted in the use of single needle dialysis and CVC. Previous use of CVC and single needle hemodialysis were significant predictors for vascular access failure.

Chapter 5 describes a study in which we investigated the factors that may be associated with difficult and complicated cannulations. The study showed that hematoma formation occurred more frequently in autogenous AVFs compared with AVGs. For both AVF and AVG, hematoma formation was a significant predictor for the need of CVC and single needle dialysis, and was also associated with vascular access failure. The years of experience of the dialysis nurse were shown to have no significant role on successful cannulation practice, cannulation-related complications or vascular access failure. Retrograde arterial needling was the single predicting factor affecting successful cannulation of AVGs. Unfortunately, we were not able to determine predictive factors regarding cannulation problems of AVFs.

Chapter 6 describes a prospective observational study in prevalent hemodialysis patients with an autogenous AVF, with the purpose to establish the pros and cons of the rope-ladder and buttonhole cannulation techniques.

This study showed that, although the buttonhole technique resulted in more miscannulations, the occurrence of hematoma and aneurysm formation was significantly fewer than in the rope-ladder group. In addition, prophylactic interventions to maintain good access function like angioplasty were significantly more frequent in patients using the rope-ladder technique. A negative outcome of the buttonhole technique was the higher incidence of access infections. Infections induced by the buttonhole method should not be underestimated, and underline the importance of aseptic and correct technique of the buttonhole procedure.

Chapter 7 reviewed the literature related to surgical techniques that enhance vascular access cannulation and improve fistula outcome. Seventeen studies were eligible for review, including various techniques to enhance access cannulation. None of the identified studies were randomized or concerned a meta-analysis. Surgical techniques, employing vein elevation/ stretching/transposition and repositioning are indicated in particular in deeply located or tortuous veins. Alternative techniques like lipectomy are useful to solve cannulation inability in obese patients. The results of the review 
showed that several surgical techniques to improve cannulation difficulties, has a high clinical success rate with good long-term patency.

Chapter $\mathbf{8}$ gives a general discussion of the results obtained in the studies and some future perspectives of access practice, and summarizes the conclusions of this thesis. These conclusions are:

1. The implementation of a vascular access quality improvement plan (QIP) results in placement of significantly more autogenous arteriovenous fistulas in incident patients and an increased number of PTAs and surgical interventions to maintain vascular accesses.

2. During the first 6 months of newly placed vascular accesses, a great percentage of incident patients encounter cannulation-related complications. The use of autogenous AVF and limited length of cannulation route negatively affect the outcome of cannulation and the occurrence of complications such as use of single needle dialysis and CVC. Previous use of CVC and single needle hemodialysis were significant predictors for vascular access failure.

3. Unsuccessful cannulation procedures, and cannulation-related complications result in the use of CVC and single needle dialysis, which occurs more frequently in autogenous AVFs. Hematoma formation as a result of unsuccessful cannulation was a significant predictor for the need of CVC and single needle dialysis.

4. The buttonhole technique has a significantly lower frequency of cannulationrelated complications like hematoma, aneurysm formation and the need for interventions compared to the rope-ladder group. A negative outcome of the buttonhole technique was the higher incidence of access infections compared to the rope-ladder method.

5. Surgical revision to improve hemodialysis vascular access cannulation such as vein superficialisation and lipectomy has a high clinical success rate with good longterm patency. 


\section{Samenvatting}

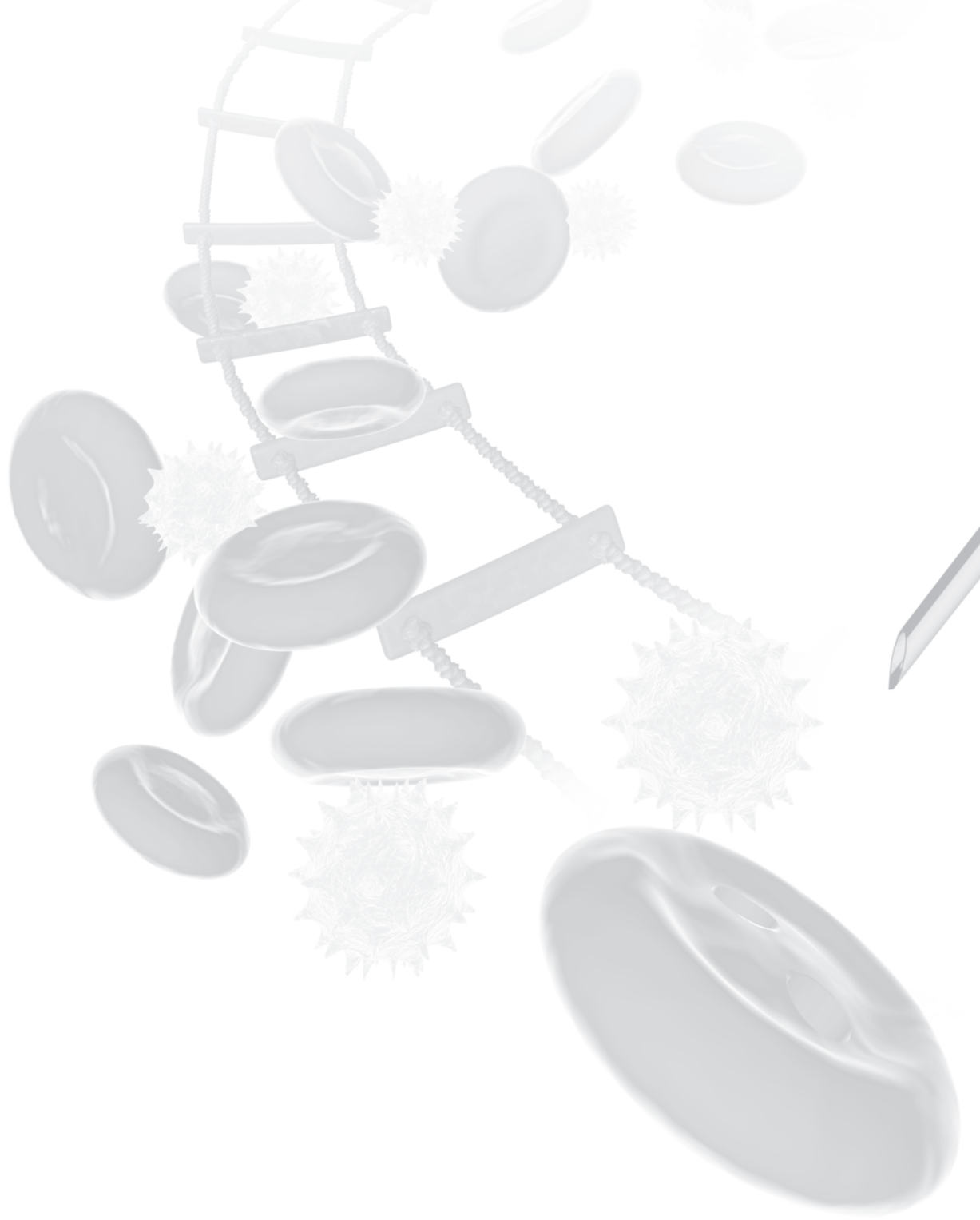




\section{Samenvatting}

Patiënten met eindstadium van nierfalen kunnen behandeld worden met hemodialyse. Voorwaarde voor een goede hemodialyse is echter een goed functionerende toegang tot de bloedbaan. Deze vaattoegang wordt met 2 naalden aangeprikt om het bloed uit het lichaam naar de kunstnier te voeren en vervolgens na reiniging weer terug te brengen in het lichaam. In hoofdstuk 1 worden drie verschillende soorten vaattoegangen beschreven: de autogene arterioveneuze fistel (AVF; verbinding tussen een slagader en ader), een arterioveneuze graft (AVG; een kunststof vaatprothese die tussen een slagader en ader wordt ingebracht), en een centrale veneuze katheter (CVK), die in een grote lichaamsader wordt ingebracht. De AVF wordt beschouwd als de meest geschikte vaattoegang omdat deze langer bruikbaar is met een laag risico op stolling en infectie. Het alternatief voor de AVF is de AVG waarbij gebruik wordt gemaakt van synthetische vaatprothese materialen. De AVG heeft een groot risico op stolling en infectie. Een tijdelijke CVK is vaak nodig indien een acute toegang tot de bloedbaan noodzakelijk is bij bijvoorbeeld acuut nierfalen. Permanente CVKs worden alleen gebruikt bij die patiënten waarbij er geen mogelijkheden zijn tot de aanleg van een goed functionerende arterioveneuze vaattoegang.

Dit proefschrift beschrijft verschillende functionele en klinische aspecten van de vaattoegang voor hemodialyse.

De doelstellingen van dit proefschrift zijn:

1. Analyse van het effect van de implementatie van een kwaliteitsverbetering programma op de kwaliteit van vaattoegangszorg.

2. Identificeren van voorspellende factoren voor het mislukken van het aanprikken van de vaattoegang, de tijdsduur tot het optreden van complicaties en het falen van de vaattoegang.

3. Analyse van aanprik (cannulatie) karakteristieken in relatie tot mislukte cannulaties, cannulatie-gerelateerde complicaties en het falen van de AVF of AVG.

4. Vergelijking van de zogenaamde touw-ladder aanpriktechniek en button-hole techniek met betrekking tot verschillende uitkomst parameters.

5. De resultaten van verschillende operatie technieken om aanprikken van de vaattoegang te verbeteren, worden onderzocht.

Hoofdstuk 2 beschrijft het controleren van de vaattoegang voor de cannulatie en de verschillende cannulatie technieken. Het controleren van de vaattoegang bestaat uit inspectie, palpatie, en auscultatie. Het is noodzakelijk dat de vaattoegang voorafgaand aan iedere cannulatie word gecontroleerd.

Er zijn drie verschillende aanpriktechnieken; de touw-ladder techniek, de button-hole techniek, en de area techniek. De touw-ladder techniek is in de Verenigde Staten, Europa en Nederland de meest gebruikte priktechniek. Hierbij worden er elke dialyse 
twee andere prikplaatsen gekozen, zodat de vorige prikplaatsen kunnen genezen met de vooronderstelling dat complicaties hiermee voorkomen kunnen worden.

De gehele lengte van de vaattoegang wordt gebruikt om aan te prikken, waarbij er ongeveer $5 \mathrm{~cm}$ wordt gelaten tussen de arteriële en veneuze naald, minstens $3 \mathrm{~cm}$ van de anastomose en de vorige prikplaatsen worden vermeden. Bij gebruik van de touw-ladder techniek treedt over het gehele vaattoegangstraject een gelijkmatige vaatverwijding op.

Bij sommige vaattoegangen is het moeilijk of zelfs onmogelijk om de touw-ladder techniek toe te passen, vaak vanwege een te kort of moeilijk priktraject. Noodgedwongen wordt dan de zogenaamde area techniek gebruikt waarbij er over een lengte van 2 á $3 \mathrm{~cm}$ van de vaattoegang frequent wordt geprikt. Van deze area priktechniek is aangetoond dat er vaatverwijdingen (aneurysma) en vernauwingen (stenose) ontstaan op de plaatsen waar frequent wordt geprikt. Ondanks het feit dat deze techniek niet de voorkeur verdient wordt deze in de praktijk frequent toegepast. Een andere priktechniek - welke recent in Europa en de Verenigde Staten een hernieuwde belangstelling heeft gekregen - is de button-hole techniek. Voor zover bekend kan deze priktechniek alleen uitgevoerd worden bij autogene fistulas. Bij de button-hole techniek wordt er bij elke opeenvolgende dialyse op exact dezelfde plaats, onder dezelfde hoek en dezelfde diepte geprikt. Door herhaaldelijk op dezelfde plaats te prikken ontstaat er een kanaaltje van littekenweefsel naar de vaattoegang, wat te vergelijken is met een oorbelgaatje. Deze priktechniek bestaat uit twee fasen. De eerste fase is het creëren van de button-hole. Hierbij wordt er één arteriële en één veneuze button-hole gecreëerd. Deze eerste fase duurt ongeveer 6 tot 10 dialyse behandelingen, en wordt bij voorkeur door één zelfde verpleegkundige uitgevoerd. In de tweede fase, als het littekenkanaaltje eenmaal gevormd is, kan de fistel gemakkelijk met een stompe naald aangeprikt worden. Om schade aan het tunneltraject te voorkomen hebben deze stompe naalden een afgeronde punt en geen scherpe randen, in tegenstelling tot de traditionele dialyse naalden. Nadat er een tunnel is gecreëerd, kan de stompe naald makkelijk worden ingebracht en wordt het ontstane weefselflapje aan het eind van de tunnel geopend. De naald moet met minimale weerstand kunnen worden opgevoerd. Vanaf dit moment kan de vaattoegang door elke verpleegkundige aangeprikt worden.

Om nabloeden en schade aan de vaattoegang te voorkomen is het verwijderen van de dialyse naald even belangrijk als het aanprikken. De naald wordt verwijderd onder dezelfde hoek als waaronder deze werd ingebracht.

Hoofdstuk 3 beschrijft de implementatie van een kwaliteitsverbeterprogramma voor de vaattoegang in 24 dialysecentra in Nederland, $46 \%$ van alle Nederlandse centra vertegenwoordigt. Het programma was bedoeld om het aantal vaattoegang gerelateerde complicaties tijdig te signaleren en te verminderen door het uitvoeren van electieve interventies (operatief of via dotteren). Deze studie toonde aan dat de implementatie van een kwaliteitsverbeterprogramma resulteerde in de aanleg van 
meer autogene AVFs bij patiënten met een nieuwe vaattoegang. Terwijl het aantal stollingscomplicaties daalde, nam het gebruik van het aantal getunnelde katheters in de halsader significant toe ten koste van de aantal ongetunnelde katheters in de armader. Er was eveneens een toename van het aantal percutane transluminale angioplastiek of Dotterprocedures en operatieve ingrepen, wat zou kunnen betekenen dat een significante vaatvernauwing eerder wordt bemerkt door de implementatie van een gestructureerd bewakingsprogramma in combinatie met een vroegtijdige behandeling.

Hoofdstuk 4 beschrijft een prospectieve, observationele multi-centrum studie waarbij de complicaties die door prikken worden veroorzaakt en de klinische gevolgen hiervan bij een nieuw aangelegde vaattoegang werden onderzocht. Deze studie toonde aan dat een groot percentage van de patiënten met een nieuw aangelegde vaattoegang, cannulatie-gerelateerde complicaties ondervinden, zoals miscannulatie, noodzaak tot éénnaalds-dialyse en het gebruik van CVKs. Miscannulatie kwam voor bij $1 / 3$ van de patiënten met een AVF en AVG, waarvan 51\% optrad tijdens de eerste drie dialyse behandelingen. Miscannulatie van een nieuw aangelegde AVF kwam tweemaal zo vaak voor in vergelijking met miscannulatie van een AVG. Een AVF in de bovenarm gaf meer cannulatie problemen ten opzichte van een AVF in de onderarm.

Uit het onderzoek bleek eveneens dat het gebruik van een autogene AVF en een beperkte lengte van het beschikbare cannulatie traject een negatieve invloed had op cannulatie en vaak resulteerde in het gebruik van één-naalds dialyses en CVKs. Eerder gebruik van een CVK en éénnaalds-dialyse waren significante voorspellers voor het falen van de vaattoegang.

Hoofdstuk 5 beschrijft een studie waarin voorspellende factoren werden onderzocht die geassocieerd kunnen worden met moeilijke en gecompliceerde cannulaties. Deze studie toonde aan dat onderhuidse bloeduitstorting vaker voorkomt bij AVFs in vergelijking met AVGs. Voor zowel AVF en AVG, was dit een belangrijke voorspeller voor de noodzaak tot het gebruik van een CVK en éénnaalds-dialyse, en werd eveneens geassocieerd met het falen van de vaattoegang. De jaren ervaring van de dialyseverpleegkundige speelden geen rol van betekenis bij al dan niet succesvolle cannulatie of het optreden van cannulatie-gerelateerde complicaties. De naald tegen de stroomrichting in geprikt was de enige significante voorspeller voor succesvolle cannulatie van AVGs. We waren niet in staat om voorspellende factoren met betrekking tot de cannulatie problemen van AVF te bepalen.

Hoofdstuk 6 beschrijft een prospectief observationeel onderzoek bij chronische hemodialyse patiënten met een autogene AVF, met als doel inzicht te verkrijgen in de voor - en nadelen van de touw-ladder versus de button-hole cannulatie techniek. Deze studie toonde aan dat, ondanks meer misprikken, het optreden van hematomen en aneurysmata significant minder voorkwamen in de button-hole groep. Bovendien 
was een Dotter procedure vaker nodig bij patiënten die met een touw-ladder techniek werden geprikt. Een ongunstig bijkomstigheid van de button-hole techniek is een grotere kans op infectie. Deze infecties, veroorzaakt door de button-hole techniek, moeten niet worden onderschat en onderstrepen het belang van een steriele en juiste toepassing van de button-hole techniek.

In hoofdstuk 7 worden de resultaten van operatie technieken beschreven, welke kunnen worden gebruikt om het aanprikken van de vaattoegang beter mogelijk te maken. Deze operaties kunnen eventueel het optreden van cannulatie-gerelateerde problemen en complicaties verminderen en het lange termijn functioneren van de vaattoegang verbeteren. Zeventien literatuur studies werden geanalyseerd, betreffende verschillende technieken om cannulatie te verbeteren. Geen van deze studies was gerandomiseerd of bestond uit een meta-analyse. De chirurgische technieken welke zijn geïndiceerd bij een te diep gelegen vaattoegang of bij kronkelige vaten zijn oppervlakkig leggen en rechttrekken van de ader, of verleggen van de ader naar een andere locatie onder de huid. Andere methoden zijn onderhuidse liposuctie (vet weghalen) met name bij patiënten met overgewicht. Uit de resultaten van deze evaluatie blijkt dat al deze operaties ter voorkoming van cannulatie-gerelateerde problemen en complicaties, zinvol zijn en gepaard gaan met een grote kans op succes.

Een discussie over de resultaten van dit proefschrift wordt in hoofdstuk $\mathbf{8}$ gegeven. Tevens wordt het toekomstperspectief geschetst, met een samenvatting van de conclusies van het proefschrift.

De conclusies zijn:

1. De implementatie van een kwaliteitsverbetering plan voor de vaattoegang resulteert in de plaatsing van meer autogene AVFs in nieuwe dialyse patiënten en gaat gepaard met een toename van het aantal PTA's en chirurgische ingrepen om de vaattoegang te behouden.

2. Tijdens de eerste 6 maanden van een nieuw geplaatste vaattoegang, ondervindt een groot percentage van de patiënten cannulatie-gerelateerde complicaties. Het gebruik van een autogene AVF en een beperkte lengte van het beschikbare cannulatie traject beïnvloeden de uitkomst van de cannulatie en het optreden van complicaties, 3. Een mislukte cannulatie procedure en cannulatie-gerelateerde complicaties resulteren in meer gebruik van CVKs en één-naalds dialyse, welke vaker voorkomen in autogene AVFs. Hematoom vorming als gevolg van een mislukte cannulatie is een belangrijke voorspeller voor de noodzaak van CVK gebruik en één-naalds dialyses.

4. De button-hole techniek heeft minder cannulatie-gerelateerde complicaties zoals hematoomvorming, aneurysmavorming en de noodzaak tot interventies dan de touwladder techniek. De button-hole techniek leidt wel tot meer infecties. 
5. Chirurgische revisie om de cannulatie van de vaattoegang te verbeteren zoals superficialisatie en lipectomie heeft een grote kans op succes met een goede lange termijn uitkomst. 


\section{Dankwoord}

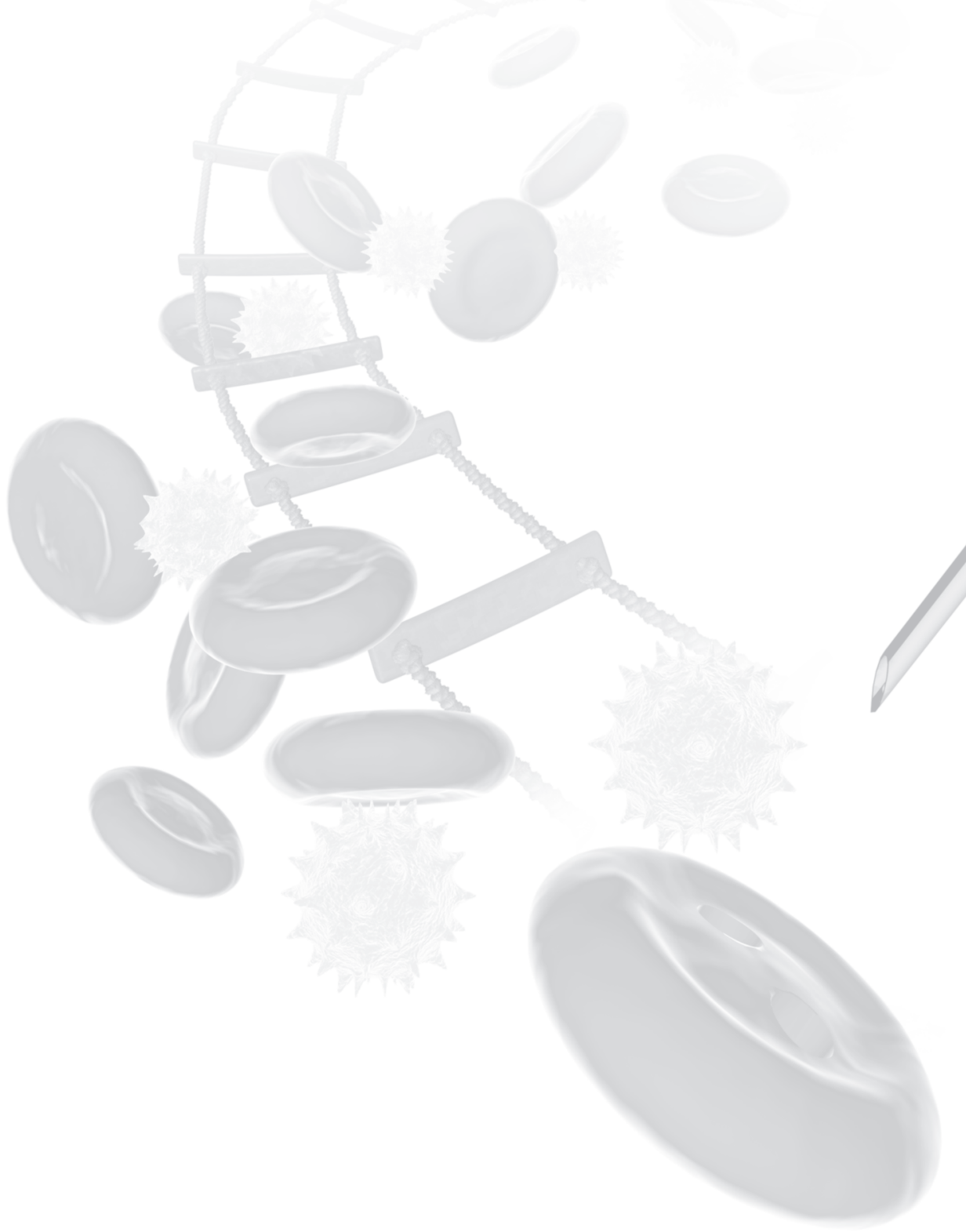




\section{Dankwoord}

Dit proefschrift is mede tot stand gekomen dankzij de medewerking, hulp en steun van velen. Graag wil ik op deze plaats dan ook iedereen bedanken die, direct dan wel indirect, een bijdrage heeft geleverd aan de totstandkoming van dit proefschrift. Een aantal mensen wil ik in het bijzonder noemen.

Allereerst ben ik veel dank verschuldigd aan de patiënten op de dialyseafdelingen voor de bereidheid deel te nemen aan het onderzoek. Zonder hun medewerking had dit proefschrift niet geschreven kunnen worden.

Dr. Tordoir. Beste Jan, dank dat je mij de kans hebt gegeven om aan dit onderzoek te beginnen. Je gaf me veel vrijheid, maar je bleef kritisch en waar nodig stuurde je bij. Elk moment kon ik bij je binnenlopen of bellen voor advies. Ik heb bewondering voor jouw deskundigheid en gedrevenheid op het gebied van de vaattoegangschirurgie op nationaal en internationaal niveau. Ik heb veel van je geleerd en met veel plezier samengewerkt.

Ik zou je tekort doen als ik niet ook mijn dank uitspreek voor de samenwerking binnen het project 'vaattoegang' van de Nierstichting Nederland en voor de kans die je mij hebt geboden om de opleiding Advanced Nursing Practice te volgen, waarbij jij mij als leermeester hebt begeleid. Jan, bedankt voor je relativerend vermogen, de steun en het in mij gestelde vertrouwen.

Dr. van der Sande. Beste Frank, na drie jaar te hebben samengewerkt in het project 'vaattoegang' werd jij mijn tweede copromotor. Graag wil ik je bedanken voor je laagdrempeligheid en steun tijdens het promotietraject. Je opbeurende woorden (tissues) en adviezen in tijden van stress heb ik zeer gewaardeerd. Je hebt gelijk gekregen dat het allemaal goed zou komen.

Prof. dr. Kitslaar, emeritus hoogleraar inmiddels, wil ik bedanken voor de kritische en zorgvuldige aanvullingen op mijn proefschrift en de bereidheid om als promotor op te treden.

Fons Kessels. Fons, jou ben ik veel dank verschuldigd voor je deskundige hulp en geduld bij de statistische analyse. Je hebt een groot aandeel gehad in het tot stand komen van dit proefschrift. Met een enorme brij van data kwam ik bij jou terecht met de vraag of je me wilde helpen met analyseren. Ik ben je dankbaar voor alle tijd die je in mijn begeleiding hebt gestoken. Met plezier denk ik terug aan onze sessies waarin jij me niet alleen wegwijs hebt gemaakt op het gebied van statistiek en SPSS maar ook goede adviezen gaf bij het structureren en het schrijven van de manuscripten, veel dank hiervoor. 
De leden van de beoordelingscommissie bestaande uit Prof. dr. K.M.L. Leunissen, Prof. dr. M.J.H.M Jacobs, Dr. H. Burger en Dr. G.M.T. de Jong, wil ik bedanken voor het beoordelen van mijn proefschrift en de bereidheid zitting te nemen in de promotiecommissie. De externe commissieleden wil ik in het bijzonder danken. Beste Hens en Gijs, jullie gedrevenheid en enthousiasme voor de vaattoegang zijn voor mij van zeer grote waarde geweest. Dank voor het kritisch lezen en becommentariëren van het proefschrift. Ik ben vereerd dat jullie deel uit maken van de beoordelingscommissie.

De leden van de landelijke werkgroep vaattoegang tevens medeauteurs van het derde hoofdstuk in dit proefschrift. Dr. Peter Blankestijn, Dr. Roel Huisman, Dr. Jan Zijlstra, Nataschja van den Berg, Wil van der Mark en Cor De Bruin, bedankt voor de fijne samenwerking gedurende het project, het heeft een mooi artikel opgeleverd.

In het bijzonder wil ik bedanken Dr. Jan Zijlstra. Je enthousiasme en betrokkenheid bij de vaattoegangsproblematiek zijn voor mij leerzaam en inspirerend geweest, dank hiervoor.

Tony Goovaerts. Beste Tony, zonder dat we elkaar kenden was je meteen bereid om aan het button-hole onderzoek mee te werken. Jouw expertise op het gebied van deze priktechniek is ongekend, bedankt dat je deze kennis en ervaring met mij wilde delen. Ik heb grote bewondering voor het enorme enthousiasme en de gedrevenheid waarmee jij je vak uitoefent. Natuurlijk wil ik je ook bedanken voor je gastvrije ontvangst in Brussel bij het ophalen van de data en onze gezellige telefoongesprekken, ik heb het zeer gewaardeerd.

Margreet ter Meer. Lieve Margreet, wat was het fijn om bij jou altijd een luisterend oor te vinden. Jouw steun, onze telefoongesprekken, je bemoedigende en inspirerende woorden, je fotografisch geheugen, je suggesties, je deskundigheid en vriendschap waren en zijn voor mij van onschatbare waarde. Bedankt voor alles.

Yvonne Daemen. Yvonne, bedankt dat je hebt mij wegwijs hebt gemaakt in alle praktische zaken en de talloze malen dat ik je lastig mocht vallen. Een mailtje of telefoontje en je regelde het weer. Nu je bent gestopt met werken wens ik je - samen met Frans - nog vele gelukkige jaren toe.

Het secretariaat van de afdeling heelkunde in het bijzonder Claudia Lenssen, bedankt voor de secretariële ondersteuning bij de laatste loodjes.

Medewerkers van het vaatlab. Bianca, Evelien, Laura, Marjon, Monique, Sandra en Simone, bedankt voor jullie gastvrijheid en het altijd bij jullie terecht kunnen voor advies en hulp. 
De studies die beschreven worden in dit proefschrift hadden niet kunnen worden uitgevoerd zonder de medewerking van de 11 deelnemende dialysecentra. Allereerst wil ik de afdelingsmanagers van deze centra bedanken voor hun bereidheid deel te nemen aan het onderzoek. Ook wil ik de nefrologen, vaatchirurgen en radiologen uit de betrokken ziekenhuizen bedanken voor hun bijdragen.

Alle dialyseverpleegkundige van de participerende centra: dank voor jullie bereidheid om - tijdens de vaak toch al drukke werkzaamheden - de vragenlijsten in te vullen. In het bijzonder wil ik de contactpersonen bedanken voor hun onmisbare hulp en inzet bij het verzamelen van de enorme hoeveelheid data, het altijd hartelijke ontvangst en de gezellige gesprekken. In het Maastrichts Universitair Medisch Centrum: Michael Geelen en Valerie Renette. In het Admiraal De Ruyter Ziekenhuis te Goes: Peter Boot, Désirée Faase, Regina Overdam en Byanka van der Veen. In het Albert Schweitzer ziekenhuis te Dordrecht: Sandra de Haas en Wilma Ringlever. In het Amphia Ziekenhuis te Breda: Judith van der Blom, Kirsten Bouwens en Mascha Marijnissen. In het Atrium Medisch Centrum te Heerlen: Ed Eussen, Marjo ter Haar, Willy Dirrix en Ilse Stohr. In het Catharina ziekenhuis te Eindhoven: Grande Hulshorst en Marie-Jose van der Schoot. In het Laurentius Ziekenhuis te Roermond: Els Cox. In het Maxima Medisch Centrum: Karin Moret. In het Orbis Medisch Centrum: Harm Haenen, Nico Kolken, Patricia Meuwissen en Chantal van de Ven. In het Universitair Ziekenhuis St. Luc te Brussel: Tony Goovaerts. In het VieCuri ziekenhuis te Venlo: Etienne Fleuren, Inge Peters en Suzan Jeuken. Jullie zijn goud waard!

Karin Moret. Lieve Karin, als dialyseverpleegkundige gelijktijdig promotieonderzoek uitvoeren schept een band en leverde altijd voldoende gespreksstof op. We hebben de afgelopen jaren dan ook veel goede, inspirerende maar vooral gezellige gesprekken gevoerd. Heel veel dank voor de momenten die we als 'lotgenoten' hebben gedeeld.

Edwin Wijnen. Lieve Edwin, na een aantal jaren te hebben samengewerkt ben jij inmiddels elders werkzaam en is onze werkrelatie overgegaan in vriendschap. Vorig jaar op 2 juni had ik de eer om jou als paranimf terzijde te staan bij jouw promotie. Je hebt het goede voorbeeld gegeven en ik hoop dat ik je kan evenaren. Edwin, bedankt voor onze fijne samenwerking, waardevolle gesprekken en vriendschap.

Sylvia Aarts. Lieve Sylvia, tijdens mijn promotietraject zijn we samen de opleiding Master Advanced Nursing Practice gestart. Het heeft ons bloed, zweet en soms ook tranen gekost maar jouw steun en vriendschap hielpen mij vaak door de lastige momenten heen. Bedankt hiervoor.

Verder bedank ik ook de medestudenten van de M-ANP voor hun belangstelling, in het bijzonder Eva van der Veen en Mirella Waber. Bedankt voor de aangename ontspanning en de gezellig etentjes bij Choko. Ik hoop dat we als MMSE deze traditie nog lang in ere zullen houden. 
Rob Mutsears. Lieve Rob, gedurende onze samenwerking heb jij mij de gelegenheid geboden om me verder te ontwikkelen op het gebied van de vaattoegang. Wie had toen kunnen vermoeden dat er een proefschrift uit voort zou komen. Dank voor je hulp, motivatie en vriendschap.

Anje Meertens. Lieve vriendin, dank voor je hulp, je interesse maar vooral voor je nooit aflatende steun en vriendschap, we kunnen weer wat leuks gaan plannen.

Marina de Lint. Lieve Marina, ondanks dat we de laatste tijd minder contact hebben wil ik je bedanken voor je hulp en adviezen waarvoor ik altijd bij je terecht kon, het was goud waard.

Tiny Wouters. Beste Tiny, bedankt voor de vanzelfsprekendheid waarmee je de layout van dit proefschrift voor me hebt verzorgd. Het was fijn om gebruik te mogen maken van je kennis en ervaring in de laatste fase van het proefschrift. Hartelijk dank voor alles.

Eric Lemmens en John Derwall van D\&L Graphics wil ik bedanken voor de fijne samenwerking en het maken van de mooie voorkant en illustraties.

Natuurlijk wil ik ook mijn (oud)kamergenoten Stella Schreurs, Guy Vijgen, Bart van Wunnik en Carina van Zandvoort bedanken voor de steun en belangstelling maar vooral voor de gezelligheid.

Aron Bode. Beste Aron, dank voor de fijne samenwerking, nuttige discussies (ook over vlijtige liesjes) en het delen van je kennis. Natuurlijk wil ik je ook bedanken voor de gezellige momenten de afgelopen jaren, ik kijk met veel plezier terug op ons congresbezoek in Rome. Veel succes met de afronding van je eigen promotie.

Alle collega's met wie ik in de loop van de jaren heb gewerkt die, direct of indirect, een bijdrage hebben geleverd aan dit proefschrift, bedankt hiervoor.

Voor de totstandkoming van dit proefschrift ben ik ook veel mensen uit mijn privéleven dankbaar. Lieve familie en vrienden: bedankt voor jullie warme belangstelling, steun en vooral de ontspanning die jullie me hebben gegeven.

Een speciaal woord van dank voor mijn schoonmoeder. Lieve schoonmoeder, uw medeleven en interesse de afgelopen jaren was hartverwarmend. 
In het bijzonder wil ik mijn paranimfen bedanken, ik vind het fantastisch dat jullie naast mij staan tijdens de verdediging van mijn proefschrift.

Babette van Loon. Lieve zus, je hebt het hele proces van de eerste tot de laatste snik van dichtbij meegemaakt. Ik ben blij en trots dat je op deze dag naast me staat. Bedankt voor je steun de afgelopen jaren, hoe fijn is het om een zusje te hebben die zo dicht bij je staat. Ik ben trots op je.

Max Gaasbeek. Max, niet voor niets ben jij mijn paranimf. Zonder jouw steun bij het creëren van de randvoorwaarden voor het onderzoek was er geen proefschrift geweest, bedankt voor je vertrouwen en inzet. Ik bewonder jou om je aanstekelijk enthousiasme en eindeloos optimisme. Ik beschouw het als een eer dat jij mij terzijde wilt staan bij mijn verdediging.

Als laatste dank ik degene aan wie ik het proefschrift opdraag.

Mijn ouders. Lieve Pa en Ma, bedankt voor de onvoorwaardelijke liefde, steun en vertrouwen, maar vooral de waarden die jullie mij hebben bijgebracht. Ik prijs me gelukkig met zulke ouders.

Lieve Hein, mijn steun en toeverlaat. Dit proefschrift had er niet gelegen als jij er niet was geweest. De vanzelfsprekendheid waarmee je mij de ruimte hebt gegund om me verder te ontwikkelen en mij daarin altijd onvoorwaardelijk hebt gesteund is geweldig. De beruchte laatste loodjes wogen zwaar, hierbij was jouw relativeringsvermogen en optimisme van onschatbare waarde. Bedankt voor je onvoorwaardelijke liefde, steun en vertrouwen in mij. Dit boekje is zeker ook van jou. 
\begin{tabular}{l|l} 
& \\
Dankwoord & 139
\end{tabular} 


\section{Curriculum Vitae}

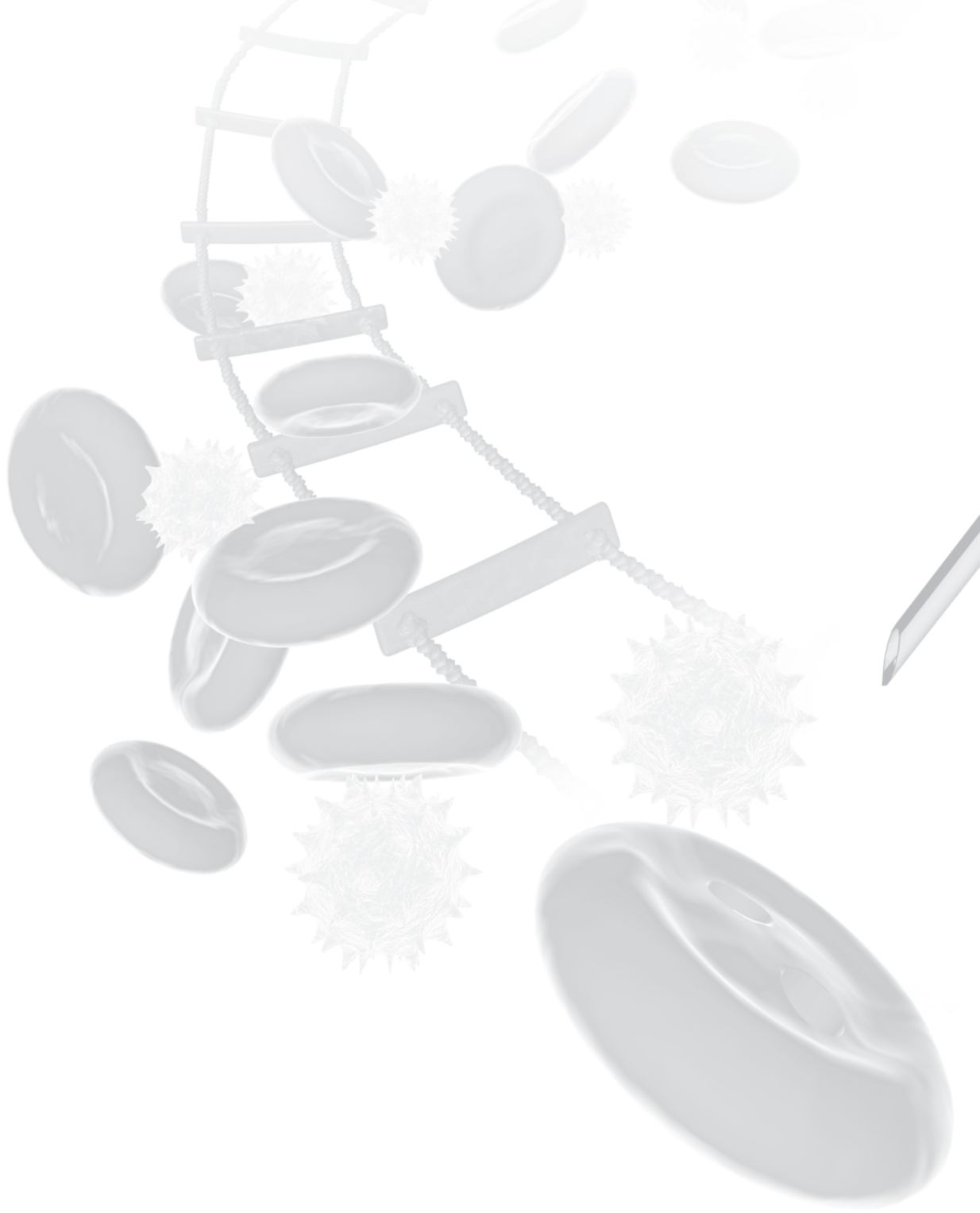




\section{Curriculum Vitae}

Magda van Loon werd geboren op 24 september 1963 te Drimmelen. Na de middelbare school startte ze in 1981 met de inservice opleiding voor Averpleegkundige in het toenmalige St. Joseph ziekenhuis te Oosterhout. Nadat zij in 1985 afstudeerde, begon zij in datzelfde jaar op de dialyseafdeling van het toenmalige Refaja ziekenhuis te Dordrecht, waar zij in 1986 de opleiding voor dialyseverpleegkundige afrondde. Op de dialyseafdeling was haar aandachtsgebied de zorg voor de vaattoegang. Tot 2001 is zij als dialyseverpleegkundige werkzaam geweest in het Albert Schweitzer ziekenhuis te Dordrecht.

$\mathrm{Zij}$ is medeoprichter van de Landelijke Verpleegkundige Werkgroep Access (VWA) waarvan zij van 2003-2008 voorzitter was. In 2003 startte zij met de opleiding Management in de Zorg waarvoor zij in 2005 haar Bachelor of Health diploma behaalde.

Van 2001-2004 was zij projectleider van het landelijk kwaliteitsverbeterproject Vaattoegang welke door de Nierstichting Nederland werd gesubsidieerd. In 2005 startte zij op de afdeling chirurgie van het Maastrichts Universitair Medisch Centrum met promotieonderzoek. De resultaten van het promotieonderzoek, onder begeleiding van Dr. J. Tordoir, Prof. dr. P. Kitslaar en Dr. F. van der Sande, staan beschreven in dit proefschrift. Onderzoeksresultaten werden gepresenteerd op verschillende nationale en internationale congressen. Van 2008 - 2010 volgde zij tevens de Masteropleiding Advanced Nursing Practice aan de Hogeschool Zuyd te Heerlen. Sinds juni 2010 heeft zij een vaste aanstelling als Nurse Practitioner vaattoegang op de afdeling chirurgie van het MUMC. 
